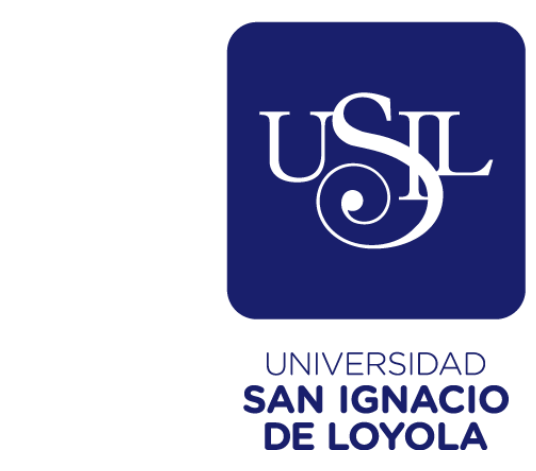

ESCUELA DE POSTGRADO

Maestría en Educación con Mención en Docencia en Educación Superior

\title{
ESTRATEGIA DIDÁCTICA PARA DESARROLLAR LA COMPETENCIA COMUNICATIVA ORAL EN LOS ESTUDIANTES DE DISEÑO GRÁFICO DE UN INSTITUTO SUPERIOR DE LIMA
}

Tesis para optar el grado de Maestro en Educación con Mención en Docencia en Educación Superior

JOSSELYN YULIANA LARA ESCALANTE

Asesor:

Míriam Encarnación Velázquez Tejeda

Lima - Perú

2020 


\section{Agradecimiento}

A mi estimada asesora, Miriam Velázquez Tejeda por todo el apoyo y paciencia en este largo proceso de investigación.

A los maestros expertos que con su experiencia y maestría pedagógica brindaron un valioso aporte al trabajo investigativo.

A mi mamá, mi papá, mi hermana y a mi adorado esposo por brindarme todo su apoyo incondicional en mi formación profesional. 


\section{Dedicatoria}

Para mis adorados padres, porque sin ellos jamás hubiera sido la profesional que soy ahora, para mi hermana Jessy por todo el apoyo y confianza que deposita en mí, para el gran amor de mi vida Renato por apoyarme en todo, para gatico por acompañarme en largas noches de desvelo y en especial a mis queridos estudiantes. 


\section{Índice}

Introducción 1

Planteamiento del problema de investigación 3

$\begin{array}{ll}\text { Preguntas científicas } & 4\end{array}$

$\begin{array}{ll}\text { Objetivo general } & 4\end{array}$

Objetivos específicos o tareas de la investigación 4

Categorías y subcategorías apriorísticas $\quad 5$

$\begin{array}{ll}\text { Justificación teórica, metodológica y práctica } & 6\end{array}$

$\begin{array}{ll}\text { Metodología de la investigación } & 7\end{array}$

$\begin{array}{ll}\text { Tipo y diseño de investigación } & 7\end{array}$

$\begin{array}{ll}\text { Población, muestra y unidad de análisis } & 7\end{array}$

Métodos teóricos $\quad 8$

$\begin{array}{ll}\text { Técnicas e instrumentos } & 10\end{array}$

$\begin{array}{ll}\text { Capítulo I Marco Teórico } & 13\end{array}$

Antecedentes internacional y nacional de la investigación 13

Bosquejo histórico de la enseñanza- aprendizaje de la comunicativa oral en el Perú $\quad 16$

Fundamentos teóricos del aprendizaje como proceso psicológico 19

Reflexiones conceptuales acerca de la competencia comunicativa oral 21

Métodos que estimulan el desarrollo de la competencia comunicativa oral 27

Fundamentos teóricos sobre la categoría conceptual estrategia didáctica 33

Exigencias del proceso de enseñanza -aprendizaje. Según 36

Capítulo II Diagnóstico o trabajo de campo 38

Análisis, interpretación y discusión de los resultados 38

Relaciones analíticas e interpretativas de las categorías emergentes sustantivas $\quad 44$

Conclusiones aproximativas de los análisis realizados en esta parte de la investigación $\quad 49$

Capítulo III Modelación, validación y aplicación de la propuesta $\quad 50$ 
Propósito de la estrategia didáctica propuesta

Diseño gráfico funcional de la propuesta de la estrategia didáctica

Estructura y características de la estrategia didáctica modelada

Concepción de la didáctica de la lengua en la propuesta

Propuesta de talleres teórico práctico para la capacitación a los docentes

Sugerencias para la implementación de la propuesta en la práctica pedagógica

Validación de la estrategia didáctica propuesta

Conclusiones

Recomendaciones

Referencias

Anexos 


\section{Anexos}

\section{Índice de anexos}

Anexo 01: Matriz metodológica

Anexo 02: Matriz de categorización

Anexo 03: Entrevista al docente

Anexo 04: Guía de observación de clases

Anexo 05: Encuesta a estudiantes

Anexo 06: Prueba pedagógica

Anexo 07: Validación de instrumentos - experto 1

Anexo 08: Validación de instrumentos - experto 2

Anexo 09: Validación de instrumentos - experto 3

Anexo 10: Matriz de reducción de datos: Guía de observación

Anexo 11: Matriz de reducción de datos: Entrevistas semi estructurada

Anexo 12: Tablas y gráficos de encuestas a estudiantes

Anexo 13: Tablas y gráficos de prueba pedagógica

Anexo 14: Tabla de codificación de datos

Anexo 15: Tabla de validación de expertos

Anexo 16: Sesión de aprendizaje Nro. 1

Anexo 17: Rubrica de coevaluación

Anexo 18: Rubrica de evaluación

Anexo 19: Sesión de aprendizaje Nro. 2

Anexo 20: Ficha de validación de la propuesta didáctica

Anexo 21: Validación de modelación - experto 1

Anexo 22: Validación de modelación - experto 2

Anexo 23: Validación de modelación - experto 3 


\section{Índice de Tablas}

Tabla 01: Dosificación de la Unidad Didáctica Número I

Tabla 02: Talleres de capacitación docente

Tabla 03: Relación de expertos que validaron la propuesta

Tabla 04: Tabla de Valoración

Tabla 05: Resultados de la validación integral por e los especialistas

Tabla 06: Resultado de la valoración interna y externa por criterio de expertos

\section{Índice de figuras}

Figura1: Categorías emergentes sustantivas resultantes del diagnóstico

Figura 2: Categorías apriorísticas y emergentes influyentes en el problema

Figura 3: Esquema teórico - funcional que representa la estrategia didáctica modelada.

Figura 4: Estructura de una unidad didáctica a través del enfoque por tareas

Figura 5: Secuenciación de una unidad didáctica desde este enfoque. 


\section{Resumen}

La investigación propone una estrategia didáctica para contribuir con el desarrollo de la competencia comunicativa oral en los estudiantes de IV ciclo de una institución superior privada de Lima. La investigación es de tipo educacional aplicada y se ubica en el paradigma socio - crítico interpretativo con un enfoque cualitativo donde el docente investigador identifica el problema en su aula, lo analiza y propone soluciones a la realidad educativa. La muestra seleccionados por muestreo no probabilístico la conforman dos docentes y diez estudiantes. Como parte del estudio se emplearon diversas técnicas e instrumentos como: entrevista y observación a clases a los docentes; cuestionario y prueba pedagógica a los estudiantes para conocer el estado real del problema y se empleó el criterio de expertos para valorar la efectividad de la propuesta modelada. La investigación se fundamenta en las

diferentes teorías, enfoques y modelos relacionados con la aplicación de la estrategia didáctica, el aprendizaje socioformativo y la relación de ambas durante la dirección del desarrollo de la competencia comunicativa oral. El resultado obtenido del diagnóstico de campo, al ser contrastado con las categorías apriorísticas permitió identificar las categorías emergentes sustantivas y las que influyen en el problema de estudio. Se logró cumplir con el objetivo general y las tareas del proceso científico programadas con la estrategia didáctica modelada que se basa en los fundamentos científicos, principios didácticos y otros argumentos pedagógicos que contribuyen al desarrollo de la competencia comunicativa oral en los estudiantes de Educación Superior.

Palabras clave: estrategia didáctica, competencia comunicativa oral, enfoque sociocultural, enfoque cognitivo. 


\begin{abstract}
The research is oriented to the design of a didactic strategy to contribute to the development of oral communicative competence in the students of IV cycle of a private superior institution of Lima. The research is applied educational and is located within the sociocritical interpretive paradigm with a qualitative approach since the research teacher tries to understand and analyze the educational problem from the classroom. The sample consisted of two teachers and ten students, selected by non-probabilistic sampling. As part of the study, various techniques and instruments were used, such as: teacher interview, teacher class observation, student questionnaire and pedagogical test for students who experience contrasting the problem statement within the context; In addition, the expert criteria were used to assess the evaluation of the proposal. The research is based on the different theories, approaches and models related to the application of the didactic strategy, as well as the socioformative learning and the relationship of both during the direction of the pedagogical process in the development of the oral communicative competence. The result obtained from the field diagnosis, when contrasted with the a priori categories identified, identify the categories that influence the study problem. The general objective and programmed scientific process tasks that facilitate the modeling of a didactic strategy based on scientific foundations, teaching principles and other pedagogical arguments that affect the development of oral communicative competence in students of Higher Education are fulfilled.
\end{abstract}

Keywords: didactic strategy, oral communicative competence, sociocultural approach, cognitive approach. 


\section{Introducción}

En el siglo XXI el volumen de información que emerge del desarrollo de las ciencias y la tecnología en todas las ramas del saber humano es vertiginoso. Se necesita tener una cultura general e integral para poder acceder a ella, asimilarla, procesarla para convertirla en conocimientos útiles para resolver los problemas de la realidad circundante del sujeto en bien de todos como plantea la Organización de las Naciones Unidas para la Educación, la Ciencia y la Cultura (Unesco,2015).

Para enfrentar ese reto se necesita que las personas hayan desarrollado el pensamiento crítico, reflexivo, valorativo, los conocimientos y las habilidades de manera tal que les permitan dilucidar lo positivo de lo negativo, lo justo de lo injusto y lo ético en general con el fin de asuma una posición instructiva, humanística y loable que contribuya a su autotransformación y al desarrollo de la sociedad como argumentan Peñaloza (2003),Morín (2011) y la Unesco (2015).

En tal sentido, la sociedad le exige a la escuela como centro formativo aplicar una didáctica crítica que contribuya a potenciar el pensamiento, el lenguaje y la competencia comunicativa oral como expresión de la cultura que adquiere el sujeto, las relaciones interpersonales, las habilidades sociales y como evidencia de los estándares de calidad del aprendizaje que ostenta el hablante en los distintos contextos de actuación profesional Superintendencia Nacional de Educación Superior Universitaria (Sunedu, 2017).

El desarrollo de la competencia comunicativa oral en los estudiantes es uno de los objetivos más debatidos e investigados por autores como Hymes (1971), Chomsky (1974),Roméu (2007), Cassany (2009- 2016) y Domínguez (2010), debido a que en su enseñanza en las aulas, ha prevalecido la aplicación de una metodología que privilegia el tratamiento de la esfera instructiva en desventaja de lo afectivo, volitivo, motivacional y emocional que requiere el sujeto para lograr un conocimiento consciente y la ejercitación de una comunicación interpersonal adecuada que le permita el desarrollo de las habilidades comunicativas orales y escritas de forma general.

Desde estas perspectivas, se necesita que los docentes al orientar el proceso de enseñanza- aprendizaje aplique los métodos y estrategias activas que se atemperan a los lineamientos de los avances de las ciencias de la educación y las tecnologías audiovisuales; se requiere que en la clase se problematice el contenido a enseñar partiendo de los saberes 
previos, las vivencias del contexto y de situaciones comunicativas que motiven a los estudiantes al interactuar en grupos durante el proceso de asimilación, procesamiento y producción de los conocimientos y los apliquen en la solución de las actividades para que desarrollen las habilidades comunicativas y las actitudes de forma integral(Castellanos, Reinoso y García,2007;Roméu, 2007 y Díaz Barriga, 2010).

De ese modo se reconoce que los enfoques teóricos y didácticos sobre la enseñanzaaprendizaje de los últimos años dan cuenta de las exigencias de la competencia comunicativa en los sujetos con el propósito de estimular el pensamiento, el lenguaje y las actitudes y la expresión de ideas, opiniones y juicios en espacios de colaboración con el interés de fortalecer el aspecto intrapersonal de los estudiantes, ya que no solo se debe tener en consideración la parte comunicativa que es lo externo, sino cómo piensan, comprenden, actúan y se desenvuelven en lo psicológico, social y cultural (Roméu,2007; Domínguez,2010 yCassany,2009).

Desde esa óptica, el tratamiento de la expresión oral reclama para comprender mejor la competencia comunicativa, el conocimiento del signo lingüístico, los niveles de la lengua, la contextualización del mensaje y la intención del hablante (Saussure, 1980). Ello evidencia la relación pensamiento lenguaje y la necesidad de atender las capacidades comunicativas individuales de cada hablante marcado por sus vivencias, características psicológicas, experiencias e intereses en el acto comunicativo (Domínguez y Sevillano, 2013 y Pérez, 2015).

Congruente con esa posición teórica y desde una perspectiva psicosocial, Roméu (2007), plantea que la competencia comunicativa es un constructo integral que se conforma por los procesos cognitivos, comunicativos y sociocultural del hablante en un contexto cultural determinado. Sus finalidades lograr el desarrollo del pensamiento, el lenguaje como capacidad humana que se adquiere en el proceso de socialización del individuo y que se comunique según la intención y las exigencias del contexto.

Al respecto, Cassany (2013), añade que la competencia comunicativa se rige y responde a las exigencias teóricas de la lingüística textual, al precisar que, con esta concepción, la didáctica de la lengua ha transitado a la didáctica del habla del sujeto por la necesidad de ajustar el discurso al contexto donde se produce, tenerse en cuenta las capacidades, los procesos cognitivos, sociales, contextuales y las necesidades comunicativas del hablante son diversas. 
En ese orden de ideas, López (2008), la Unesco (2015) y la Comisión Económica para América Latina y el Caribe (Cepal, 2015), señalan que el desarrollo de la competencia comunicativas imprescindible para lograr la formación interpersonal y el liderazgo en el sujeto en cualquier campo del saber. En ese orden, las investigaciones de Vargas (2014) y Guerrero (2017), reflejan la existencia de dificultades en el desarrollo social y comunicativo del alumnado, debido a la falta de la aplicación de métodos y estrategias que contribuyan a la problematización, el diálogo, la interacción en la construcción del conocimiento para de esa manera lograr el desarrollo de las habilidades comunicativas.

En cuanto a la competencia comunicativa, la Ley General de Educación para los Institutos $\mathrm{N}^{\circ} 28044$ (2005), de Perú en su Artículo $\mathrm{N}^{\circ} 25$, indica que el proceso pedagógico se dará dentro y fuera de las aulas de clase y tendrá como propósito en la construcción del conocimiento estimular el desarrollo de las relaciones interpersonales, fortalecer las relaciones sociales, y su incidencia en el desarrollo de competencias comunicativas.

En el perfil de la carrera de Diseño Gráfico de un instituto privado de Lima (2017), se indica que los estudiantes de $\mathrm{V}$ ciclo deben desarrollar los conocimientos y las habilidades del diseño gráfico en todas sus manifestaciones; ganar en el dominio de las herramientas y las estrategias comunicacionales que lo conduzcan al desarrollo de las competencias comunicativas que deberá ir alcanzado en su tránsito por los distintos ciclos de la carrera.

Sin embargo, en la práctica docente de la asignatura Producción Gráfica de los estudiantes de IV ciclo, se evidencian carencias en los conocimientos y las habilidades comunicativas, reflejadas en la falta de argumentos al sustentar sus ideas; dificultades al dialogar con fluidez y expresividad, pobreza de vocabulario, dificultades en el dominio de las estructuras gramaticales al construir textos y en general se observa falta de creatividad y originalidad al expresarse tanto de forma oral como 'por escrito.

En consecuencia, de ello se formula el siguiente problema de investigación:

\section{Planteamiento del problema de investigación}

¿Cómo desarrollar la competencia comunicativa oral en los estudiantes de IV ciclo de la disciplina de Producción Gráfica de la carrera de Diseño Gráfico de un instituto superior privado de Lima? 


\section{Preguntas científicas}

¿Cuál es el estado actual del desarrollo de la competencia comunicativa oral en los estudiantes de IV ciclo de la disciplina de Producción Gráfica de la carrera de Diseño Gráfico de un instituto superior privado de Lima?

¿Cuáles son los fundamentos teóricos y metodológicos del desarrollo de la competencia comunicativa oral en los estudiantes de IV ciclo de la disciplina de Producción Gráfica de la carrera de Diseño Gráfico de un instituto superior privado de Lima?

¿Qué criterios teóricos y metodológicos sirven de base a la modelación de la estrategia didáctica para contribuir al del desarrollo de la competencia comunicativa oral en los estudiantes de IV ciclo de la disciplina de Producción Gráfica de la carrera de Diseño Gráfico de un instituto superior privado de Lima?

¿Cómo evaluar por criterio de expertos la efectividad de la estrategia didáctica modelada para contribuir al del desarrollo de la competencia comunicativa oral en los estudiantes de IV ciclo de la disciplina de Producción Gráfica de la carrera de Diseño Gráfico de un instituto superior privado de Lima?

\section{Objetivo general}

Diseñar una estrategia didáctica para contribuir al desarrollo de la competencia comunicativa oral en los estudiantes de IV ciclo de la disciplina de Producción Gráfica de la carrera de Diseño Gráfico de un instituto superior privado de Lima.

\section{Objetivos específicos o tareas de la investigación}

Diagnosticar el estado actual del desarrollo de la competencia comunicativa oral en los estudiantes de IV ciclo de la disciplina de Producción Gráfica de la carrera de Diseño Gráfico de un instituto superior privado de Lima.

Sistematizar los fundamentos teóricos y metodológicos del desarrollo de la competencia comunicativa oral en los estudiantes de IV ciclo de la disciplina de Producción Gráfica de la carrera de Diseño Gráfico de un instituto superior privado de Lima.

Determinar los criterios teóricos y metodológicos que sirven de base a la modelación de la estrategia didáctica para contribuir al del desarrollo de la competencia comunicativa oral en los estudiantes de IV ciclo de la disciplina de Producción Gráfica de la carrera de Diseño gráfico de un instituto superior privado de Lima. 
Evaluar por criterio de expertos la efectividad de la estrategia didáctica modelada para contribuir al del desarrollo de la competencia comunicativa oral en los estudiantes de IV ciclo de la disciplina de Producción Gráfica de la carrera de Diseño gráfico de un instituto superior privado de Lima.

\section{Categorías y subcategorías apriorísticas}

Refiriéndose a las categorías apriorísticas Cisterna (2005) enfatiza que estas son tópico o constructo teórico en sí mismo, y las subcategorías explican aspectos de dicho tópico en micro aspectos. Sustenta que las categorías pueden ser apriorísticas sistematizadas de forma teórica antes de iniciar el proceso de diagnóstico de campo y las categorías emergentes se identifican a partir de la propia indagación, exploración y recojo de información a través de los instrumentos aplicados. En el estudio se definieron las categorías apriorísticas y sus subcategorías:

\section{Competencia comunicativa oral}

La competencia comunicativa es definida por Roméu (2007), como la configuración psicológica que integra diversos componentes cognitivos, comunicativo, sociocultural, metacognitivo, motivacionales y cualidades del hablante.

Las subcategorías apriorísticas identificadas: Habilidades cognitivas, habilidades comunicacionales y las habilidades socioculturales.

\section{Estrategia didáctica}

La estrategia didáctica como un modelo, compuesto por métodos, procedimientos, técnicas y actividades a través de los cuales el docente y los estudiantes organizan las acciones de manera consciente para construir y lograr metas previstas e imprevistas en el proceso enseñanza - aprendizaje, adaptándose a las necesidades de los participantes de manera significativa (Feo, 2010). 
Las subcategorías que se nombraron fueron las siguientes: Exigencias del proceso enseñanza -aprendizaje, sistema de las categorías didácticas, rol del docente y el rol del estudiante.

\section{Justificación teórica, metodológica y práctica}

\section{Justificación teórica}

La investigación realizada partió de la sistematización de los fundamentos teóricos sobre el aprendizaje como proceso complejo y dialéctico y la competencia comunicativa oral abordada por distintos especialistas como Chomsky (1995), Morín (2011), Castellano set al, (2007), Roméu (2007), Cassany (2009), Díaz Barriga (2010) y Freire (2017). Estos sustentan que la competencia oral como precisa la lingüista del texto permite el desarrollo del pensamiento crítico y reflexivo, mejora en el vocabulario, las formas de expresión del pensamiento y enriquece las relaciones interpersonales de los estudiantes. La repercusión teórica radica en cómo se abordan las perspectivas teóricas actualizadas sobre cómo cada hablante desarrolla la competencia comunicativa ora y el tratamiento a seguir en el proceso enseñanza- aprendizaje por su relevancia e incidencia en las relaciones interpersonales, para cooperar con su desarrollo se necesita aplicar una estrategia didáctica que contribuya al desarrollo de la competencia comunicativa oral en los estudiantes.

\section{Justificación metodológica}

Desde la perspectiva metodológica el proceso investigativo diseña una estrategia didáctica como producto científico resultado de la sistematización teórico- práctico, el diagnóstico de campo y el análisis de las categorías emergentes que contribuye a que los docente analicen y reflexionen sobre los distintos enfoques teóricos y didácticos a través de una manera innovadora con el fin de conducir la enseñanza- aprendizaje de la competencia comunicativa oral desde la asignatura Diseño gráfico. El propósito de la propuesta es mejorar el desempeño profesional en la clase y el rol estudiantil en la adquisición, procesamiento de la información hasta lograr la producción de un nuevo conocimiento y ejercitar las habilidades en las distintas situaciones comunicativas de aprendizaje de manera que estimule el desarrollo de la competencia oral y la formación integral de los educandos.

\section{Justificación práctica}

Se aporta a la práctica pedagógica universitaria una estrategia didáctica como producto teórico práctico que orienta al docente al dirigir el tratamiento metodológico de la competencia comunicativa oral como esencial en la formación del profesional. De ahí que 
la estrategia didáctica aportada por la investigación sistematiza los referentes teóricos y didácticos sobre su tratamiento en la enseñanza- aprendizaje a fin de lograr el protagonismo de los estudiantes en la producción oral en el área de Comunicación. En ese sentido la propuesta en las manos de los docentes se convierte en un material metodológico que los guía a fin de alcanzar la eficiencia en el proceso de enseñanza- aprendizaje de los estudiantes de IV ciclo de la disciplina de Producción Gráfica de la carrera de Diseño Gráfico de un instituto superior privado de Lima.

\section{Metodología de la investigación}

\section{Tipo y diseño de investigación}

La investigación responde al paradigma socio- crítico interpretativo que se basa en el valor de la objetividad y comprensión sobre los sujetos de estudio, lo que permite orientar las acciones para el cambio. Es una investigación educacional de tipo aplicada porque a partir de un problema científico identificado en la práctica pedagógica se potencia la búsqueda de los referentes teóricos para producir un nuevo conocimiento que permita hacer, actuar, construir y modificar el problema de estudio como refiere Bisquerra (2009). Su identificación se concreta a partir de la observación, análisis e interpretación del problema de estudio visto desde diferentes perspectivas teóricas con un tono holístico por parte de la investigadora. En ella se destaca la naturaleza social del lenguaje y los fundamentos de las didácticas crítico, social y colaborativas generadoras del conocimiento desde la gestión del docente y que orienta al educando a relacionarse con los otros sujetos a través del aprendizaje consciente, comunicativo y significativo.

Mediante la aplicación del método científico se organiza y clasifica los fundamentos teóricos y didácticos, dando paso al análisis de las causas que generan el problema de investigación, así mismo permitirá producir y generar conclusiones avaladas por diversas bases teóricas, que aportan una estrategia didáctica al desempeño pedagógico.

\section{Población, muestra y unidad de análisis}

En la investigación de tipo cualitativa la muestra puede estar conformada por un grupo de personas, acontecimientos, conjunto de comunidades en la cual se extraerán datos significativos sin que necesariamente represente a la población en su totalidad, así como lo define Hernández, Fernández y Batista (2006). 


\section{Población}

La población la conforman ,30 docentes de la carrera de Diseño Gráfico, 310 estudiantes distribuidos en seis ciclos académicos en los turnos diurno y nocturno de un instituto superior privado de Lima

\section{Muestra}

La muestra seleccionada por muestreo no probabilístico por conveniencia, la integran dos docentes de la carrera de Diseño Gráfico que ejercen la docencia en el IV ciclo, así como diez estudiantes del código 34002 DGM de una institución educativa superior de Lima.

\section{Unidades de análisis}

El objeto de estudio está constituido por las siguientes unidades de análisis: docentes, estudiantes, las fuentes teóricas especializadas y la consulta de los documentos normativos que rigen el trabajo en la institución educativa a nivel nacional.

\section{Métodos teóricos}

Para concretar los objetivos propuestos en la presente investigación se emplearán un conjunto de métodos científicos del nivel teórico y empírico, tales como:

los estudiantes de V ciclo de la carrera.

\section{Histórico- lógico}

Según Martínez y Ávila (2011), el método histórico está definido como el estudio del trayecto de los hechos sucedidos durante un determinado tiempo. El método lógico se encarga de investigar en las leyes generales de los diversos fenómenos, así como en el estudio de su naturaleza. Se aplicó en la investigación para conocer los antecedentes históricos vinculados al origen, desarrollo y el estado actual de la competencia comunicativa oral en los estudiantes de Diseño Gráfico.

\section{Método analítico - sintético}

Al respecto, Cerezal y Fiallo (2016), refieren que el análisis consiste en estudiar el comportamiento de las partes que conforman un todo, así mismos los elementos que influyen inherentemente en las otras partes del tema de investigación determinando su conducta. La síntesis se da como resultado del análisis previamente realizado, deduciendo que la investigación pueda estar marcada por una u otra parte de una fase, considerando los procesos cognitivos. Se empleó el análisis y síntesis durante el estudio y sistematización de 
los referentes teóricos y el procesamiento de los resultados obtenido con la aplicación de los instrumentos y en todo el proceso investigativo.

\section{Análisis documental}

Según refieren Cerezal y Fiallo (2016), permite el análisis y recolección de una información objetiva sobre el uso de documentos. Se logra a partir de una recopilación adecuada de datos que permiten redescubrir hechos, situaciones, sugerir problemas, orientar hacia otras fuentes o instrumentos de investigación. Se consideran como parte fundamental del proceso porque enriquece el recojo de datos sobre el problema de la investigación. Se empleó para realizar el análisis de los documentos normativos que aportan y sirven de base a la fundamentación de la investigación. Como instrumento listado de cotejo.

\section{Método de modelación}

Martínez y Ávila (2011), refieren que el método de modelación permite reproducir el objeto que se está estudiando, ya que constituye una reproducción de la realidad para cumplir con la función de descubrir nuevas características del objeto de estudio. Se usó para diseñar la estrategia metodológica para contribuir al desarrollo de la competencia comunicativa oral en los estudiantes de IV ciclo de la disciplina de Producción Gráfica.

\section{Métodos matemáticos}

Según Hernández, Fernández y Baptista (2014), es el método genético indica el origen del objeto, el número entero es originado por la adición indefinida de la unidad a sí misma. Se emplean con la finalidad de realizar los análisis numéricos expresados en porcentajes en cuanto al procesamiento de datos que son obtenidos a través de los diversos instrumentos que se aplicaran en los estudiantes y docentes.

\section{Métodos estadísticos}

Así como refiere Hernández, Fernández y Baptista (2014), la estadística agrupa metódicamente los hechos sociales y susceptibles de descubrirse, y de las ciencias sociales y principalmente de la economía política, las indicaciones precisas que le permiten conocer el origen de los hechos estudiados. Se realizó el procesamiento de datos obtenidos mediante la estadística descriptiva, que permitirá el realizar el análisis y diagnóstico correspondientes. 


\section{Criterio de expertos}

Cerezal y Fiallo (2016), precisan que el criterio de especialistas es un método que exige de la experiencia profesional en una rama del saber que le facultan para ofrecer juicios y valoraciones científicas y considerar la pertinencia y la validez del producto propuesto. Se aplicó con el objetivo de validar la efectividad de la estrategia didáctica modelada para contribuir al desarrollo de la competencia comunicativa oral de los estudiantes en la enseñanza - aprendizaje de la asignatura Producción Gráfica. Como instrumento se emplearon dos rúbricas para evaluar el aspecto interno y externo de la propuesta.

\section{Técnicas e instrumentos}

En la presente investigación se emplearon diversos métodos e instrumentos del nivel empírico que proponen Cerezal y Fiallo (2016), porque argumentan que estos permiten obtener una información objetiva de la realidad investigada.

\section{Observación de clases a los docentes}

Cerezal y Fiallo (2016), refieren que es una técnica de observación de gran valor porque asegura obtener información objetiva al realizarse a través de un estricto control. Se empleó con la finalidad de verificar el nivel de conocimientos teóricos y metodológicos que tienen los docentes sobre la competencia comunicativa oral al dirigir el proceso de enseñanza aprendizaje de la asignatura de Producción Gráfica en el IV ciclo de la carrera de Diseño Gráfico. Se utilizó una guía de observación de clase, una grabadora y se aplicó a tres docentes del área de Diseño Gráfico.

\section{Entrevista semiestructurada a los docentes}

Se aplicó una entrevista semiestructurada a los docentes para constatar el nivel de conocimientos teóricos y didácticos que poseen sobre la competencia comunicativa oral, y las actitudes y habilidades que observan los docentes en los estudiantes frente al desarrollo de una sesión de clase. Para la cual se empleó una guía de entrevista estructurada.

\section{Encuestas a los estudiantes}

La encuesta es una técnica impersonal, se realiza de forma anónima y permite obtener información a través de un cuestionario (Martínez y Ávila, 2011). Se aplicó a los estudiantes del IV ciclo para conocer el nivel de satisfacción que experimenta por la calidad del proceso 
de enseñanza -aprendizaje al tratar la competencia comunicativa oral en la calase de Producción Gráfica. Como instrumento se aplicó un cuestionario con varios ítems.

\section{Prueba pedagógica a los estudiantes}

Es un método que permita acopiar información estandarizada que puede ser cuantitativa y cualitativa para analizarla, contrastarla y llegar a conclusiones, como precisan Cerezal y Fiallo (2016). En la investigación se aplicó a los estudiantes con el propósito de comprobar el nivel de conocimiento y las habilidades desarrolladas sobre la competencia comunicativa oral de la asignatura Producción Gráfica. Como instrumento se usó un cuestionario con cinco ítems.

\section{Novedad científica}

La novedad científica se esboza a partir de la sistematización de los referentes teóricos de forma holística sobre las categorías y subcategorías apriorísticas sobre la competencia comunicativa oral y la modelación de la estrategia didáctica como producto de la investigación que es una herramienta teórica- metodológica para los docentes al guiar la enseñanza- aprendizaje de la asignatura Producción Gráfica, a fin de contribuir al desarrollo de la competencia comunicativa oral en los estudiantes de $\mathrm{V}$ ciclo de la carrera.

\section{Estructura de la tesis}

La tesis se desarrolla a través de la introducción y tres capítulos:

Capítulo I: Se presenta la sistematización teórica de las categorías y subcategorías apriorísticas fundamentadas desde posiciones holísticas a partir de la aplicación del método histórico lógico que ha permitido analizar cómo ha evolucionado el objeto en el campo y asumir posiciones acordes al problema que le dan solidez científica a la investigación y concluye con la matriz de categorización.

Capítulo II: Corresponde al diagnóstico de campo que facilitó constatar el estado actual del problema investigado. A partir del diseño, validación, aplicación, procesamiento y triangulación de la información recolectada en la práctica pedagógica se identificaron las categorías emergentes generales y las influyentes en el desarrollo de la competencia comunicativa oral de los estudiantes de IV ciclo en la enseñanza- aprendizaje de la asignatura Producción Gráfica.

Capítulo III: Se presenta la estrategia didáctica modelada como producto científico resultado del proceso investigativo que aporta fundamenta socioeducativo, psicológico, 
pedagógico y curricular; dosificación de una unidad didáctica y dos clases modelos; concepción de la actividades de aprendizaje para estimular la competencia comunicativa, propuestas de talleres de capacitación orientados a los docentes para contribuir a su desempeño y la validación de la efectividad de la misma mediante el criterio de expertos para su aplicación práctica en la institución educativa donde se identifica el problema de investigación.

Como aspectos finales se presentan las conclusiones generales como resultado del proceso de investigación, las recomendaciones, las referencias y los anexos. 


\section{Capítulo I}

\section{Marco Teórico}

\section{Antecedentes internacional y nacional de la investigación}

La finalidad de este capítulo es presentar algunas referencias acerca de trabajos de investigación tales como tesis de maestría y doctoral aniveles internacionales y así mismo nacional, donde se considera los factores epistemológicos acerca de la competencia comunicativa oral y la estrategia didácticas.

\section{Antecedentes internacionales}

A nivel internacional diversos autores dedican sus estudiosas la comunicación, como Vargas (2014), quien realizó una tesis de maestría en Educación en la Corporación Universitaria Minuto de Dios. Con la finalidad de desarrollar las competencias comunicativas como estrategia pedagógica para favorecer el aprendizaje de los estudiantes de Primaria. La metodología es cualitativa con un diseño de tipo expost facto, descriptivo, cualitativa. La muestra constituida por 20 estudiantes a la cual le aplicó el método aprueba Wechsler de inteligencia, prueba de vocabulario, tamizaje de desarrollo Battelle Screening, prueba de procesamiento fonológico de Lara Serra y Aguilar. Concluyó que el desarrollo de las competencias comunicativas es un resultado del docente por ser el mediador para estimular la motivación y el interés y el aprendizaje significativo en los estudiantes.

Lara (2013), desarrolló una tesis de maestría en educación en el Tecnológico de Monterrey en México, con el fin de reconocer las competencias comunicativas y creativas en la enseñanza-aprendizaje usando las TIC. La metodología es cualitativa descriptiva a través de un proyecto y un diseño de tipo no experimental, descriptivo y cualitativo. La muestra constituida por 18 estudiantes de los primeros ciclos de la carrera de Psicología. Emplearon varios métodos: entrevistas, encuestas y observación que permitieron analizar el problema investigado. Concluye que el pensamiento creativo se expresa a través de la competencia comunicativa oral al expresar ideas originales, por la aplicación de una didáctica activa y la creación de situaciones en el aula que propicie el interés por nuevos contenidos de manera creativa.

Méndez (2013), propone una tesis de maestría en educación del Tecnológico de Monterrey en México, con la finalidad de analizar las competencias comunicativas en la producción escrita de historias de vida por los estudiantes de IX grado noveno. La metodología es cualitativa descriptiva con un diseño de tipo no experimental, etnográfico y 
cualitativo. La muestra constituida por 40 estudiantes a los cuales le aplicó varios métodos: observación, cuestionario, rejilla de evaluación y análisis de documento. Concluye que las competencias comunicativas no se fortalecen debido a que los docentes siguen un plan de trabajo que no se basa en las necesidades del alumnado es por ello que plantear didácticas en las clases motiva a los estudiantes para el adecuado fortalecimiento de estas competencias escritas.

Jaramillo (2009), propuso una tesis de maestría en educación y desarrollo humano en la Universidad de Caldas, Colombia, cuyo propósito es desarrollar la competencia comunicativa oral en el proceso docente educativo. La metodología es cualitativa a través de un proyecto, con un diseño descriptivo, interpretativo. La muestra constituida por 30 docentes de la escuela de Administración, a la cual aplicó: guías de observación y la técnica de estudios de casos. Concluye que la competencia comunicativa oral en los docentes está muy poco valorada, ya que en su formación académica no fue desarrollada y por ello el nivel de estrategias aplicadas en las clases están enfocadas a la parte práctica del estudiante, pero no del desenvolvimiento comunicativo.

Del Risco (2008), desarrolló una tesis de doctor en educación en la Universidad de Granada, España, con el fin de desarrollar la competencia comunicativa oral en el proceso de enseñanza-aprendizaje del idioma español como segunda lengua. La metodología es cualitativa con un diseño de tipo no experimental, descriptivo y cualitativo. La muestra integrada por 157 estudiantes de preparatoria, a los cuales les aplicó diversos métodos: prueba de comprobación del rendimiento escolar, así como cuestionarios y guías de observación. Concluye que el desarrollo de la competencia comunicativa oral está reflejado en el grado de interés que muestran los estudiantes frente a determinados cursos, así como la metodología que aplica el docente para motivar su aprendizaje y generar nuevos recursos lingüísticos.

\section{Antecedentes nacionales}

Guerrero (2017), presenta una tesis de maestría en Ciencias Educativas en la Universidad Nacional de Cajamarca, Perú; el propósito es analizar las estrategias activas interdisciplinarias para fortalecer las habilidades comunicativas en los estudiantes del VII ciclo, de formación magisterial de la provincia de San Ignacio. La metodología es cuantitativa con diseño explicativo causal, preexperimental. La muestra constituida por 20 estudiantes del VII ciclo de la especialidad de educación Primaria, empleando la entrevista 
y observación para analizar el problema de investigación. Concluyó que, la dimensión del habla, no se desarrolla en los estudiantes, puesto que el docente no aplica las adecuadas estrategias en sus sesiones de clase para estimular el interés por parte del educando y fortalecer las habilidades comunicativas.

Rivera (2016), propone una tesis de maestría en investigación y docencia universitaria de la Universidad Inca Garcilaso de la Vega, Perú, con el propósito de analizar el desarrollo del enfoque comunicativo y el aprendizaje del idioma inglés en los estudiantes. La metodología es cuantitativa llevándose a cabo a través de un proyecto, con diseño descriptivo - correlacional. La muestra constituida por 80 estudiantes de V ciclo para la cual se empleó el método de encuesta para analizar el problema de investigación. Finalmente concluyó que la relación del enfoque comunicativo y la fluidez del idioma inglés están altamente relacionado, siendo así que el docente que imparte el curso debe estar capacitado en la enseñanza práctica más que la teórica, logrando así fortalecer las habilidades desde un enfoque comunicativo.

Pedraza (2016), desarrolló una tesis de doctorado en educación de la Universidad César Vallejo, Cutervo, Perú, con el propósito de proponer un programa de estrategias didácticas cognitivas para desarrollar la competencia comunicativa en los estudiantes de Secundaria. La metodología cualitativa aplicada través de un proyecto, con diseño pre experimental, cualitativo. La muestra constituida por 71 estudiantes de primero de Secundaria, empleándose los métodos: histórico tendencial, análisis y síntesis, deducción e inducción, modelación, logrando así analizar el problema de investigación. Concluye que la creación de estrategias didácticas favorece y motiva al educando a desarrollar un nivel de competencia comunicativa con el desempeño del docente, en la aplicación de estrategias en forma organizada y didáctica con ese fin.

Domínguez (2015), presenta una tesis de maestría en educación de la Universidad Nacional de Educación Enrique Guzmán y Valle, Perú, con el objetivo de identificar las estrategias didácticas y el rendimiento académico de los estudiantes de Secundaria. La metodología cuantitativa con alcance correlacional, diseño fue el no experimental de corte transaccional. La muestra constituida por 348 estudiantes, a quienes se les aplicó un cuestionario tipo Likert. Concluyó que las estrategias didácticas son una falencia en los docentes los cuales deben ser capacitados en su correcta aplicación, así como la metodología que imparten los docentes frente a las diversas personalidades de los estudiantes. 
Peña (2014), desarrolló una tesis de maestría en educación en la Universidad de Piura, con la finalidad de identificar la aplicación sistemática de estrategias didácticas de historia, geografía y economía por los docentes de la educación básica regular. La metodología cualitativa través de un proyecto, con diseño no experimental, interpretativo. La muestra integrada por 69 estudiantes, empleándose los instrumentos de lista de cotejo, fichas de análisis documental, encuestas de opinión. Concluye que no todos los docentes aplican las estrategias didácticas atendiendo el contexto cultural y la falta de capacitación en los docentes para mejorar el aprendizaje.

Como resultado del análisis de las investigaciones consultadas se ha profundizado en los conceptos teóricos y metodológicos relacionados con el problema objeto de estudio. Se comprobó que se han realizado diversos intentos por explicar la categoría competencia comunicativa oral y su enseñanza a través del empleo de las estrategias didácticas, aplicadas en las sesiones de clase atendiendo a cada estudiante universitario.

\section{Bosquejo histórico de la enseñanza- aprendizaje de la comunicativa oral en el Perú}

Para realizar el análisis de la evolución de la competencia comunicativa oral y su enseñanza en el Perú se realiza un lacónico estudio, el cual se divide por etapas destacadas como se menciona a continuación:

Etapa de inicio de la competencia comunicativa de 1960 a 1979 del siglo XX.

Sobre los fundamentos teóricos de la competencia comunicativa es necesario realizar un análisis previo para comprender los diversos conceptos que la avalan desde el plano psicológico, donde la disciplina cumple un rol importante en el comportamiento humano; la lingüística como ciencia del lenguaje por su incidencia en el desarrollo del pensamiento, el lenguaje y las habilidades comunicativas, así como la pragmática tratada como una disciplina multifactorial que aporta los referentes teóricos y prácticos de cómo se realiza la comunicación entre los hablantes según sus necesidades y el contexto sociocultural.

Desde esa mirada teórica, se reconoce la categoría conceptual competencia, a partir de la crítica que Chomsky realizó a Skinner sobre su perspectiva del lenguaje, sustentado en el esquema de aprendizaje basado en el binomio estimulo-respuesta, sin considerar el proceso cognitivo, afectivo, volitivo, emocional de la personalidad y el medio sociocultural de los distintos contextos humanos. 
En ese sentido, Chomsky (1960), aporta a la teoría la definición de competencia lingüística, entendida como las capacidades y disposiciones del sujeto para la interpretación y la actuación, pero cabe aseverar que este concepto por sí solo es superficial porque no garantiza una comunicación integral eficiente.

Más tarde, Hymes (1971) amplia las nociones de Chomsky y la propone como el conocimiento tácito de la lengua del hablante - oyente, para lo cual se definen un número determinado de reglas para la creación y producción de oraciones en determinada lengua, contando con la actuación lingüística en diversas situaciones asociados a los factores fisiológicos y sociales.

Analizada desde la perspectiva psicosocial, encontramos los aportes de McClelland (1973), dentro la teoría de las necesidades y la identificación de variables sociales a partir de las cuales explica cómo llegar a la eficacia en el trabajo, situando el término competencia en el campo laboral, tal como se conoce hoy.

En esta etapa prevaleció la competencia lingüística que, aunque fue un avance al dirigir el proceso de enseñanza- aprendizaje desde esa perspectiva, tuvo como limitación su aplicación en términos sociales, ya que en un contexto real todo el proceso E-A se ha mecanizado de tal manera que los estudiantes solo conocen la teoría y sus normas, pero al momento de contrastarlo y aplicarlo en una actuación con su entorno se observa las falencias de este.

Avances en la enseñanza de la competencia comunicativa de 1979 a 1999.

Desde esa óptica psicológica del lenguaje, Piaget (1981) planteó la teoría del desarrollo cognitivo y el uso de las operaciones mentales, considerando la existencia de un conocimiento abstracto del sujeto que interviene en el desarrollo de sus habilidades, pero no hace alusión al rol sociocultural en la formación y desarrollo del pensamiento y el lenguaje en el sujeto.

En contra posición de ello, Canale y Swain (1981), proponen la integración de los procesos comunicacionales y el contexto social, puesto que consideran que la competencia comunicativa está formada por el desarrollo de cuatro dimensiones esenciales las cuales son la competencia lingüística, la sociolingüística, la discursiva y la estratégica. Todas estas dimensiones están inmersas en un aspecto verbal y pragmático donde se evidencia las primeras relaciones de la teoría y la praxis. 
Otro aspecto a tener en cuenta en la competencia comunicativa se aborda congruente con ello, Austin (1982), desde una perspectiva pragmática hace referencia al dominio del código comunicativo, pero argumenta el valor del contexto donde se producen los actos comunicativos en los que los interlocutores argumentan, niegan y formulan preguntas, cuestionan la realidad social y proponen alternativas de soluciones en espacios de colaboración y participación.

Más tarde, Maingueneau (1984), se opone a la concepción chomskiana de la competencia comunicativa, formula en su teoría el concepto de competencia interdiscursiva, donde plantea que el interlocutor debe tener la capacidad de comunicarse eficazmente con su entorno, teniendo como premisa que el discurso debe darse de manera clara y concisa, trabajando un mensaje entendible por los receptores dentro del proceso comunicacional.

Es en esta etapa donde surge el término competencia comunicativa en el entorno social, renovando los paradigmas antes planteados, ya que múltiples autores infieren que la comunicación es un proceso inmerso en la sociedad y la cultura donde este tiene que ser la base para crear un proceso comunicativo donde se trabaje la teoría, pero también su aplicación de manera real, donde se pueda evidenciar la relación entre ambos puntos.

Incorporación de la competencia comunicativa en la enseñanza 2000 a 2015.

Al analizar e integrar los fundamentos planteados por Canales y Swain y los conceptos de interacción, Cot (2000) hace referencia a las funciones sociolingüísticas, textual y la estrategia, con una función meramente interactiva donde plantea el enfoque pragmático como principal eje en el proceso comunicativo.

En esta etapa se destaca el valor de la pragmática, la enunciación y la sociolingüística basado en el hablante, puesto que la interacción de los sujetos permite la construcción del sentido, donde los recursos del lenguaje consideran son empleados en una situación de intercambio comunicativo dependiendo el contexto social en la cual se da la comunicación. Basado en ello, el autor propone la integración de tres niveles del saber-hacer referido a la composición de texto; construcción gramatical y el uso adecuado de las palabras y vocabulario.

Una conceptualización más integral lo propone Van Dijk (2001), quien reflexiona sobre los elementos inmersos en el proceso comunicativo desde el contexto sociocultural; la dimensión lingüística y la dimensión pragmática que están irreversiblemente relacionadas y usadas por el hablante en el acto comunicativo. 
Cabe resaltar que el autor considera que la dimensión cognitiva integrada al proceso comunicativo, ya que en ello se trabaja la producción de significados según el contexto sociocultural del sujeto, es así como plantea el trinomio del discurso: cognición, discurso y sociedad como añaden otros especialistas del tema (Roméu, 2007; Domínguez, 2010, y Cassany, 2016).

Como conclusión, se reconoce en esta etapa la introducción de nuevos elementos teóricos sobre la competencia comunicativa como es el tratamiento a la dimensión cognitiva y el entorno sociocultural para estimular la comunicación y algo esencial es que se privilegia en su enseñanza, las características del hablante, su interacción y adquisición de los conocimientos a partir de sus saberes y experiencias sociocultural previas en el cual se concreta la lengua como enfatiza la lingüística textual como factores esenciales que dan cuenta de su integración en el desarrollo del aprendizaje de la competencia comunicativa.

\section{Fundamentos teóricos del aprendizaje como proceso psicológico}

Para comenzar el análisis sobre el aprendizaje de la competencia comunicativa oral en los estudiantes, es necesario reflexionar y sistematizar los referentes teóricos del aprendizaje escolar como un proceso complejo desde distintas perspectivas.

El término aprendizaje, según refiere la Real Academia de la Lengua Española (RAE, 2014) tiene dos significados: primero. La acción y efecto de aprender algún arte, oficio u otra cosa y segundo. La adquisición por la práctica de una conducta duradera. De ahí se comprende que el aprendizaje se deriva de la acción de aprender de manera práctica, y de forma permanente, ya que los conocimientos adquiridos son mantenidos en la memoria durante toda nuestra vida.

Se reconoce el aprendizaje como un proceso social e individual que incide en la modificación de las esferas cognitivas como producto de las experiencias individual del sujeto al interactuar con el objeto en un contexto sociocultural en que se desenvuelven (Vygotsky 1979; Ausubel, 1983; Piaget, 1981; Castellanos et al, 2007; Ortiz, 2008; Crispín, Caudillo, Doria y Esquivel, Bahamón, 2013 y Mora, 2017).

Existen diversas perspectivas teóricas según la formación de los especialistas que dan cuenta de este proceso de aprendizaje, por ello a continuación se exponen algunos argumentos aportados por los científicos que permiten tener una concepción más amplia y en consecuencia comprenderlo mejor: 
Para Gagné (1965), el aprendizaje es una variación en las capacidades de las personas dependiendo de la retención, ya esta forma parte del proceso de crecimiento del sujeto debido a que el conocimiento está ligado a la disposición y el nivel de interés del receptor.

Relacionado con ese punto de vista Hilgard (1979), asevera que el aprendizaje es un proceso que varía según la reacción frente a determinada situación, considera esto como un fundamento válido para una respuesta inherente, siendo así que el individuo generará su propio conocimiento en base a su nivel de maduración.

Como se aprecia en los argumentos de estos autores, conceptúan el aprendizaje como el proceso que efectivamente genera diversos cambios en el sujeto en lo cognitivo, pero no hace referencia al rol que desempeña lo psicológico, lo social, las motivaciones y lo emocional en el sujeto ante el proceso de aprendizaje de una actividad.

En tal sentido, Piaget (1981), dio un gran aporte a la concepción del aprendizaje de su época, al definirlo como un proceso individual activo de construcción del conocimiento por el sujeto a partir de la asimilación, desequilibrio, acomodación y organización que se produce en las estructuras cognitivas del sujeto por la acción voluntaria y generada por la relación del sujeto con el objeto.

Desde esta perspectiva, asevera que el aprendizaje es un proceso de construcción que se da en la esfera cognitiva enfatizando en el pensamiento y según los periodos etéreos del sujeto, su pensamiento y valor de la enseñanza en el alcance de los objetivos propuesto, sin embardo no explícita el rol decisivo de lo social en el proceso de adquisición y desarrollo del conocimiento y lo circunscribe lo biológico.

Otra posición teórica demuestra Ausubel (1983), con su aporte del aprendizaje significativo. Lo define como un el proceso individual activo, donde se relaciona los saberes previos con el nuevo conocimiento solo si la información se encuentra bien organizada de tal manera que el sujeto pueda asimilarla, procesarla y comprender su valor y utilidad al aplicarlo en la práctica. Como resultado el individuo analiza lo que aprende dándole un valor e importancia relacionado a la aplicación en el contexto sociocultural en la cual se encuentra, logrando así el aprendizaje significativo.

Una posición teórica holística sobre el aprendizaje sostiene Vygotsky (1979), al precisar que es un proceso social (interpersonal) y no solo individual (intrapersonal). Insiste que es a través de la relación del sujeto con el objeto y con los otros sujetos en ambientes 
comunicativos donde se da la apropiación activa y consciente del conocimiento, se genera el desarrollo de las habilidades y las actitudes de forma integral en un contexto sociocultural.

En esa posición teórica se explicita que el proceso de aprender se da a través de dos niveles: interpersonal e intrapersonal, puesto que considera la relación con el objeto y con otros sujetos a través de la comunicación estimulándose el desarrollo de las capacidades, los conocimientos y las habilidades que favorecerán sus actitudes en los contextos socioculturales (Castellano set al; 2007, Gonzáles, 2008; Rico, Santos y Martín, 2013; Ortiz,2012, Freire, 2017 y Mora, 2017).

Como se aprecia en el aprendizaje escolar es un proceso complejo que se da una relación entre el sujeto, la actividad, la comunicación y otros sujetos a partir de la mediación del docente donde se activa la esfera cognitiva, afectiva, volitiva y emocional de la personalidad. Su efectividad se logra con la colaboración, el intercambio de experiencias, la ayuda mutua y la socialización que hace posible la transformación de las formas de pensar, sentir y hacer de los estudiantes influyendo en los niveles crecientes del desarrollo y la formación integral para la vida.

\section{Reflexiones conceptuales acerca de la competencia comunicativa oral}

Sobre la lingüística como ciencia del lenguaje y la comunicación humana como expresión de las lenguas y la comunicación humana existe un gran debate referido a la relación entre pensamiento, lenguaje, el contexto sociocultural y las experiencias como condiciones para lograr comunicativa oral y escrita de los hablantes. Por ello se impone realizar un análisis conceptual que permita una sistematización precisa según los especialistas:

Desde una perspectiva social, Vygotsky (1989) expresa que, el ser humano por ser un ser social que se desarrolla en la socialización con los demás sujetos y que la adquisición del lenguaje tiene su base en las influencias socioculturales estimulándose la esfera cognitiva, afectiva, actitudinal y comunicativa en general a través de su interacción con la actividad y la comunicación en un contexto determinado. En esa interacción lingüística se potencia el desarrollo de las funciones psicológicas superiores (González, 2008; Pérez, 2015 y García y Huamás, 2017).

En general los lingüistas del campo social aseveran que el lenguaje se adquiere y desarrolla en la actividad o el hacer y la comunicación, expresión de ideas y la colaboración del hablante en un contexto con un carácter pragmático que le facultan Enel acto de hablar y en el que intervienen los factores de locución y la per-locución donde se expresa la 
intención y el efecto del mensaje respectivamente. De ese modo la concepción de la competencia oral tiene un fundamento filosófico por la relación entre el pensamiento y el lenguaje y su apropiación tienen carácter instrumental porque su dominio da pase a nuevas conceptualizaciones que le permiten mejorar los significados y aplicaciones en la práctica según las circunstancias (Vygotsky, 1989; Roméu, 2007 y Pérez, 2015).

Al respecto, Chomsky (1972), define la competencia lingüística como las capacidades del hablante a partir del uso de la sintaxis o la normativa del idioma que son los que le permite formar y expresar un mensaje, interpretarlo y asumir una actuación en el acto comunicativo por la posibilidad del sujeto hablante de conceptualiza la realidad a partir del uso del signo lingüístico en la interacción comunicativa.

Esta posición de Chomsky se aprecia que, si bien reconoce la competencia, enfatiza en lo lingüístico y el lenguaje como una forma del pensamiento que permite la comunicación entre los seres humanos, aunque no se hace alusión al rol del contexto donde el hablante produce el discurso ni el carácter pragmático según la intención comunicativa del sujeto por lo que es específica en lo lingüístico.

Otra posición sostiene, Canales y Swain (1981), al referir que la competencia oral es parte de la competencia lingüística y se concreta en tres puntos claves: la lingüística del hablante referida al dominio del vocabulario, la semántica y la fonética. En ese sentido la sociolingüística hace alusión a las normas socioculturales presentes al expresar el mensaje según la lengua materna y la discursiva donde se revela la coherencia en la formulación de las frases, oraciones, el texto y la estrategia donde trata de compensar el fallo de otras su competencia (Cassany,2009; Domínguez,2010 y Pérez,2015).

En este orden de ideas, Van Dijk (2001), incluye como premisa los argumentos de la sociolingüística por su incidencia en la apropiación del contenido para expresarse y comunicar sobre el mismo. Enfatiza en la necesidad de activar los saberes del contexto social en el sujeto para potenciar los procesos cognitivos por su relación con los esquemas mentales como resultado de la interacción del sujeto con los sujetos en la actividad comunicativa. El contexto social es la esencia para potenciar las habilidades comunicativas, el pensamiento y expresarse en función de sus experiencias culturales provocando un nivel de satisfacción en lo que expresa y una mejor interacción con los sujetos y crea condiciones para nuevos aprendizajes (Pérez, 2015 y García y Huamás, 2017). 
A partir de los argumentos analizados se reconoce que los requisitos esenciales para estimular el desarrollo de la competencia comunicativa oral en los educandos son: conocer el tema del discurso, dominio del vocabulario, uso de las normas culturales, cohesión y coherencia del texto, ya sea oral o escrito. Estos requisitos trabajados con intencionalidad, se convierten en habilidades necesarias que contribuyen a la producción y fortalecimiento de la competencia oral que orientan al educando a respetar las características de los distintos textos y a concientizar de manera metacognitiva cuáles son sus logros y las carencias idiomáticas y comunicativas en general (Sales, 2007; Cassany,2009; Domínguez,2010 y Pérez,2015).

En línea con esa posición teórica, Cot (2000), considera que la competencia comunicativa recae en la pragmática que surge como necesidad de los hablantes de expresar sus ideas y su sentir ante un hecho o una circunstancia en un contexto sociocultural específico. Desde esa perspectiva integradora propone la dimensión sociolingüística como una estrategia comunicativa y el texto o mensaje como el componente interactivo que estimula el desarrollo de las habilidades comunicativas en los hablantes, lo cual es compartido por Roméu (2007), Cassany (2009), Domínguez (2010), Lomas y Tusón (2012) y Pérez (2015).

Desde esa óptica, Díaz y Hernández (2010) asevera que en la competencia comunicativa se identifican cuatro factores que debe poseer el hablante para que se concrete el acto comunicativo oral: la capacidad de escuchar y comprender; aceptar las diversas perspectivas de los sujetos, la búsqueda y procesamiento de la información de manera analítica, crítica y el autocontrol emocional en el acto comunicativo, como añaden Sales (2007) y Cassany (2016).

En ese orden de ideas, Sales (2007), postula que la competencia comunicativa se relaciona con las dimensiones del saber hacer y el saber actuar. Ello se concrete y expresa en el acto comunicativo entre los interlocutores según su intencionalidad en un contexto sociocultural. Al respecto, Niño (2008), añade que cuando el hablante sabe comunicarse porque domina estos aspectos, lo aplica al interactuar con sus semejantes a través de las habilidades, las actitudes y asume posiciones autorreguladas según sus intereses e intención comunicativa y el contexto como una persona que ha desarrollado la competencia comunicativa en la sociedad (Domínguez, 2010 y Cassany, 2013). 
Es evidente que ambos autores consideran que el proceso de comunicación es inherente a los seres humanos y a las relaciones interpersonales que entablan estos en los distintos contextos sociales donde la construcción lingüística se da no solo en el plano verbal, sino en lo extraverbal donde se da el acto comunicativo a partir de las influencias culturales del sujeto, del valor que le asigne cada interlocución a lo que se dice y cómo se dice en la realidad.

$\mathrm{Al}$ analizar integralmente las posiciones teóricas sobre la competencia comunicativa, se hace necesario que los docentes conozcan estos argumentos teóricos, los métodos y las estrategias adecuadas para conducir la enseñanza- aprendizaje, de manera que atienda la diversidad del aula con el propósito de estimular la formación y ejercitación de las habilidades comunicativa orales en los estudiantes. En esa línea, Neyra y Ferreira (2011), agregan que el progreso del estudiante se debe entre otros objetivos, al desarrollo del pensamiento y la competencia comunicativa por la necesidad de interactuar en los procesos del ámbito académico, social y producir textos orales y escritos (Sales, 2007 y Lomas y Tusón,2012).

Desde estas concepciones, Reyzabal (2012), añade que, en el desarrollo de la competencia comunicativa, el hablante debe manifestar un saber global, así como la ejercitar las destrezas conceptuales y actitudinales en espacios de diálogos a fin de potenciar el pensamiento, el lenguaje, las construcciones verbales ajustadas las reglas lingüísticas y paralingüísticas para expresarse con fluidez, precisión y coherencia en el discurso (Sales, 2007 y Domínguez,2010).

En relación al argumento anterior, Lomas y Tusón (2012), sostienen que sobre la competencia comunicativa existen diversos enfoques orientados a la enseñanza- aprendizaje de la lengua, teniendo claro que no solo se trata de fomentar la mejora de las habilidades, sino la orientación y el tratamiento de la didáctica del habla, los intereses y el entorno sociocultural de los estudiantes para así lograr un aprendizaje consciente y significado al construir los conocimientos y desarrolle las habilidades..

En la misma línea de ideas, Sergeeva et al. (2018), sostiene que la competencia comunicativa integra el desarrollo de la esfera cognitivo- lingüística- social del sujeto. Se necesita atenderse en la clase desde los primeros niveles educacionales a fin de potenciar los conocimientos y las habilidades intelectuales como: analizar, escuchar, comprender, 
interpretar y expresar ideas, juicios, opiniones, a partir de los saberes previos y en general establecer la comunicación interactiva.

A partir de estos argumentos teóricos, se entiende que la competencia comunicativa oral está formada por un conjunto de conocimientos y habilidades como la fluidez, pronunciación, ajuste al tema y al contexto, el tono de voz y producción coherente del discurso que se requiere potenciar en el estudiante en la enseñanza activa y dialógica de la clase. Al respecto, Loor (2015), expresa que en el ámbito educativo el desarrollo de las habilidades comunicativas necesita para su desarrollo aplicarse las metodologías participativas que permite el intercambio de mensajes comunicativos en los interlocutores a partir de su rol social en el contexto donde se desarrolla.

Según los objetivos que orientan la investigación, se asume como autor de base a Roméu (2007), al definir la competencia comunicativa como un todo integrado por los procesos cognitivos, afectivos, y comunicacionales a través del enfoque sociocultural. Considera que el uso de estas competencias se perfecciona en su aplicación práctica a través de las relaciones interpersonales en el contacto con el mundo social.

De acuerdo con el razonamiento teórico realizado sobre la categoría apriorística, competencia comunicativa oral, se determinó asumir como autora de base a Roméu (2007) y sus seguidores ( Cassany, 2009- 2016; Domínguez, 2010; Neyra y Ferreira, 2011; Reyzabal, 2012; Lomas y Tusón, 2012; Mercer, 2013; Loo,r2015; García y Huamás, 2017) y Neira et al. 2018), por ajustarse al propósito de la investigación.

Desde esta perspectiva teórica integral de la competencia comunicativa oral, se identificaron las subcategorías apriorísticas y los indicadores que permitieron elaborar la a matriz de categorización (Anexo. N. 2)

\section{Subcategorías e indicadores}

\section{Habilidades cognitivas}

Como refiere la autora Roméu (2009), las habilidades cognitivas consisten en la asimilación de un sistema complejo, cuyas operaciones son las encargadas de organizar la información obtenida y contenida en los conocimientos, así mismo se encarga de revelar dicha información al sujeto (Sales, 2007; Niño, 2008; Cassany, 2009- 2016; Domínguez, 2010 y Addine et al. 2015).

Indicadores: 
Explica los fundamentos teóricos de la comunicación

Diferencia la intención comunicativa y la finalidad del autor

Caracteriza los procedimientos y habilidades cognitivas y metacognitivas

\section{Habilidades comunicacionales}

Según Roméu (2007), define las habilidades comunicacionales como una integración de los procesos lingüísticos que se establecen a lo largo de la vida humana, donde se tiene como objetivo la participación efectiva y dinámica con los ámbitos sociales que nos rodean. Es a partir de ello que hablar, escuchar, leer y escribir son inherentes al lenguaje y vitales para establecer vínculos con la cultura y sociedad, modelando así la competencia comunicativa (Sales, 2007; Niño, 2008; Cassany, 2016; Domínguez, 2010; Lomas y Tusón, 2012; Mercer 2013; Loor 2015 y Neira et al. 2018).

Indicadores:

Caracteriza los medios comunicativos: verbales y no verbales.

Argumenta los distintos tipos de textos orales

Maneja los diversos estilos de comunicación

\section{Habilidades socioculturales}

Al respecto plantea Romeu (2007), que las habilidades socioculturales están definidas como el estudio de la conducta y su aplicación en la resolución de problemas de contexto social de manera efectiva, es por ello que se considera como el conjunto de estrategias y capacidades del sujeto para con la sociedad (Cassany, 2009- 2016; Lomas y Tusón, 2012; Mercer 2013; Loor 2015 y Neira et al. 2018).

\section{Indicadores:}

Identifícala cultura y la sociedad en su dimensión semiótica y discursiva

Conoce las relaciones entre participantes a partir de sus intenciones y la clase, grupo social o instituciones a las que pertenecen

Valora la influencia del contexto en lo que se dice y cómo se dice. 


\section{Métodos que estimulan el desarrollo de la competencia comunicativa oral}

Acerca de la categoría método de enseñanza Álvarez (1999), Díaz Barriga (2010), y Addine (2013), postulan que forman un sistema coherente y que orientan la vía, el camino, o la manera de presentar y regular la actividad del docente y la de los alumnos en aras de lograr los objetivos propuestos. El método permite la dinámica del proceso de enseñanzaaprendizaje congruente con el objetivo y el contenido a tratar. Su selección, organización y aplicación trae como consecuencia la interacción necesaria entre el estudiante, el docente y el grupo para garantizar la apropiación activa y consciente del contenido objeto de estudio.

A continuación, se sugieren distintos métodos que pueden usarse en la enseñanzaaprendizaje a fin de estimular la competencia comunicativa oral desde el enfoque cognitivo, comunicativo y sociocultural como refiere Romeu (2007), Sales, 2007; Niño, 2008; Cassany, 2009- 2016; Domínguez, 2010 y otros especialistas.

\section{El método dialéctico}

Definido por Vygotsky (1989), como un método general de aproximación al estudio de las leyes que rigen la sociedad, el pensamiento, la conducta humana y su adaptabilidad en diversos entornos sociocultural, atendiendo a la evolución psicológica de cada individuo como ser social y parte del desarrollo histórico de la humanidad.

En congruencia con ello Romeú (2007), asevera que este método permite la identificación de la proyección del ser humanidad a partir de su pensamiento en los actos comunicativos. En la enseñanza- aprendizaje los estudiantes reconocen la importancia que tienen la comunicación a lo largo de su evolución para lograr la comprensión entre los sujetos y reconocer los diversos factores que intervinieron en el acto propiamente dicho como es el pensamiento, el lenguaje, la sociedad y el contexto para poder expresarse sobre la realidad ante los hechos y fenómenos estudiados.

Al aplicarse en la práctica pedagógica en la clase, se debe partir del análisis del lenguaje de las palabras del contexto, analizar su significado y construir frases, oraciones y otros textos en colaboración con sus compañeros a fin de potenciar el pensamiento, aprender cómo los niveles de la lingüística le permiten construir textos coherentes y con cohesión ajustados a, cómo reaccionado o se produce el habla en cada educando y cómo contextualiza la realidad. Su aplicación requiere de la preparación del docente a fin de abordar la teoría desde variados ejemplos y situaciones de aprendizaje que potencien la comunicación oral entre los estudiantes y asuman posiciones. 


\section{Método global de análisis estructural}

Según Rosano (2011), el método global incide en los estudiantes gracias a su memoria visual el cual permite identificar diversas palabras, frases e incluso oraciones completas que genera en el individuo una imagen asociada a un significado. Obteniendo como resultado la lectura inteligente dejando la mecanización del proceso lector.

Congruente con ello Roméu (2009), refiere que es un método empleado en la clase con el propósito de incidir en la percepción de las diferentes significaciones que puede generar la lectura y discusión de un texto cuando se motiva e interesar a los educandos por su análisis y estudio es una vía para ahondar en la información, para juzgar los personajes, los hechos, los diseños éticos y estéticos que aborda y que al integrarse con las experiencias del hablante, se dan múltiples oportunidades para darle sentido y significado al texto y ser un objetivo excepcional para estimular el desarrollo de la comunicación oral entre los estudiantes (Sales, 2007; Niño, 2008; Cassany, 2009- 2016 y Domínguez, 2010).

$\mathrm{Al}$ aplicarlo de forma práctica en la clase real, se debe partir de la exploración de los saberes previos para adentrarse al análisis del lenguaje, haciéndoles ver cómo han evolucionado a partir de la ampliación de las ciencias, las formas lingüísticas a lo largo de la historia. Su esencia metodológica está en que el docente presente variados ejemplos y establezca un sistema de preguntas para lograr la interacción comunicativa ante las situaciones de aprendizaje que devienen en actos comunicativos.

\section{El método heurístico}

Al respecto, Roméu (2007) y Domínguez (2010), asegura que el método heurístico parte en su aplicación de los saberes empíricos del educando y a partir de un sistema de preguntas mayéutica definir un concepto. El proceder metodológico requiere del diálogo y la interacción comunicativa entre el docente y los estudiantes en el análisis del objeto de estudio. En ese proceso dialéctico se estimula ir de los saberes conocidos a lo desconocido, de lo fácil a lo difícil a fin de ejercitar las habilidades de observación, el análisis, el razonamiento lógico con una rica expresión de ideas hasta descubrir el nuevo conocimiento al que han arribado.

$\mathrm{Al}$ aplicar este método el docente debe presentar situaciones pedagógicas que orienten a las contradicciones cognitivas para estimular el diálogo y hallar soluciones al problema objeto de estudio de forma colaborativa, aplicar lo aprendido y exponer el proceso y el resultado 
obtenido en un ambiente de expresión y de comunicación asertiva (Domínguez, 2010 y Lomas y Tusón, 2012).

\section{Método creativo}

La creatividad es el factor impulsor y pujante de la vida moderna. Ya que favorece un pensamiento y actitud divergente en los individuos; es decir, un cambio, innovativo, diverso, novedoso y de satisfacción para las personas. Álvarez (1999) y Castellanos et al (2007), enfatizan que este método prioriza: promueve la originalidad del pensamiento en la realización de la actividad; ello requiere de una orientación completa para estimular el interés y la motivación en los educandos por realizar las tareas cada vez mejor desde el trabajo colaborativo que realizan en equipos. Ello los interesa por saberse orientados tanto en el qué hacer como en el cómo hacerla a través de situaciones comunicativas. Desde estas posiciones son capaces de evaluarel proceso y los resultados de la actividad y se ponen metas altas (Cruz y Velázquez, 2016).

\section{Método decisorio}

Sobre el método decisorio, Muñoz y Pagés (1991), precisan que asumir posiciones y saber decir como método decisorio tiene como propósito que el sujeto pueda intervenir en la realidad de manera coherente para lograr la comprensión del objeto analizado para poder actuar, hacer o decidir ante una situación equis. Álvarez (1999), considera que es una manera de ejercitar el pensamiento crítico para determinar y tomar decisiones en la ejecución de la solución de problemas comunicativos (Moreno y Velázquez, 2017).

La misma autora, sostiene que por la diversidad y autonomía en que se vive este método es esencial para profundizar en los conocimientos y desarrollar habilidades comunicativas. Por su carácter social e interactivo puede aplicarse a las diversas disciplinas curriculares. Este método es potenciador de la independencia cognoscitiva y personal porque el educando se entrena en la toma de decisiones ante determinadas situaciones de aprendizaje que luego traslada a la vida real.

Al respecto Álvarez (1999), señala los siguientes procedimientos metodológico para lograr la actuación decisoria durante su tratamiento en la clase: identificar una situación e informarse, valorar las distintas alternativas que se puedan presentar para ofrecer un juicio de valor sobre cada situación concretay actuar consecuentemente. 


\section{Método para fortalecer el pensamiento crítico}

El especialista en la didáctica Álvarez de Zayas (2016), refiere que es necesario estimular en los educandos las actitudes críticas, la valoración, la flexibilidad en el aprendizaje y trabajar de forma colaborativa donde todos expresen sus ideas y reflexionen ante una situación de aprendizaje. Es una necesidad generalizada en los diseños curriculares contemporáneos que la escuela, por la urgencia que viven las sociedades, debe tratarse desde las didácticas críticas el fomento de los procesos lógicos del pensamiento (Ennis,2011 y Moreno y Velázquez,2017). La esencia de este método es enseñar a pensar, a tener criterio propio, emitir juicio de valor, formar un pensamiento flexible, cambiante y asertivo con los demás y consigo mismo. Los autores referidos consideran que los pasos metodológicos para activar el ejercicio de la crítica son: identificarel problema a tratar; tener claridad de los puntos a tener en cuenta; acopiar la información sobre la situación estudiada; corroborar la información recogida y; establecer las diferencias de los hechos de las opiniones.

La aplicación de esta metodología estimula en los estudiantes la reflexión la organización del pensamiento al expresarse con seguridad y confianza porque trabajan en equipos donde todos vierten sus criterios, escuchan a sus compañeros y toman acuerdos. Además de asimilar nuevos conocimientos, amplían el vocabulario, ejercitan las acciones en cómo observar, analizar; en cómo sus pares realizan las acciones al resolver los problemas e imitan sus procederes al cooperar y colaborar en los grupos para hacer común los objetivos, compartir las metas, aplican las habilidades metacognitivas, su autoevaluación la calidad de sus productos en un ambiente de convivencia democrática y comunicativa (Cruz y Velázquez, 2017).

\section{El método comunicativo}

Los resultados de las investigaciones lingüísticas refieren que es necesario formar una base lingüística adecuada al estudiar cualquier lengua materna o extranjera con el interés de potenciar las habilidades generales: comprensión, hablar, leer y escribir. En tal sentido, el docente debe recurrirá los métodos y estrategias dialógicas y colaborativa que potencien el desarrollo de las habilidades comunicativas en los estudiantes como refieren Roméu (2007), Domínguez (2010), Lomas y Tusón (2012) y Cassany (2013).

Los métodos comunicativos cuentan con los instrumentos para lograr que los estudiantes se apropien de las habilidades esenciales de la comunicación como es la escucha y la comprensión del mensaje para que se dé la interacción comunicativa. Debe lograrse a través de una situación comunicativa donde se aplique un sistema de preguntas que van de 
lo fácil a lo difícil, a fin de potenciar el pensamiento, el lenguaje con el propósito que los estudiantes empleen estrategias dialógicas tanto en el que como en el cómo expresarse en un ambiente de interacción hasta gradualmente descubrir el objeto.

En el aprendizaje deben aplicarse metodologías activas para incentivar el interés y reforzar los analizadores auditivos, visuales y comunicativos en los estudiantes, conociendo sus formas de aprendizaje, sus niveles de aprendizaje y el tipo de personalidad de cada estudiante desde sus saberes previos, el contexto y actividades que partan de situaciones comunicativas reales en las que deben expresarse libremente al construir los textos orales y escritos.

\section{Método viso - audio - gnòsico - motor}

Es un método que emplea múltiples procedimientos en la enseñanza - aprendizaje a fin de desarrollar las habilidades idiomáticas como: fonológico, la percepción visual, auditiva, lo gnoseológico y se ejercita lo nuevo aprendido en la actividad práctica como precisan Mandojana (1970), Roméu (2007), Domínguez (2010), Cassany (2013) y García y Huamás (2017).

Su propio nombre del método esboza la secuencia metodológica del mismo en la clase. Al trabajar con las palabras no sujetas a reglas se potencian los analizadores: visuales, auditivos, gnoseológico y motor. Se parte de la presentación y análisis de las palabras desde lo fonológico, auditivo y visual, luego loseducandosdeben expresar lo que recuerden de su escritura que comprueban al escuchar o ver la imagen de la palabra; es esencial conocer el significado semántico y lo motor se concreta en que aplica en la actividad práctica la escritura correcta de la palabra a través de diferentes ejercicios a fin de ejercitar las habilidades comunicativas orales y por escrito.

Al respecto, Roméu (2007), señala que la aplicación de este método en la enseñanza - aprendizaje del contenido lingǘstico, requiere del uso de variados procedimientos que generan en el estudiante un reconocimiento visual, auditivo, semántico para favorecer la comprensión de las palabras y las asociaciones lingüísticas y ejercitarlas de forma variada a través de distintos ejercicios en la producción oral y escrita.

Se necesita en la práctica pedagógica, aplicar diferentes métodos de enseñanza en las sesiones de clase con la intención de que los estudiantes se motiven cada día con actividades novedosas que incida en la ampliación de los conocimientos y las habilidades al producir textos orales y redacten mensajes publicitarios con adecuados diseños en los que el docente 
previamente le demuestre primero cómo proceder y luego construyen sus textos publicitarios.

\section{Método del análisis discursivo social}

Sobre el método del análisis discursivo social, expresa VanDjik (1992), que se relaciona directamente con el contexto de los individuos y su desarrollo lingüístico. Es usado con frecuencia con mensajes de costumbres, de religión, cultura, tradiciones, saberes y opiniones de los seres humanos de una región o poblado determinado.

En ese sentido, Roméu (2009), Domínguez (2010) y Cassany (2013), aseveran que la sociedad ha cambiado y hay que despojarse de los dogmatismos tradicionales y rescatar lo positivo que aporta a la cultura idiomática, a la flexibilidad, y vivencial de cada contexto porque en el plano pedagógico promueve la comunicación auténtica bien dirigida por el docente. La prioridad es enfatizar en los procesos de comprensión y construcción de los textos según las exigencias de los diferentes contextos. Por ello se impone atender con carácter prioritario en el proceso de enseñanza- aprendizaje la semántica, la sintaxis, la pragmática discursiva y atender la singularidad al expresarse de cada estudiante.

\section{Método de proyectos}

Es un método que exige de actividades de aprendizaje organizadas a partir de un objetivo que responda a un problema común del grupo de estudiantes o el contexto. A través de las exigencias del trabajo en proyecto los estudiantes previamente orientados se le asigna una tarea que deben resolver entre todos los integrantes (Pimienta, 2012 y Tobón, 2013).

Para lograr el objetivo, debe problematizar sobre la realidad, analizar la información teórica, procesarla, debatirla, comprenderla, asumir posiciones individuales y colectivas para arribar a consensos. De esa manera comunicativa proponen la solución del problema planteado con un plan de intervención que luego proponen ante la sala de clase. De esta manera, los estudiantes tienen la oportunidad de demostrar lo que han aprendido de manera metacognitiva, con autonomía y desarrollan los conocimientos y las habilidades comunicativas sobre su propio aprendizaje y así expresan sus intereses. El método de trabajo en proyectos educativos representa una oportunidad para consolidar la integración de saberes en los estudiantes, ya que a través de ellos confluyen la práctica, la teoría y el trabajo en equipo (Moreno y Velázquez,2017).

Se recomienda el uso sistemático en las clases de los métodos analizados por ser potenciadores del pensamiento y las habilidades comunicativas a fin de lograr el análisis del objetivo, el contexto y el contenido lingüístico con la intención de estimularla producción textos orales diversos. Se debe priorizar el análisis semántico al producir las frases 
publicitarias desde esas experiencias culturales con arreglo a la normativa gramatical, resaltando la coherencia, cohesión en la expresión oral, la escritura del texto, y el diseño.

\section{Fundamentos teóricos sobre la categoría conceptual estrategia didáctica}

Para comenzar el análisis teórico de los fundamentos de la estrategia didáctica es necesario conceptualizar los términos semánticos que componen esta categoría.

Al respecto, De la Torre (2002), suscribe que la estrategia deriva del término strategós el cual se conceptualiza como el arte de dirigir diversas operaciones con la finalidad de lograr la victoria, es por ello que según el autor se consideró un término aceptado en el ámbito educativo después de finalizado la tan famosa Segunda Guerra Mundial.

El término estrategia, según refiere la Real Academia Española RAE (2014), tiene dos significados: uno, el arte de dirigir diversos asuntos, y también como un proceso que se ajusta a las reglas que definen una decisión para cada situación.

Desde esa mirada, Nava (2015), considera la estrategia como un proceso formado por un conjunto de reglas y saberes previos antes de tomar una decisión en la que evidencia diversas actitudes como astucia, imaginación e interpretación entre otras habilidades y destrezas que deberá aplicar en la práctica.

A partir de estos conceptos se concluye que, la categoría estrategia está relacionado directamente a la experiencia y los saberes previos frente a una determinada situación en la cual es necesario la toma de decisiones vista desde un punto racional.

Acerca de la didáctica, Díaz (1992), Álvarez (1999), Manglares y Mejía (2011), Pimienta (2012) y Addine et al.(2015),enfatizan que es una rama de la pedagogía como ciencia que se basa en los fundamentos teóricos, las leyes específicas, las categorías didácticas y los principios didácticos aplicables al proceso de enseñanza- aprendizaje como su objeto de estudio en un contexto sociocultural determinado que tiene como función esencial influir en las formas de pensar, sentir y hacer de los estudiantes de forma integral (Castellanos et al.2007).

Desde la perspectiva didáctica, la estrategia se caracteriza por la aplicación de diferentes procedimientos a fin de lograr en los estudiantes un nivel de motivación para asimilar, procesar la información de forma interactiva la información en el trabajo colaborativo. El docente es un mediador que créalas situaciones de aprendizaje a fin de que 
potencie la adquisición de los saberes en los educandos y producir los textos orales para exponerlos con claridad.

En esa posición teórica, se hace referencia a la estrategia didáctica como un plan de acciones que ejecuta el docente de formar estratégica, teniendo en cuenta el cumplimiento de los objetivos trazados en el proceso de aprendizaje del educando (Pérez, 2015 y Díaz Barriga, 2010).

El docente al guiar o dirigir la enseñanza- aprendizaje, debe aplicar diversos métodos y estrategias con el objetivo de problematizar los saberes previos del estudiantado con el fin de lograr una dinámica, atractiva, novedosa e investigativa durante la asimilación que estimule el pensamiento, las habilidades comunicativas y en general un aprendizaje consciente y metacognitivo que inciden en su formación académica y general.

Sobre la estrategia didáctica, Martínez y Bonachea (2002), expresan que esta se orienta a la enseñanza con diversas acciones educativas, teniendo como referente al docente, que debe cumplir la función de concientizar al estudiante en el aprendizaje significativo, ya que la adecuada motivación y generación de interés de este, permitirá que los conocimientos sean adquiridos de manera eficaz.

En esa posición teórica se comprende que en la estrategia didáctica tiene un rol principal el docente, cuyo propósito es concientizar al estudiante en el aprendizaje y para lograrlo debe definir el objetivo principal a cumplir, tener en cuenta el contexto social, la diversidad de los educandos, sus intereses, la calidad de la actividad para que asimile y aplique lo aprendido en la solución de las tareas.

Por su parte Cruzata (2007), considera que la estrategia didáctica constituye una variante específica de estrategia de enseñanza-aprendizaje, ya que la etapa de planificación está dirigida fundamentalmente a la enseñanza, y la etapa de ejecución está destinada al aprendizaje, aunque ambos procesos se dan juntos y en unidad dialéctica.

En esa misma línea de acción Bixio (2010), refiere que, la estrategia didáctica está formada por un conjunto de acciones que realiza el docente con clara intencionalidad pedagógica. Estas acciones son la puesta en práctica de las teorías y las experiencias que constituyen el conocimiento pedagógico del docente.

Una posición amplia asume, Manglares y Mejía (2011), al definir la estrategia didáctica como el camino indicado para lograr un aprendizaje eficaz en dependencia de que la docente responda a la interrogante: ¿cuáles son los criterios para seleccionar una adecuada 
estrategia didáctica? Porque toda estrategia didáctica debe orientarse a cubrir las necesidades y expectativas de los educandos: 'por ello el maestro innovador crea nuevas estrategias que se adecuen a su contexto para motivar e interesar a los estudiantes.

A partir de ello se comprende que las estrategias didácticas como habilidades, procedimientos o métodos que organizados permiten generar en el educando cierto nivel de interés y un aprendizaje significativo a partir de la calidad de las sesiones de clases y del protagonismo que alcancen los estudiantes en la producción del conocimiento y formación profesional integral.

Es reconocido que cualquier estrategia didáctica orientada a la enseñanzaaprendizaje tienen como principal mediador y motivador al docente, pues es el encargado poner en práctica su maestría pedagógica a fin de estimular, concentrar la atención y el protagonismo de los educandos durante el proceso de observación, asimilación de la información, su procesamiento, producir un nuevo conocimiento y aplicarlo de forma consciente, significativa, metacognitiva y autorregulando su comportamiento en un espacio de socialización y actividad razonada y lúdica.

Una posición teórica más integradora de estrategia didáctica que se corresponde con los objetivos de la investigación, aporta Feo (2010), al definirla como un modelo, compuesto por métodos, procedimientos, técnicas y actividades a través de los cuales el docente y los estudiantes organizan las acciones de manera consciente para construir y lograr metas previstas e imprevistas en el proceso enseñanza- aprendizaje según las necesidades de los participantes de manera significativa.

En resumen, se resalta que la estrategia didáctica se orienta a lograr una clase contemporánea, que responde a las exigencias del alumnado, al programa de asignatura y a los métodos que estimulen el pensamiento y la comunicación a fin de lograr la interacción y la reflexión en los estudiantes en la producción del conocimiento. La estrategia didáctica como un modelo teórico- práctico resultado del proceso de investigación, se argumenta desde posiciones teóricas interdisciplinarias y científicas en general, convirtiéndose en un aporte al campo pedagógico como precisan (Perdomo y Lorence 2003; Velazco y Mosquera,2010, Tobón, 2010).

Los referentes teóricos sistematizados permiten asumir a Feo (2010), como autor de base dela categoría apriorística, estrategia didáctica por ser coherente con los objetivos de la investigación; además se consultaron los aportes dados por otros especialistas que han 
enriquecido la posición teórica de la investigadora como es el caso de: Álvarez (1999), Manglares y Mejía (2011), Tobón (2013), Addine (2013) y Álvarez de Zayas (2016), Desde esta posición teórica se identificaron las subcategorías apriorísticas y los indicadores, cuya matriz de categorización se expone en el (Anexo $\mathrm{N}^{\circ} 2$ ).

\section{Subcategoría e indicadores}

Exigencias del proceso de enseñanza -aprendizaje. Según Castellanos et al. (2007), es un proceso donde tanto la enseñanza como el aprendizaje se basan en una educación desarrolladora caracterizada por la comunicación y una actividad intencionadas, cuyo accionar didáctico genera estrategias de aprendizajes que influyen en el desarrollo de una personalidad integral y autodeterminada del educando en la escuela como institución social portadora de la cultura (Silvestre y Zilbertein, 2011 y Ricoet al; 2013).

Indicadores: Aplica de manera coherente las categorías didácticas; Aplica el diagnóstico y caracteriza el grupo.

Sistema de las categorías didácticas. Está definido como la organización de los medios de enseñanza presentes en las sesiones de clase donde el docente plantea objetivos y metas concretas para lograr un aprendizaje significativo, es por ello que la implementación de un sistema de categorías permite diferir el uso correcto de estos dependiendo de la finalidad deseada por el docente para con los estudiantes, (Silvestre y Zilberstein, 2002; Castellanos et al; 2007; Martínez,2010; Tobón,2013y De Corte, 2015).

Indicadores: Organiza el aprendizaje a partir de los métodos heurísticos, comunicativo, creativo e investigativo; y Orienta la actividad de aprendizaje según la necesidad del estudiante.

Rol del docente. Debe tener maestría pedagógica y dominio de su especialidad y aplicar métodos que potencien el protagonismo estudiantil en la enseñanza- aprendizaje para alcanzar los objetivos instructivos y formativos en los estudiantes de forma integral; debe demostrar madurez, ecuanimidad, seguro de sí que orienta con asertividad el aprendizaje y estimula el desarrollo de las capacidades, los conocimientos y las habilidades integrales. Su accionar profesional se orienta a explorar el nivel de desarrollo real de los estudiantes con el fin de potenciarlos al desarrollo próximo para contribuir al desarrollo integral de la personalidad (Recarey, 2004, Castellanos et al.2007, Ortiz, 2012 y Addine et al. 2015).

Indicadores: Demuestra ser un mediador eficaz que domina el contenido y atiende la diversidad del grupo; Organiza el aprendizaje desde la zona de desarrollo próximo. 
Rol del estudiante. Asume una actitud en la clase que lo hace protagónico, activo, problematizador, dialógico, colaborativo e interactivo que investiga y construye el conocimiento y desarrolla habilidades que le permiten transformar sus formas de pensar, hacer y sentir al actuar. Se convierte en un educando que se motiva e interesa por la actividad de estudio, que incentiva la investigación, la reflexión, la autonomía y aprende de forma significativa y demuestra en sus modos de actuación actitudes positivas y capacidad de autoconocimiento, autoevaluación, autocontrol y autorregulación en su desempeño (Silvestre y Zilberstein, 2011; Castellanos et al. 2007; González, 2008; Martínez, 2010, Tobón, 2013y De Corte,2015).

Indicadores: Demuestra ser responsable y consciente de su propio aprendizaje; Resuelve tareas de aprendizaje individual y en colaboración de manera significativa.

\section{Sistema de métodos sugeridos en la estrategia desde la didáctica con enfoque cognitivo, comunicacional y sociocultural}

La propuesta didáctica sienta sus bases en los fundamentos de un conjunto de métodos desde la aplicación de una didáctica con enfoque cognitivo, comunicacional y sociocultural que permita guiar adecuadamente la enseñanza- aprendizaje; proporcionar las técnicas para que el docente pueda llevar a cabo una adecuada sesión de aprendizaje.

La principal característica del sistema de métodos es su orientación hacia el desarrollo de las competencias establecidas como objetivos en la dosificación de las unidades didácticas puesto que estas se plantean en la evaluación por competencias que se trabaja actualmente en el ámbito educativo.

Los métodos empleados en el marco teórico son el método dialéctico, análisis síntesis, heurístico y modelación, que aportan en la planificación y aplicación de la didáctica con enfoque cognitivo, comunicacional y sociocultural que genera un aprendizaje significativo y la toma de importancia de los educandos en cuanto a los conocimientos, capacidades, competencias y habilidades que deben desarrollar a lo largo de toda la carrera. (Mandojana, 1970; Vygotsky,1989; Castellanos et al; 2007; Roméu, 2009; Cassany, 2010; Díaz Barriga, 2010; Rosano, 2011; Addine, 2013 y Freire, 2017). 


\section{Capítulo II}

\section{Diagnóstico o trabajo de campo}

El diagnóstico de campo se realizó en un instituto privada de Lima, ubicada en el distrito de Lince, provincia de Lima. El propósito de este proceso se orientó a comprobar el nivel de desarrollo de la competencia comunicativa oral desarrollada por los estudiantes del IV ciclo de la asignatura Producción Gráfica de la carrera de Diseño Gráfico.

Durante la sistematización teórica de las categorías apriorísticas permitió adquirir la preparación adecuada para diseñar las técnicas y los instrumentos como: encuesta y prueba pedagógica a estudiantes; y entrevista observación a clases a docentes (Anexos II, III, IV, V). Estos fueron validados, aplicados y procesados a partir de la muestra seleccionada intencionalmente por poseer las condiciones reales para cumplir con el objetivo del proceso de diagnóstico (Anexo 1).

El procesamiento de los datos cualitativos y cuantitativos se realizó mediante las tablas de reducción de los datos de frecuencias; los de orden cualitativo por medio de tablas de reducción de datos y los cualitativos se procesaron con tablas de frecuencias. La información obtenida permitió identificar las categorías emergentes generales o sustantivas del problema de investigación.

\section{Análisis, interpretación y discusión de los resultados}

\section{Análisis de la entrevista a los docentes de la disciplina de Producción Gráfica}

Se realizó una entrevista semiestructurada a dos docentes de la asignatura Producción Gráfica. El proceso de codificación de la información figura en el Anexo Nro. 9 y 10 , y los resultados interpretativos son los siguientes.

Al indagar sobre los fundamentos teóricos de la comunicación, un docente hizo referencia a los orígenes y el segundo manifestó en sus argumentos desconocimientos de los fundamentos. Con ello se demostró falta de preparación teórica y en consecuencia deficiencias al dirigir la enseñanza- aprendizaje su influencia negativa en el desarrollo de los conocimientos y las habilidades estudiantes.

En cuanto a las diferencias entre la intención comunicativa y la finalidad del autor, uno expresó que la intención comunicativa es el preámbulo al objetivo concreto de lo que se quiere lograr en el mensaje; mientras que el segundo lo define como la interpretación de manera subjetiva, pero ninguno de los dos, argumentó los fundamentos concretos que los 
diferencian. Se concluye que los profesores evidencian desconocimientos de los procesos que integran la competencia comunicativa.

Relacionado con la clasificación de las formas elocutivas, ambos manifestaron carencias acerca del tema, evidenciado en la manera superficial de explicarla, puesto que ro no las definieron con exactitud. De ello se infiere que, si los docentes no dominan las formas de elocución, inciden de forma negativa en el desarrollo de las habilidades comunicativas de los educandos.

A cerca de las características de la cultura peruana en la comunicación oral, uno de ellos enfatizó sobre los hábitos que los jóvenes deben practicar, considerando ejemplos adecuados para los estudiantes; y el segundo considera como el nivel de pertinencia de los estudiantes al interactuar y que en el diálogo se puede observar las expresiones de los contextos socioculturales de ellos. Aunque en sus respuestas revelaron algunas ideas ciertas, evidencian desconocimiento del rol de los saberes y las experiencias socioculturales en la construcción del conocimiento.

En cuanto al desarrollo discursivo de los estudiantes, ambos indicaron que los temas familiares no son parte del intercambio docente- estudiante y no es profesional tratarlo. Se aprecia dificultad en la aplicación de métodos dialógicos y comunicativos que le permitan exploras desde la enseñanza- aprendizaje cuáles son las debilidades del educando a fin de darle el tratamiento requerido.

En cuanto a los principios didácticos aplicados en la sesión de clase, uno refiere utilizar videos e imágenes para motivar y facilitar la asimilación del tema; mientras que el segundo indica que al aplicar las teorías constructivistas y al orientar la participación de los estudiantes. Se constata que uno de los docentes refleja determinada preparación didáctica, pero en general se evidencian dificultades en el nivel profesional al dirigir la clase.

Al cuestionar sobre el diagnóstico y tratamiento en la sesión de clase, ambos expresaron que, sí realizan el diagnóstico, pero en el proceso final del semestre, siendo este último el examen final. Se evidencia que no activan los saberes previos y experiencias para constatar el nivel de conocimiento de los estudiantes, lo cual es vital para guiar el proceso de enseñanza - aprendizaje durante el desarrollo de la sesión de clase.

En las actividades de aprendizaje adaptadas a las necesidades del estudiante, un docente manifiesta dialogar con los estudiantes para recabar información sobre las necesidades, y utiliza el método de casuística en el aula; y el segundo indica que solo se guía 
del sílabo de la asignatura. Las actividades orientadas por el docente no están en función de lograr un aprendizaje significativo al no considerar las necesidades de los estudiantes.

Acerca de la preparación previa para la clase, ambos mencionan que buscan información online, para realizar las diapositivas que emplearán en la sesión de clase, la diferencia está en que el primero lee libros y trabaja el tema investigativo, resumiendo esta parte se puede inferir que ambos realizan una investigación en diferentes niveles teóricos, más no involucran la práctica diaria o aplicación de experiencias reales.

Sobre los criterios de cómo aplican en el trabajo individual y colaborativo en las tareas de aprendizaje, ambos plantean que orientan las actividades según las exigencias del proyecto, ya que evalúan si hay gran cantidad de estudiantes en el aula para poder determinar si es individual o grupal. Sus fundamentos son elementales para comprender la complejidad del proceso de aprendizaje, debido al desconocimiento de la didáctica.

En general se constata en los docentes la existencia de falencias en los referentes teóricos y didácticos sobre el tratamiento a la competencia comunicativa oral al desarrollar las clases y guiar la enseñanza- aprendizaje de los estudiantes.

\section{Análisis de la observación a clases a los docentes}

Se observó de forma no participante una clase a un docente de la disciplina Producción Gráfica de la carrera de Diseño Gráfico; el proceso de codificación se presenta en el Anexo Nro. 11, con el resultado siguiente:

Respecto al empleo de la forma elocutiva al vincular el conocimiento previo con el tema de la clase, el docente no se expresó de manera clara, se identificó un inadecuado manejo del aula y la poca indagación en los saberes previos de los estudiantes.

Se pudo visualizar que los estudiantes tienen diversas necesidades de aprendizaje que el docente no identifica de manera precisa, además el diálogo no es participativo ni activo con preguntas aisladas que influye en un ambiente de desinterés en los educandos al inicio de la clase.

En cuanto al desarrollo de la motivación y orientación hacia los objetivos, se observó que el docente no logró crear las condiciones adecuadas para generar una motivación por el tema de la sesión de clase, no aplicó estrategias didácticas, ni contenido novedoso dialógico, lo cual influyó en el desinterés por parte de los estudiantes, evidenciado la falta de orientación hacia los objetivos propuestos para la sesión de clase. 
Relacionado al desarrollo del proceso de enseñanza - aprendizaje, el docente demuestra falta de dominio en el tema, ya que realiza solo una lectura del material cargada de información que no genera ningún tipo de motivación en los estudiantes; se añade a ello, la falta de diseño de la diapositiva presentada, teniendo en cuenta que los estudiantes son de la carrera de Diseño Gráfico es esencial la creatividad e innovación, como referente a los docentes que son especialistas en el tema.

El docente explica toda la sesión y al finalizar realiza una actividad sin mostrar un ejemplo como guía, generando ciertas dudas sobre la finalidad de la actividad; no orienta las acciones adecuadas para la búsqueda de información, razón por la cual se puede visualizar que los estudiantes ingresan a páginas poco confiables para realizar sus piezas gráficas.

En consecuencia, se observar que los estudiantes realizan otras actividades diferentes a las encomendadas, puesto que la actitud del docente no genera precisión en las acciones ni empatía; una evaluación improvisada al finalizar de la clase que genera una alerta entre los estudiantes quienes realizan la actividad por cumplir con una evaluación cuantitativa que no mide con exactitud 1 nuevas ideas ni cómo llevaron a cabo la tarea ni el comportamiento de los estudiantes.

Al finalizar la sesión de clase se observa que el docente carece de criterios de enseñanza y psicológicos al apreciarse su malestar ante el incumplimiento de la actividad encomendada a los estudiantes reflejándose en ellos desinterés y desmotivación por la actividad de aprendizaje que debían realizar.

A su vez se comprueba que el producto de la clase no cumple los lineamientos establecidos indicados por el docente, por tal razón reorienta la actividad para una próxima sesión, explicando categóricamente que los estudiantes deberán cumplir con la labor planteada sin excepción alguna. En general se aprecian deficiencias enel desempeño del docenteal orientar la enseñanza -aprendizaje por la aplicación de una metodológica inadecuada que frena el desarrollo libre de los conocimientos y las habilidades comunicativas orales y escritas en los estudiantes.

\section{Análisis de las encuestas realizadas a los estudiantes}

La encuesta se llevó a cabo con diez estudiantes que reciben la asignatura deProducción Gráfica, el proceso de análisis cuantitativo aparece en el Anexo Nro. 13, reflejando los siguientes resultados interpretativos: 
En cuanto a la utilización de autores que sustenten el contenido visual del diseño gráfico presentados por el docente en la clase, siete estudiantes (70\%) expresan que nunca los utiliza; dos $(20 \%)$ a veces, y uno $(10 \%)$, casi nunca. Ello indica que los docentes no utilizan fuentes de investigación verídicas para promover el diálogo y las habilidades investigativas.

Acerca de cómo identifican el contenido de la clase, siete (70\%), manifestaron que a veces, y tres (30\%), refieren que casi nunca. Se demuestra que el manejo del docente en cuanto a los recursos didácticos es insuficiente y por tanto se limita la asimilación objetiva del aprendizaje planteado en la sesión de clase.

En cuanto a si el docente los incentiva a realizar organizadores visuales en la clase, seis $(60 \%)$, refirieron que nunca realizan organizadores visuales, mientras que cuatro (40\%), expresan que casi nunca. Ello permitió identificar que las estrategias cognitivas y metacognitivas no se emplean en la clase, pues más de la mitad del salón no realizó ningún organizador visual que pueda facilitar una mejor comprensión del contenido.

Respecto al uso de la comunicación verbal y la extraverbal en las publicidades empleada por el docente, siete (70\%), refirieron que a veces logran identificar el tipo de comunicación y tres $(30 \%)$, indico que casi nunca. Se aprecia que los estudiantes no dominan el tema de la comunicación, siendo un punto vital dentro del aprendizaje estudiantil y la base del problema investigado.

$\mathrm{Al}$ indagar por la expresión oral, clara y precisa, cinco (50\%), indicaron que a veces y, dos (20\%), expresan que nunca. Los estudiantes son conscientes de las falencias en cuanto a la buena argumentación y justificación dentro de una exposición, siendo un factor clave en desarrollo interpersonal de los educandos.

En el lenguaje empleado en las publicidades que se analizan en clases, cinco (50\%), expresan que casi nunca; y cuatro (40\%) expresan que a veces logran identificar el lenguaje. Se aprecia que los estudiantes consideran que el análisis del lenguaje no es de importancia y es preocupante porque la asignatura, Producción Gráfica tiene como finalidad la creación de piezas gráficas relacionadas con el lenguaje que se emplea para expresar un mensaje.

En el indicador si el docente los motiva a indagar sobre su contexto para extraer características del público objetivo, 8 (80\%), manifestaron que el docente nunca los motiva a indagar sobre su contexto. Se aprecian deficiencias en cuanto a la metodología docente y 
su integración al contexto sociocultural de los estudiantes en las actividades de aprendizaje, que claramente podrían ayudar a su formación.

Sobre las actividades de aprendizaje a realizar en equipo, se identificó que tres $(30 \%)$ indicaron que nunca y tres (30\%) respondieron que a veces; en el empleo de estrategias didáctica en la clase, se determina que nueve (90\%), indicaron que nunca las utilizan, constituyendo una falencia en la metodología aplicada por el docente de la asignatura de Producción Gráfica.

En general, se comprobó que los estudiantes no le dan la debida importancia al contenido de la asignatura por la falta de aplicación por el docente de los métodos y estrategias didácticas que provoquen el protagonismo de los estudiantes en el desarrollo de las actividades de aprendizaje y por ende afecta su interés y la motivación por lograr el desarrollo de las habilidades comunicativas en general.

\section{Análisis de la prueba pedagógica aplicada Alos estudiantes}

La prueba pedagógica se aplicó a 10 estudiantes del IV ciclo de la carrera de Diseño Gráfico, que reciben la disciplina de Producción Gráfica, sus resultados cuantitativos aparecen en el Anexo Nro. 14 y el análisis de los datos permitió arribar a la siguiente interpretación:

En cuanto al contenido presentado por los 10 estudiantes, se determinó que nueve (90\%), presentaron la información de manera general, sin realizar indagaciones con un nivel de complejidad inferior al resto, a excepción de uno (10\%) que desarrolló de manera original la presentación de la información.

Sobre el ejercicio donde debían evaluar la postura corporal de los estudiantes se determinó que 5 (50\%), realizaron una presentación medianamente efectiva, demostrando algunas posturas incorrectas, así como el poco manejo de la audiencia; tres (30\%), demostraron una presentación nada efectiva ante el público, puesto que reflejan falencias en el dominio del tema y las posturas corporales no fueron las adecuadas para la presentación.

Ante la comprensión del vocabulario empleado 8 (80\%), demostraron dificultades en el empleo de vocabulario acorde a la sustentación y justificación de los temas expuestos y dos estudiantes (20\%) emplearon un vocabulario regular para la presentación del proyecto educativo. 
En cuanto al mensaje planteado en el proyecto, siete (70\%), concluyen que el mensaje comunicativo de la pieza gráfica no es entendible, dos (20\%), emplearon un mensaje algo confuso y 1 estudiantes (10\%), lo expresó de manera coherente y precisa la finalidad del mensaje. De forma general, los estudiantes requieren de una orientación profesional eficiente que los ayude a manifestar de forma adecuada sus hallazgos, e interpretar la finalidad del proyecto plateado con total seguridad.

De los 10 estudiantes, solo cuatro (40\%), obtuvieron un puntaje de ocho según la rúbrica de evaluación; tres (30\%), alcanzaron una calificación de cinco, seis y siete respectivamente y tres (30\%) dieron un promedio de 11 al 16 respectivamente. Evidenciando que la gran mayoría no obtuvo una buena calificación considerando los ítems de la rúbrica de evaluación que se planteó para la prueba pedagógica.

En cuanto a los niveles de competencia comunicativa, se pudo determinar que siete (70\%) se encuentran en el nivel de logro en proceso, indicando que el desarrollo de la competencia no se consolida totalmente, alternando factores didácticos por parte de los docentes; dos (20\%), permanecen a inicio del logro revelándose en el bajo puntaje obtenido; solo un estudiante (10\%) obtuvo el logro destacado y la mayor calificación.

En conclusión, se comprobó que ocho estudiantes desaprobaron al no cumplir con los requisitos de la rúbrica donde se evalúa la competencia comunicativa oral, y solo dos aprobaron. El resultado demuestra que más del 50\% desaprobó, por la falta de una base conceptual, procedimental y actitudinal de la competencia comunicativa de manera general. Ello refleja que el nivel de conocimientos, habilidades y en general el desarrollo de la competencia comunicativa oral de los estudiantes es inferior a las exigencias curriculares del ciclo académico que cursan.

\section{Relaciones analíticas e interpretativas de las categorías emergentes sustantivas}

Al triangular la información obtenida por medio de los resultados alcanzados con la aplicación de los instrumentos del diagnóstico de campo, permitió analizar las coincidencias y las discrepancias existentes al contrastarlos con las referentes teóricos a fin de identificar las categorías emergentes general eso sustantivas del proceso investigativo como se representadas en la siguiente figura. 


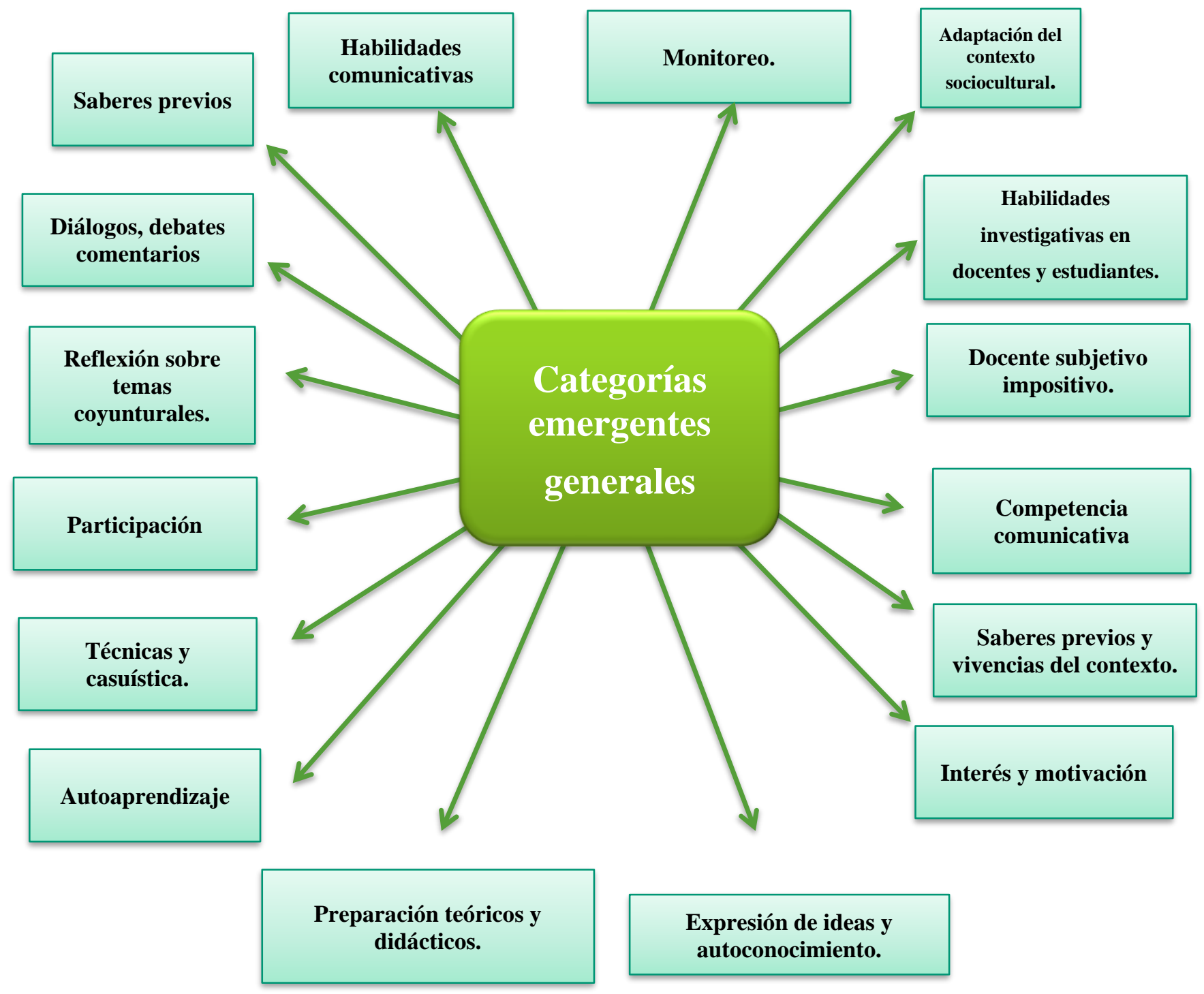

Figura 1. Categorías emergentes sustantivas resultantes del diagnóstico.

Fuente. Elaboración propia (2019).

El análisis integral llevado a cabo alrededor de las categorías emergentes generales o sustantivas, facilitó descubrir las categorías emergentes que influyen negativamente en el problema objeto de la investigación: Falta de preparación didáctica en los docentes al guiar la enseñanza- aprendizaje; El nivel de competencia comunicativa oral de los estudiantes es inferior a las exigencias curriculares; Falta de habilidades investigativas en los estudiantes y falencia institucional.

A continuación, se presenta la figura Nro. 2, en la que se muestra el resultado conclusivo del proceso de triangulación, donde se muestran las categorías y subcategorías 
apriorísticas principales, y las categorías emergentes incidentes negativamente en el problema objeto de la investigación.

\section{Presentación de las categorías apriorísticas y las emergentes incidentes en el problema investigado}

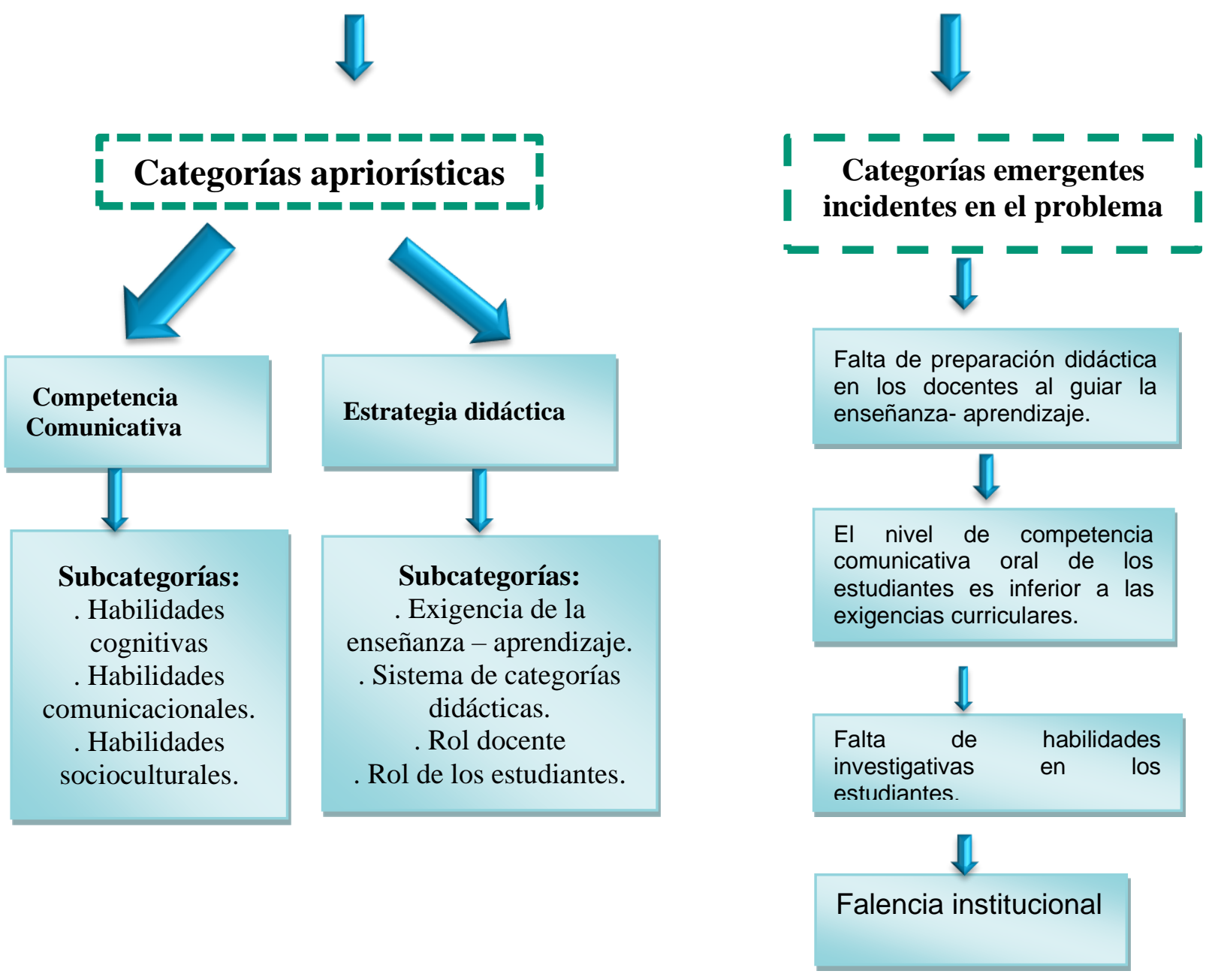

Figura 2. Categorías apriorísticas y emergentes influyentes en el problema.

Fuente. Elaboración propia (2019).

Contratación de las categorías emergentes influyentes en el problema de estudio con los fundamentos teóricos las sustentan

La falta de preparación didáctica de los docentes sobre el aprendizaje y las competencias comunicativas. 
Según La Nuez (2003), Silvestre y Zilberstein (2002), De Armas, Perdomo y Lorence (2003), Castellanos et al. (2007), Feo (2010), Martínez (2010), Tobón (2013) y De Corte (2015), la didáctica es el eje central dentro del proceso enseñanza - aprendizaje, puesto que la aplicación de la diversidad de métodos y las estrategias genera interés, motivación y propicia el aprendizaje significativo en los educandos, razón por la cual las bases de la investigación proponen la estrategia didáctica como centro del accionar del docente al dirigir el proceso de enseñanza- aprendizaje.

En consecuencia, de ello se debe entender la estrategia didáctica como una propuesta a aplicarse en el desarrollo de una clase determinada del programa de asignatura que se lleva a cabo enel aula, con la estrategia didáctica como un modelo teórico- práctico resultado del proceso de investigación que se argumenta desde posiciones teóricas interdisciplinarias y científicas en general, y se convierte en un aporte al campo pedagógico.

Al respecto, se comprobó tanto en la observación a clases y como en la encuesta aplicada a los docentes deficiencias en los principios didáctico que carecen los docentes, puesto que son de vital importancia en el manejo de una sesión de clase, pues estos factores están asociados al nivel de motivación e interés de los estudiantes para con el curso, lo cual se apreció también en las encuestas de los estudiantes, como es el desinterés por las actividades encomendadas por el docente dentro de la asignatura Producción Gráfica, así mismo se pudo constatar la falta de preparación docente en temas de pedagogía ya que no tenían estudios de educación y solo de especialidad .

\section{El docente presenta desconocimientos teóricos sobre la competencia}

\section{comunicativa}

En cuanto a la competencia comunicativa,Chomsky (1995), Ortega (2000), Roldán (2002), Forgas(2006), Romeú(2007), Cassany (2009), y Domínguez /2010), expresan que sus fundamentos teóricos son importantes para el educando, puesto que la competencia lingüística está definida como las capacidades del hablante, donde se trabaja el nivel interpretativito y la actuación de este en el acto comunicativo, entendido por la forma correcta de expresarse y los usos de los signos lingüísticos en la interacción comunicativa.

Los fundamentos teóricos permiten tener una base objetiva y científica acerca del acto comunicativo que se produce en un aula de clase, ya que como docentes competente y profesional se debe tener una base teórica que le permita autorreflexionar al profesor sobre el desempeño personal y asumir nuevos retos al orientar el proceso enseñanza - aprendizaje. 
Respecto a la observación a clases y lasentrevistas aplicadas a los docentes se concluye que existen deficiencias en los fundamentos teóricos y métodos activos sobre abordar la categoría habilidades cognitivas y comunicacionales y su tratamiento adecuado en cada hablante paraestimular un cambio en el proceso de aprendizaje de las habilidades y competencias comunicativas de los estudiantes.

\section{Falencia en las exigencias curriculares e institucionales en el proceso pedagógico}

En el perfil de la carrera de Diseño Gráfico en laasignatura Producción Gráfica que se desarrolla en el cuarto ciclo, se exige a los estudiantes mostrar habilidades comunicativas para lograr la finalidad del curso, así como las relaciones interpersonales que son clave para el proceso de aprendizaje. En cuanto a las exigencias institucionales existenfalencias, puesto que el desarrollo del silabo es creado por los docentes, a lo que incurre en una falta debido que estos no son profesores de carrera, la gran mayoría son especialistas de otras profesiones, lo cual le impide aplicar unametodología variada y especializada que influya en la calidad del proceso de enseñanza- aprendizaje.

En la observación a clases y en la encuesta aplicada a los estudiantes se constató la falta de aplicación de metodologías activas en la clase y que los contenidos del sílabo no se adaptan a las necesidades de los estudiantes, al dejarse de lado contenidosesenciales que deberíanser atendido como parte del contenido. Ahí se notan las deficiencias en la gestión institucional al no trazarse las directrices precisas a fin de lograr en los docentes un desempeño cualitativamente superior que incida en el desarrollo de la competencia comunicativa oral en los estudiantes; en general la institución deja al libre arbitrio de los docentes el diseño de los sílabos de las asignaturas.

\section{Falta de habilidades investigativas en docentes y estudiantes}

Al respecto, Martínez (2010), Díaz y Hernández (2010), Pimienta (2012), Tobón (2013), Addine et al. (2015) y Álvarez (2016), infieren que las habilidades investigativas tienen que estar inmersas en las estrategias didácticas, ya que en la actualidad uno de los principales ejes de la educación es la innovación, razón por las cual debemos fomentar la investigación tanto en estudiantes y docentes.

De acuerdo a lo mencionado, se apreció en la observación a clase, que los estudiantes ingresan a páginas poco confiables para indagar y analizar información para crear una pieza gráfica, razón por la cual se demuestra el bajo nivel investigativo de los estudiantes y la falta 
de supervisión docente para establecer una guía correcta en la búsqueda de información que alimente su desempeño y logre un aprendizaje significativo.

\section{Conclusiones aproximativas de los análisis realizados en esta parte de la investigación}

A partir del análisis de los indicadores en el diagnóstico de campo, se pudo determinar que la pedagogía aplicada en el aula de clase por parte del docente cuenta con una carencia en la metodología didáctica que aplica en las sesiones de clases, puesto que se pudo comprobar que los docentes no aplican estrategias didácticas para motivar y generar el interés por el aprendizaje significativo de los educandos en la asignatura de Producción Gráfica.

En consecuencia, se pudo analizar que el nivel de competencia comunicativa en los estudiantes objetos del estudio, denotan una clara falencia en el desarrollo de dichas capacidades. A ello se suma la falta didáctica en la aplicación de actividades grupales que motiven e incentiven en el desarrollo de la comunicación interpersonal de los estudiantes.

Por su parte, el Instituto cuenta con falencias en la base pedagogía debido a que no se observa un monitoreo constante del aprendizaje de los estudiantes ni de la metodología aplicada por sus docentes, así como la falta de infraestructura que no acota participación en el proceso pedagógico ni a la comodidad de los estudiantes en su crecimiento estudiantil.

La triangulación de los resultado obtenidos y la contratación de los fundamentos teóricos con el diagnóstico de campo, permitió obtener una comprensión holística del problema objeto de estudio, así como la identificación de las categorías emergentes influyentes en el problema, que permiten la adecuada modelación de la estrategia didáctica y su contribución el desarrollo de la competencia comunicativa oral en la asignatura de Producción Gráfica en los estudiantes de IV ciclo de una institución superior privada de Lima. 


\section{Capítulo III}

\section{Modelación, validación y aplicación de la propuesta}

Como resultado del proceso de diagnóstico o trabajo de campo se identificaron las categorías emergentes sustantivas y las que inciden negativamente en el aprendizaje y desarrollo de la competencia comunicativa oral de los estudiantes en el proceso enseñanza - aprendizaje de la asignatura Producción Gráfica por lo que procedió con la modelación de la estrategia didáctica para transformar la realidad.

\section{Propósito de la estrategia didáctica propuesta}

El objetivo de la estrategia didáctica modelada se orienta a contribuir al desarrollo de la competencia comunicativa oral en los estudiantes desde la dinámica del proceso de enseñanza- aprendizaje de la disciplina de Producción Gráfica, como respuesta al problema científico de contribuir al desarrollo de los conocimientos y las habilidades comunicativas orales de los estudiantes.

\section{Fundamentos de la estrategia didáctica propuesta}

\section{Fundamento socioeducativo}

La propuesta está dirigida a los estudiantes de laasignatura de Producción Gráfica del IV ciclo de la carrera de Diseño Gráfico de un instituto superior privado de Lima, ubicada en el distrito de Cercado de Lima. Este es uno de los 43 distritos que componen la ciudad capital en la parte Oeste del territorio peruano, en el que viven 268,352habitantes según el Instituto Nacional de Estadística e Informática (2017).

El instituto educativo es una empresa privada con prestigio profesional y sin fines de lucro que cuenta con 2000estudiantes distribuidos en seis carreras. La población estudiantil del ciclo 2018-1 de la carrera de Diseño Gráfico que recibe la asignatura Producción Gráfica es de30 educandos, distribuidos en dos secciones de clase en el turno diurno y nocturno. En el claustro pedagógico se cuenta con dos profesores especializados en la carrera que se desempeña en la docencia. En general, la institución educativa muestra una gran disposición por la investigación científica planteada, al igual que el resto de los docentes involucrados de la escuela, expresan su consentimiento por la investigación, así como el interés por mejorar los procesos educativos de su gestión. 


\section{Fundamento psicológico}

La edad de los estudiantes que asisten a la institución cursa el IV ciclo, oscilan entre los 18 años y 27 años. En el instituto se brindan los servicios de formación a las carreras técnicasa través de distintas especialidades. Se aprecia que muchos estudiantes no están interesados por la teoría que reciben en las sesiones de clases, es así que en la propuesta didáctica se ha considerado el tratamiento a la motivación a partir de los métodos y actividades que propicien cambiar la realidad. En tal sentido el docente tendrá un desempeño idóneo a fin de orientar con precisión y según las necesidades a los estudiantes, los cuales aún afrontan el desarrollo psicológico, físico y biológico de su personalidad.

En tal sentido se fortalece en el docente como eje metodológico permanente, la comunicación con el estudiante a fin de conocerlo e indagar acerca de sus necesidades y características peculiares que puedan ayudarlo a mejorar su situación. Por ello se aplica el diagnóstico psicopedagógico, para identificar sus fortalezas, necesidades e intervenir con el tratamiento peronológico con el propósito de estimular el interés y la motivación en los estudiantes y se logre un nivel de conocimiento y habilidades comunicativas superior como indica los lineamientos de la carrera.

Al conocer las necesidades de los estudiantes se puede orientar y guiar el proceso de aprendizaje atendiendo a las capacidades y estilos de aprendizaje de cada uno. El docente se convierte en el facilitador y ejemplo del futuro profesional. Es el guía que interviene los aspectos psicológicos y afectivos sobre la realidad que lo rodea, ya que muchos de los estudiantes que se encuentran en el turno noche, no siempre tienen la ayuda económica familiar, y tienen que trabajar en otros sectores para tener una solvencia económica que les permita obtener una educación y lograr ser un futuro profesional. Estas situaciones que intervienen en el proceso educativo, son vitales en la propuesta didáctica desarrollada dentro de la investigación, ya que se basa en fundamentos teóricos y prácticos de la aplicación pedagógica a través de la estrategia didáctica, teniendo a diferentes referentes teóricos (Gonzáles, 2008; Cassany, 2009; Tobón, 2013; De Corte, 2015; Ortiz, 2012 y Mora, 2017), entre otros teóricos consultados.

\section{Fundamento pedagógico}

En cuanto a la pedagogía se parte de esta como ciencia social que tiene como objeto de estudio la formación integral del ser humano para la vida (Álvarez, 1999 y Addine, 2013). Congruente con ello se asume la didáctica de la lengua con el enfoque 
comunicativo, cognitivo y sociocultural propuesto por Roméu (2007), por sus fundamentos en cómo estimula la capacidad de pensar, expresar ideas y producir el propio conocimiento, a partir del análisis situacional sociocultural.

En ese sentido se asume la estrategia como el soporte de las teorías contemporáneas, pues al ser practicadas en el proceso de enseñanza - aprendizaje se convierten en las famosas estrategias didácticas pues su funcionalidad es meramente educativa.

Es a través de la estrategia didáctica modelada desde los fundamentos de Feo, (2010), se logró un modelo teórico práctico integrado por objetivos, contenidos, métodos, procedimientos, técnicas y actividades a través de los cuales el docente y los estudiantes organizan las acciones de manera consciente para construir y lograr metas previstas e imprevistas en el proceso enseñanza - aprendizaje, adaptándose a las necesidades de los participantes de manera significativa.

Ello se cumple refuerza en la enseñanza- aprendizaje a partir del conjunto de leyes, principio y teorías de la didáctica que le dan lógica y coherencia a la clase para lograr un aprendizaje consciente, a través de la unidad dialéctica entre la instrucción, la educación y el desarrollo integral del estudiante en sus formas de pensar, hacer y sentir en el estudiante (Silvestre y Zilberstein (2002 y Castellanos et al; 2007).

\section{Fundamentos de la asignatura Producción Gráfica}

Enel perfil de la carrera de Diseño Gráfico de un instituto superior de Lima, se plantea que los estudiantes deben desarrollar los conocimientos y las habilidades del diseño gráfico en todas sus manifestaciones; ganar en el dominio de las herramientas y las estrategias comunicacionales que lo conduzcan al desarrollo de las competencias comunicativas como diseñador, que deberá ir alcanzado en su tránsito por los distintos ciclos de la carrera. Sin embargo, en la práctica docente de la disciplina Producción Gráfica para los estudiantes de IV ciclo se evidencian carencias en el dominio de los conocimientos y las habilidades, reflejados en la falta de argumentos al sustentar sus ideas, muestra de un pensamiento reproductivo, pobreza de vocabulario y de construcciones gramaticales, de falta de comprensión en lo escuchado, dificultades al explicar la justificación de las piezas gráficas creadas, no sabe cómo iniciar y terminar un diálogo sencillo, y falta de creatividad al expresar su punto de vista, emitir juicios o hacer valoraciones y al construir textos orales escritos. 


\section{Fundamentos curriculares}

El diseño de la propuesta didáctica se basa en el aprendizaje de la competencia comunicativa oral, en la Ley General de Educación para los Institutos N 28044 (2005) del Perú, en su Artículo $\mathrm{N}^{\circ} 25$, donde precisa que el proceso pedagógico se dé en las aulas de clase con el propósito que los educandos construyan el conocimiento, desarrollen las relaciones interpersonales, lo cual incide en la ejercitación de la competencia comunicativa.Ese propósito se refuerza con los fundamentos teórico de la concepción curricular del aprendizaje por competencia, su tratamiento a través de métodos comunicativos, heurísticos y dialógicos en aras de potenciar las capacidades, conocimientos, actitudes, valores y las habilidades comunicativas orales. Esta propuesta concibe al como centro y un ente activo en el proceso educativo (Álvarez 1999, Addine 2013yTobón 2013).

Por otro lado, el marco curricular está orientado a satisfacer las demandas del estudiante sobre el mundo globalizado, las necesidades nacionales y las del aula. En este sentido se resalta el desarrollo de las habilidades comunicacionales y socioculturales para su aplicación en la práctica y la contribuir al desarrollo de la competencia comunicativa oral en los estudiantes (Minedu, 2016).

Para una comprensión docente de cómo promover el desarrollo de la competencia comunicativa oral en el aula como lo establece el Currículo Nacional dentro de la asignatura de Producción Gráfica se diseña, planifica, sistematiza la siguiente unidad didáctica. La unidad se inicia con el título que describe de manera creativa y precisa la idea central de la sesión de clase, reflejando toda la secuencia didáctica y el desarrollo del aprendizaje empleado en situaciones reales.

Los enfoques transversales propuestos para las unidades permiten el fortalecimiento de los valores como el respeto, tolerancia y responsabilidad. Estos deben integrarse en las todas las áreas de la carrera para poder complementar los contenidos educativos, logrando así el enfoque de las necesidades establecidas por el instituto y el contexto del estudiante.

El tratamiento de las competencias, capacidades e indicadores en la concepción de la enseñanza, se convierten en los objetivos cualitativos que se espera lograr en los estudiantes en la enseñanza-aprendizaje. Los indicadores orientan a conseguir los niveles de logro del perfil del estudiante con respecto a cada una de las capacidades y el ciclo que les corresponden. 
La estructura de la secuencia didáctica, se orienta a fomentar el desarrollo de las capacidades establecidas por unidades de estudio. En ello se precisan los métodos de enseñanza - aprendizaje para guiar las actividades de aprendizaje por el docente a fin de estimular en los estudiantes la motivación y el interés por realizar las tareas en las sesiones de clases para potenciar el aprendizaje significativo de los estudiantes.

Después de haber detallado la secuencia lógica de las sesiones es preciso estructurar cada una de ellas empezando con el título, puesto que debe representar los conocimientos que se imparten en cada una de las sesiones, seguido de la especificación de la competencia, capacidad y desempeño o indicador desarrollado.

Se finaliza con la descripción de cada una de las actividades que serán evaluadas y los materiales necesarios para el desarrollo de las sesiones. La evaluación plantea las técnicas e instrumentos, para identificar la competencia, capacidad e indicador que se espera lograr.

Para una adecuada interpretación de las dimensiones que integran el currículo de la carrera de Diseño Gráfico de un instituto de educación superior, se presenta a continuación la dosificación de la unidad temática número uno de la asignatura de Producción Gráfica, como se observa en la siguiente tabla $\mathrm{N}^{\circ} 1$, donde se analiza la planificación didáctica de la unidad propuesta, y en el Anexo $\mathrm{N}^{\circ} 17$ que presenta la unidad de forma más detallada.

Como parte de la disciplina Producción Gráfica se propone la siguiente dosificación de la unidad didáctica $\mathrm{N}^{\circ} 1$ para una mejor planificación y organización del sistema de clases. 
Tabla 1

Dosificación de la Unidad Didáctica Número I

\begin{tabular}{|c|c|c|c|c|c|c|}
\hline $\begin{array}{c}\text { SESIÓN DE } \\
\text { APRENDIZAJE } \\
\end{array}$ & CONOCIMIENTOS & COMPETENCIAS & CAPACIDADES & VALORES & $\begin{array}{l}\text { INDICADORES DE } \\
\text { EVALUACIÓN }\end{array}$ & MÉTODOS \\
\hline $\begin{array}{l}\text { Sesión 1: } \\
\text { Conociendo el origen de la } \\
\text { escritura en el mundo } \\
\text { antiguo. }\end{array}$ & $\begin{array}{l}\text { Selecciona los } \\
\text { conceptos } \\
\text { fundamentales de la } \\
\text { Producción Gráfica. }\end{array}$ & $\begin{array}{lr}\text { Interpreta } & \text { los } \\
\text { conceptos } & \text { de } \\
\text { Producción } & \text { Gráfica } \\
\text { en un } & \text { nivel }\end{array}$ & $\begin{array}{l}\text { Reconoce momentos } \\
\text { importantes de la } \\
\text { historia y } \\
\text { movimientos los } \\
\text { del }\end{array}$ & \multirow{5}{*}{$\begin{array}{l}\text { Responsabilidad } \\
\text {, laboriosidad, } \\
\text { honestidad } \\
\text { Solidaridad, } \\
\text { ética, } \\
\text { emprendimiento } \\
\text {, puntualidad, } \\
\text { tolerancia } \\
\text { Igualdad. }\end{array}$} & \multirow{5}{*}{ 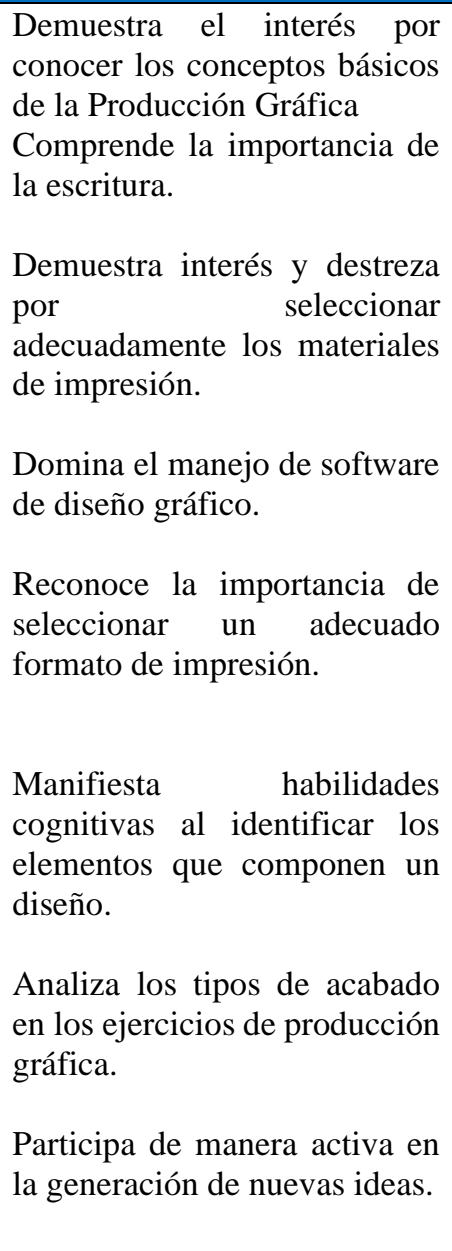 } & $\begin{array}{l}\text { Método investigativo, } \\
\text { problémico, creativo y } \\
\text { método crítico. }\end{array}$ \\
\hline $\begin{array}{l}\text { Sesión 2: } \\
\text { Desarrollando } \\
\text { habilidades en } \\
\text { Producción Gráfica. }\end{array}$ & $\begin{array}{l}\text { Comprende la } \\
\text { importancia del } \\
\text { origen de la historia } \\
\text { y la escritura. }\end{array}$ & investigativo. & diseño gráfico. & & & $\begin{array}{l}\text { Método investigativo, } \\
\text { heurístico y método } \\
\text { decisorio. }\end{array}$ \\
\hline $\begin{array}{ll}\text { Sesión 3: } & \\
\text { Experimentando } & \text { en } \\
\text { diversos formatos de } \\
\text { impresión. }\end{array}$ & $\begin{array}{l}\text { Identifica los tipos } \\
\text { de impresión y } \\
\text { formatos } \\
\text { disponibles. } \\
\text { Determina las }\end{array}$ & $\begin{array}{l}\text { Comprende } \\
\text { utilización de tipos de } \\
\text { impresión en la } \\
\text { creación de piezas } \\
\text { gráficas. }\end{array}$ & $\begin{array}{l}\text { Analiza los tipos de } \\
\text { impresión por cada } \\
\text { tipo de pieza gráfica. }\end{array}$ & & & $\begin{array}{l}\text { Método de solución de } \\
\text { problemas, método } \\
\text { investigativo y método } \\
\text { crítico. }\end{array}$ \\
\hline 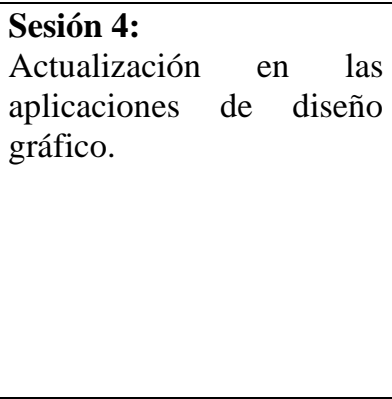 & $\begin{array}{l}\text { diferencias entre las } \\
\text { aplicaciones de } \\
\text { diseño gráfico. } \\
\text { Manejo adecuado de } \\
\text { los formatos de } \\
\text { impresión. } \\
\\
\text { Identifica } \\
\text { elementos los } \\
\text { lenforman }\end{array}$ & & & & & $\begin{array}{lr}\text { Método heurístico, } \\
\text { método de solución de } \\
\text { problemas, método } \\
\text { decisorio y método } \\
\text { crítico. }\end{array}$ \\
\hline $\begin{array}{l}\text { Sesión 5: } \\
\text { Creación de productos } \\
\text { gráficos. }\end{array}$ & $\begin{array}{l}\text { diseños } \\
\text { publicitarios. } \\
\text { Identifica los tipos } \\
\text { de acabado y }\end{array}$ & $\begin{array}{l}\text { Integra los medios } \\
\text { convencionales en la } \\
\text { creación de nuevas } \\
\text { propuestas gráficas. }\end{array}$ & $\begin{array}{l}\text { Identifica los medios } \\
\text { convencionales para } \\
\text { la elaboración de } \\
\text { piezas. }\end{array}$ & & & $\begin{array}{l}\text { Método de solución de } \\
\text { problemas y método } \\
\text { decisorio. }\end{array}$ \\
\hline
\end{tabular}




\begin{tabular}{|c|c|c|c|c|c|}
\hline $\begin{array}{l}\text { Sesión 6: } \\
\text { Elementos que conforman } \\
\text { los diseños de impresos. }\end{array}$ & \multirow{3}{*}{$\begin{array}{l}\text { resuelve } \\
\text { adecuadamente las } \\
\text { tareas planteadas. } \\
\text { Desarrolla } \\
\text { ejercicios sobre la } \\
\text { implementación de } \\
\text { pre-prensa. }\end{array}$} & & & $\begin{array}{l}\text { Evidencia dominio de } \\
\text { habilidades en los trabajos en } \\
\text { equipo para mejorar el } \\
\text { aprendizaje sobre pre prensa. }\end{array}$ & $\begin{array}{l}\text { Método heurístico, } \\
\text { Método de solución de } \\
\text { problemas y método } \\
\text { decisorio. }\end{array}$ \\
\hline $\begin{array}{l}\text { Sesión 7: } \\
\text { Reconociendo los tipos de } \\
\text { acabados en los productos } \\
\text { impresos. }\end{array}$ & & \multirow[t]{2}{*}{$\begin{array}{l}\text { Identifica la } \\
\text { presentación final de } \\
\text { las piezas gráficas. }\end{array}$} & \multirow[t]{2}{*}{$\begin{array}{l}\text { Evalúa y toma } \\
\text { medidas correctivas } \\
\text { en la presentación } \\
\text { final y acabados } \\
\text { gráficos. }\end{array}$} & & $\begin{array}{l}\text { Método investigativo y } \\
\text { método crítico }\end{array}$ \\
\hline $\begin{array}{l}\text { Sesión 8: } \\
\text { Ingresando al mundo de } \\
\text { pre-prensa }\end{array}$ & & & & & $\begin{array}{l}\text { Método heurístico y } \\
\text { método investigativo }\end{array}$ \\
\hline
\end{tabular}

Fuente: Elaboración propia (2019). 


\section{Diseño gráfico funcional de la propuesta de la estrategia didáctica}

A continuación se presenta el esquema teórico- funcional que representa la lógica interna de la estrategia didáctica diseñada basada en los principios, las leyes y teorías didáctica planteadas por (Castellanos et al; 2007; Roméu, 2007; Cassany, 2009; Ortiz, 2008; Díaz- Barriga, 2010; Domínguez, 2010, Feo, 2010) y Addine, 2013), contextualizadas al objeto de la investigación, así como los fundamentos: socioeducativos, psicológicos, pedagógicos, curriculares y propios de la asignatura Producción gráfica en los estudiantes de V ciclo de la carrera de Diseño Gráfico de un instituto educativo de Lima.

La proyección del sistema de clases de la unidad analizada, se proyecta al docente que debe aplicar los fundamentos del aprendizaje como proceso social e individual complejo a fin de lograr el desarrollo de la competencia comunicativa oral de los educandos desde la aplicación del proceso de enseñanza- aprendizaje y los sustentos teóricos de la estrategia didáctica enfatizando en los métodos que le dan protagonismo a los estudiantes al asimilar los contenidos tratados en la sesión de clase según la dosificación realizada y la integración del contexto sociocultural del grupo de estudiantes.

Para ello se aplicó el diagnóstico pedagógico, que permitió identificar las fortalezas y carencias de los estudiantes en las habilidades comunicativas y el empleo de los métodos investigativos, heurístico, creativos y dialógicos que deben aplicarse de forma variada en la clase, con el propósito de estimular el desarrollo de un aprendizaje consciente, metacognitivo y autorregulado en los educandos. Considerando el camino cognoscitivo y práctico se deben ejercitar los conocimientos y las habilidades adquiridas en la solución de los problemas como se expresa en el esquema teórico funcional que representa la interrelación lógica de la propuesta modelada como producto teórico- práctico del proceso de investigación. 


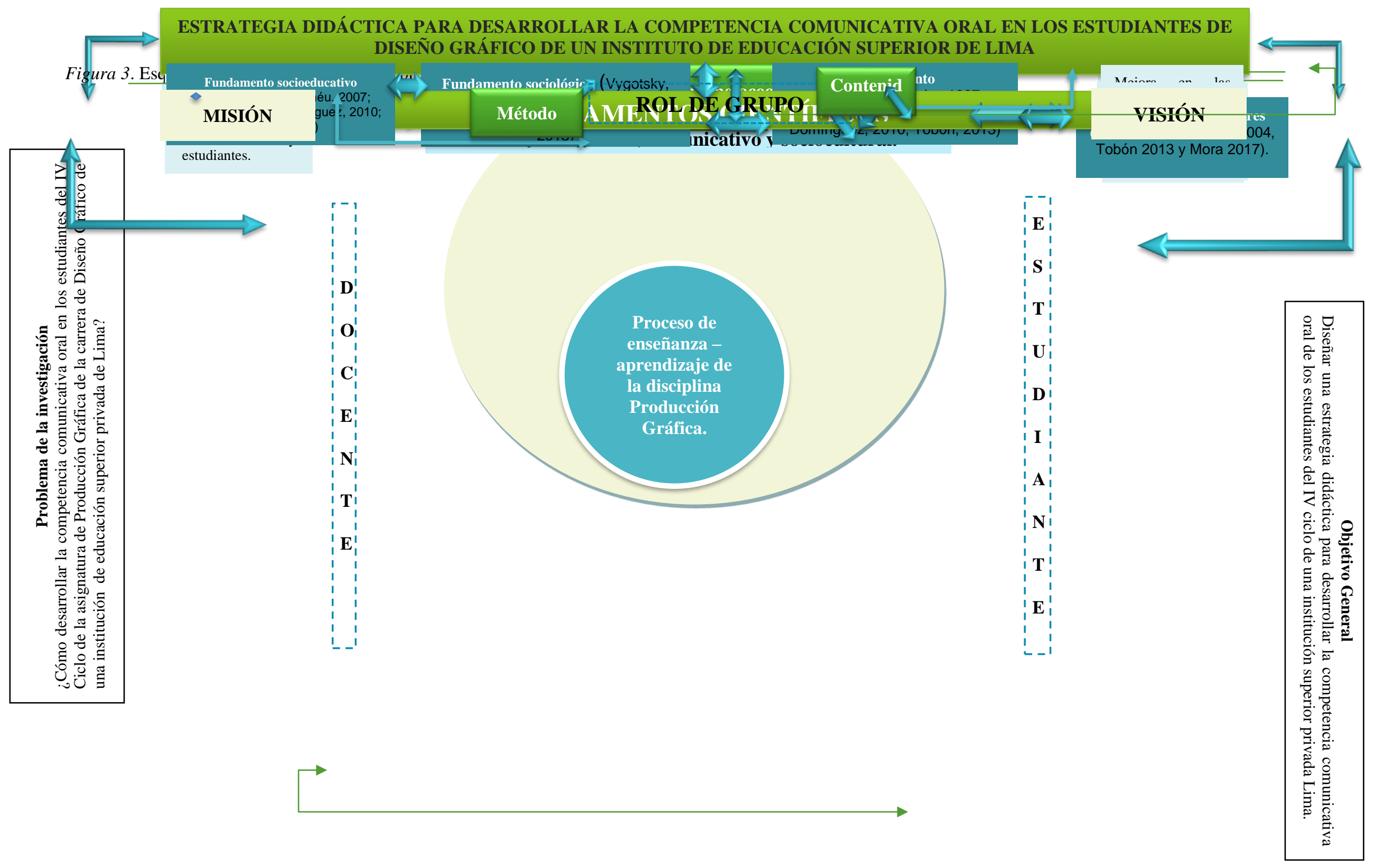




\section{Principios didácticos que rigen la enseñanza- aprendizaje de la estrategia propuesta}

La estrategia didáctica propuesta se sustenta en las bases científicas de la Pedagogía y la didáctica como ciencia que concibe la enseñanza- aprendizaje como un proceso planificado, organizado, conducido y controlado, integrado por categorías, principios y leyes didácticas. Se asumen los principios didácticos planteados por Díaz (1999) y Addine et al. (2015), contextualizados al modelo que se propone según el diagnóstico:

Principio del carácter científico. El carácter científico está el dominio por el docente del contenido de la asignatura Producción Gráfica y la didáctica para garantizar la dirección de la actividad cognoscitiva, valorativa y práctica que proporcione el desarrollo de la competencia comunicativa oral en los estudiantes.

Principio de la vinculación de la educación con la vida. El contenido de la enseñanza aprendizaje parte de los saberes, experiencias y vivencias previas del estudiante. El docente debe a través de sus acciones intencionadas, el vínculo del contenido con su contexto social, y el educando al producir los conocimientos según las necesidades comunicativas, la comprensión y la producción de texto orales.

Principio de la asequibilidad. Se requiere que el contenido de la clase se aborde desde lo sencillo a lo complejo, de lo conocido a lo desconocido, de lo fácil a lo difícil y de lo concreto a lo abstracto atendiendo a las características cognitivas de los estudiantes.

Principio de la sistematización de la enseñanza. Se presentan los contenidos de manera sistémica de manera que puedan ser asimilados por los educandos a partir de una secuencia lógica de lo aprendido, aprendan el nuevo contenido y reflexionen sobre las actitudes positivas que deben demostrar en sus acciones al compartir con sus compañeros.

Principio de la relación de la teoría con la práctica. El estudiante se enfrenta a una serie de contenidos teóricos que debe procesarlo a través de diversas habilidades cognitivas que pone en práctica en la actividad en diferentes situaciones de aprendizaje; ello le permite vincular la teoría con la práctica con el fin de que interioricen su valor, utilidad y se interesen por aprender y solucionar problemas.

Principio de la unidad de lo abstracto y lo concreto. Los estudiantes mediante la observación y análisis de las situaciones de aprendizaje, problematizan y socializan sus puntos de vista a fin de identificar, interpretar sus abstracciones, comprensión y las generalizaciones con la actividad concreta de estudio al comunicarse oralmente. 
Principio del carácter educativo de la enseñanza. El análisis humanístico donde se integran la dimensión instructiva y educativa del contenido. El estudiante aprende el valor y utilidad de lo que aprende al interactuar, reflexionar y producir un nuevo conocimiento que al ejercitarlos desarrolla las habilidades comunicativas orales.

Principio del carácter activo y consciente de los estudiantes. Los estudiantes orientados por el docente desarrollarán el pensamiento y son conscientes de lo que aprenden, de su responsabilidad al dar opiniones, al participar en los debates y expresar sus ideas. Ello se logra con la aplicación de métodos que favorezca el rol protagónico del educando, pues cuanto más conscientes mejor se orientarán y tomarán decisiones para mejorar sus comportamientos y comunicarse mejor.

Principio de la solidez de la asimilación de los conocimientos y las habilidades. Sobre la base de lo aprendido, se ejercitan diversos ejercicios con el fin de potenciar lo aprendido y lograr la solidez en la asimilación del nuevo contenido con el propósito de que los estudiantes construyen el conocimiento y desarrollan las habilidades y hábitos de socialización y comunicación al trabajaren equipos como una vía para formar y consolidar las actitudes y la competencia comunicativa oral.

Principio de la atención a las diferencias individuales dentro del carácter colectivo. Se requiere de un diagnóstico para conocer carencias y fortalezas de cada estudiante con el objetivo de brindarle el tratamiento respetando las individualidades, pero enfocado al trabajo cooperativo y colaborativo, socializador y la convivencia a fin de estimular la competencia comunicativa oral.

En resumen, los principios didácticos al desarrollar las clases y proponer las actividades de manera que estos se integren y le dan rigor científico, lógica y ritmo a la enseñanza- aprendizaje a través de la problematización, el diálogo y la reflexión al tratar el contenido para estimular un aprendizaje metacognitivo en los educandos que los empodera de los conocimientos y las habilidades para comunicarse oralmente.

\section{Estructura y características de la estrategia didáctica modelada}

\section{Carácter integrador}

El diseño de la estrategia se fundamenta en la integración de diversos factores que contribuyen en la organización y el desarrollo de las actividades de aprendizaje, de acuerdo a lo mencionado se proporciona un sistema basado en el adecuado desarrollo de las habilidades 
comunicativas de los estudiantes, y el análisis interno de los contenidos a nivel afectivo, cognitivo, actitudinal y emocional.

Carácter sistémico. Se organizó la propuesta desde una perspectiva compleja que integra en su estructura el área académica, laboral, investigativa y personal, que permite una interacción activa en el ámbito educativo (Fingermann, 2012). Lograr una sistematización optima requiere de un proceso coherente e integrador que cumpla con todas las etapas estipuladas como: el diagnostico, el diseño, la implementación y la evaluación cualitativa de los estudiantes.

Carácter creativo. Las estrategias propuestas contribuyen con el fortalecimiento de las diversas destrezas que permiten ejercitar los conocimientos de manera innovadora, logrando que el estudiante explore nuevas direcciones y sean capaces de transformar la realidad. El principal objetivo es estimular la autoexpresión reflejada en el potencial individual y la concientización del aprendizaje en el contexto profesional, es por ello que el docente debe integrar la creatividad en la resolución de actividades complejas que permita desarrollar ampliamente en los estudiantes el sentido de transformación de la realidad desde su perspectiva como futuro profesional.

Carácter comunicativo. La propuesta se origina desde la naturaleza comunicativa real extraída de la actualidad social y lingüística de los estudiantes, reforzando su participación en diversos contextos necesarios para el proceso de enseñanza - aprendizaje de la Producción Gráfica. Dentro de ese marco, autores como Romeú (2007), Domínguez (2010) y Cassany (2013), concluyen que la tarea comunicativa permite la integración del realismo y autenticidad de la sesión de clase que genera en los estudiantes la necesidad de comunicarse y asignar significados. Razón por la cual los docentes cumplen el rol de facilitadores del aprendizaje, estructurando objetivos claros y específicos aplicados a su contexto.

\section{Misión de la estrategia didáctica propuesta}

La estrategia presentada involucra las categorías emergentes incidentes en el problema de estudio de la competencia comunicativa oral de los estudiantes y el nivel de preparación teórica y didáctica de los docentes con la finalidad de trasformar el proceso de enseñanzaaprendizaje de la disciplina Producción Gráfica.

\section{Visión de la estrategia}

La estrategia presentada cumple la misión de transformar el proceso de enseñanzaaprendizaje de la disciplina Producción Gráfica, con el fin de lograr el máximo desarrollo de la competencia comunicativa oral de los estudiantes y el nivel de preparación teórica y 
didáctica de los docentes con la finalidad de transformar su desempeño en un rol eficiente en la enseñanza, que involucren los diversos paradigmas sociales, lingüísticos, psicológicos y culturales de los educandos para alcanzar un nivel de motivación e interés por la investigación, el autoaprendizaje, así como la autoevaluación necesarios para lograr el desarrollo de la competencia comunicativa oral.

\section{Objetivo de la estrategia}

El principal objetivo de la estrategia es contribuir perfeccionar el nivel de preparación teórica y didáctica de los docentes, al dirigir la enseñanza- aprendizaje desde el paradigma social, linguiístico, psicológico y cultural de la disciplina Producción Gráfica, a fin de lograr el desarrollo de la competencia oral en los estudiantes e incidir en el interés por la investigación, el autoaprendizaje, la autoevaluación y autoaprendizaje que redunde en el desarrollo de la competencia comunicativa oral del educando.

A partir del objetivo se establecen las alternativas para potenciar el desarrollo de las capacidades, los conocimientos, las habilidades y la competencia comunicativa oral que se concretan en dos líneas de acción estratégicas orientadas a los participantes principales y los lineamientos metodológicos específicos de la propuesta:

El primer lineamiento, reorienta la aplicación de actividades que propicien internalización del contenido a partir de problemáticas, situaciones dialógicas, cognoscitivas y reflexivas que desencadenen en el estudiante la necesidad de comunicación y dominio de sus habilidades permitiéndole su actuar personal o colectivo, académica y profesional.

La segunda se proyecta a la capacitación teórica, didáctica y metodológica de los docentes de la disciplina de estudio con el objetivo de incidir en su desempeño profesional para dirigir el proceso de enseñanza- aprendizaje a partir de la aplicación de situaciones comunicativas problematizadoras, colaborativas y creativas desde un enfoque integral a fin de ejercitar las habilidades de reflexionar por sí mismo, analizar, analizar el contenido, comunicar sus puntos de vistas, sentimientos y relacionarse asertivamente con sus iguales al realizar las tareas donde debe primar la construcción de textos orales para potenciar el desarrollo de la competencia comunicativa oral y la formación integral de los educandos.

Congruente con la segunda línea de acción orientada a la capacitación metodológica de los docentes de la institución diagnosticada, se diseñaron un conjunto de talleres teóricopráctico para contribuir a su preparación profesional para dirigir el proceso de enseñanza aprendizaje y lograr el desarrollo de la inteligencia emocional. 


\section{Concepción de la didáctica de la lengua en la propuesta}

Los fundamentos teóricos y científicos de la didáctica de la lengua se integran dialécticamente al enfoque cognitivo, comunicativo y sociocultural (Roméu, 2007 y Cassany, 2009). Desde esta posición teórica, las categorías didácticas se proyectan con el objeto de desarrollar la competencia comunicativa oral en los estudiantes a través del proceso de enseñanza - aprendizaje de la disciplina de Producción Gráfica.

La categoría didáctica problema. Es el resultado de la contracción originada en el estudiante frente a los conocimientos nuevos con los ya establecidos, produciéndose de ese modo que el aprendiz vaya en busca de otras fuentes de información próxima "otros participantes" a fin de encontrar soporte y orientación en el proceso de dar una solución a la problemática propuesta, generándose un andamiaje de tipo cognitivo. Asimismo, este proceso impulsa la utilización del autocontrol y la autorregulación de los procedimientos lógicos mentales, facilitando el aprendizaje significativo y contribuyendo a la formación integral del estudiante.

Dentro de este marco, el papel del docente se ve reflejado en esta categoría ya que su rol orientador se evidencia durante el desarrollo de las actividades ya sea en la interiorización de los conocimientos, habilidades o destrezas como en la apropiación actitudinal y valorativa. En virtud de la propuesta, la problemática radica en el bajo nivel de desarrollo de las habilidades orales en los estudiantes.

Categoría objetivo. Se orienta al reconocimiento del problema en el acto pedagógico, igualmente el objetivo se procesa tomando en cuenta las acciones para modelar el resultado anhelado. Se concreta en la contradicción que se da entre los saberes adquiridos ya por el estudiante y el nuevo aprendizaje que va a desarrollar en el proceso de enseñanza aprendizaje.

Por ello se requiere del docente un sistema de preguntas para explorar lo conocido, sobre sus vivencias y experiencias del contexto y formulará otras interrogantes, cuyas respuestas no conocen para genera el conflicto cognitivo. Atendiendo a estas consideraciones, el alcanzar un nivel adecuado en la motivación e interés de los educandos se formula y orienta el logro de aprendizaje esperado en la clase.

Categoría contenida. Según Castellanos et al. (2007), Addine, Recarey, Fuxày Fernández, (2015) y Álvarez de Zayas (2016), el contenido cumple una funcionalidad integral. Desde su función instructiva, educativa y desarrollador se integran en la actividad de aprendizaje de tal forma que el estudiante aplique sus conocimientos, refleje su manera de 
pensar, actuar, sentir y el hacer dándole el valor personal y social a lo aprendido para la vida con un carácter pedagógico. El contenido de la asignatura de Producción Gráfica comprende temas de los distintos niveles de la lengua que se tratan en la clase con un enfoque profesional propios de la especialidad o carrera con la intención de que reafirmen el interés por la asignatura a partir de la base gnoseológica, procedimental y actitudinal. La estrategia propuesta tiene por contenido de la enseñanza- aprendizaje el aprendizaje de los conocimientos y las habilidades de oralidad que le permitirá a los estudiantes desde su estudio, fomentar los valores éticos - profesionales y comunicarse de forma eficiente.

Categoría métodos de enseñanza. Los métodos permiten establecen un sistema estructurado de actividades y procedimientos que indica el camino, la vía o la forma que regula la actividad del profesor y la de los estudiantes por alcanzar los objetivos trazados. El método orienta la dinámica del proceso de enseñanza - aprendizaje en su relación con el objetivo y el contenido a tratar. Su selección, organización y aplicación deviene en interacciones vitales entre el estudiante, el docente y el grupo para garantizar la asimilación consciente del contenido objeto de estudioque van acorde con los contenidos específicos propios de la especialidad (Álvarez, 1996; Castellanos et al ,2007; Pimienta, 2012; Zilberstein, y Silvestre, 2011; Addine, Recarey, Fuxà y Fernàndez,2015 y Álvarez de Zayas, 2016).

La estrategia diseñada potencia el aprendizaje de la comunicación oral a través de la aplicación de los métodos comunicativos, productivos, dialógicos, heurísticos, colaborativos y actividades que exigen del esfuerzo mental, la interacción cognoscitiva y la creatividad, a fin de desarrollar los conocimientos lingüísticos y la competencia comunicativa oral. La elaboración de las tareas cognoscitivas llevará al aprendiz aplicar sus conocimientos a través de procedimientos polémicos, heurísticos, colaborativos y participativos que favorezca la estimulación del pensamiento, el lenguaje y la comunicación oral de los estudiantes en la clase de la asignatura de Producción Gráfica.

Categoría medios de enseñanza. Este componente permite la objetivación del contenido de la enseñanza, provoca en los educandos la observación, el activismo y facilitan la comunicación bidireccional efectiva entre los protagonistas permitiéndoles alcanzar los objetivos planteados sin llegar a suplir la función educativa en el proceso. En este sentido, los docentes deben tener pleno conocimiento de cómo usar los medios audiovisuales elegidos con el objetivo de facilitar la comprensión del contenido, avivar el interés y objetivar la enseñanza- aprendizaje. Los medios de enseñanza propuestos deben incidir en la memoria visual, auditiva y gnoseológico de las clases de palabras, frases, oraciones y el diálogo que son esenciales desde la Didáctica de la lengua integrado dialécticamente al enfoque cognitivo, 
comunicativo y sociocultural (Roméu, 2007; Cassany, 2009 y Díaz y Hernández, 2010) que fundamenta la asimilación, las funciones intelectuales para la adquisición del conocimiento, el desarrollo de la competencia comunicativa en los educandos.

Categoría evaluación. Desde el punto de vista de Álvarez de Zayas (1999), Castellanos (2007) y Addine (2013), afirman que la evaluación es una categoría didáctica esencial para incidir en el desarrollo, evolución y efectos satisfactorios en r el estudiante en el ámbito educativo, ya sea por su naturaleza totalizadora al obtener una funcionalidad compleja de índole instructiva - educativa al lograr la calidad en el hecho de evaluar o de ser evaluado. Basa el progreso integral de los estudiantes a la recolección de información pertinente y análisis prospectivo de acuerdo con los resultados evidenciados por el docente que llevara a la mejora sistemática y la redirección de la futura planificación.

La estrategia modelada, sugiere la aplicación de la evaluación diagnóstica, formativa, procesual, criterial y sumativa como parte del proceso de aprendizaje que influye en que el educando sea consciente de lo que aprende y cómo aprende. Es una concepción evaluativa del aprendizaje que potencia el desarrollo de la crítica, la reflexión y la formación del sujeto en los aspectos cognitivos, procedimentales y actitudinales. Es un tipo de evaluación que requiere del docente una orientación constante del qué y cómo aprende, a partir de los métodos participativos que fomenta el interés, la motivación y eleva los niveles de calidad del aprendizaje y fomenta la independencia cognoscitiva y el proceder ético- moral del estudiante.

Se recomienda hacer uso de las técnicas e instrumento de la evaluación formativa como: las rúbricas, el cuestionario, la ficha de observación, lista de cotejo, ficha de autoevaluación, coevaluación y heteroevaluación que propicia el desarrollo de las habilidades metacognitivos, interpersonales, el autoconocimiento de sí y el ejercicio de la crítica y la autocrítica. Estos instrumentos orientan al estudiante a reflexionar respecto a su desempeño en la tarea realizada en cuanto a qué hizo, cómo y orientarse mejor en las acciones a realizar para mejorar tanto en lo académico como en lo actitudinal.

El rol del docente. En la opinión de Castellanos et al. (2007) y Díaz y Hernández (2010), el rol docente es de mediador, guía y orientador social entre la cultura y el estudiante. La interiorización de los contenidos seleccionados ayuda a la formación de la personalidad del educando frente a la sociedad, siendo necesaria la instauración de un espacio pedagógico oportuno que exhorte a todos a aprender y a construir su aprendizaje de forma progresiva hacia niveles superiores.

El docente cumple una función orientadora y metodológica articulando el trabajo pedagógico con las competencias transversales durante el proceso de asimilación y 
producción del conocimiento; su rol docente va más allá de instruir y responder a las dudas que se presentan, sino que se contempla el tratamiento psicológico, la inclusión de actividades creatividad, la innovación y la autonomía en el ejercicio profesional con miras de lograr un aprendizaje desarrollador.

En este sentido la estrategia diseñada acoge la perspectiva de Cassany (2010) y Díaz Barriga (2013), sobre la función del docente en aula catalogándolo de organizador de metodologías y facilitador de saberes en un proceso de consolidación de conocimientos en donde el educando autoevalúa su propia práctica estimulando a buscar, seleccionar y procesar de forma significativa su aprendizaje. En consecuencia, el educador debe proporcionar y aplicar una variedad de tareas de aprendizaje que vayan de lo fácil a lo difícil; emplear diversos recursos didácticos para estimular la motivación y métodos problémicos, heurísticos y comunicativos que den respuesta a las expectativas, intereses y capacidades de los estudiantes donde asuman un rol protagónico.

El rol del estudiante. A juicio de Castellanos et al. (2007), Ortiz (2008), Tobón (2009) y Addine (2013), el estudiante debe ser protagonista, responsable y activo en el proceso de asimilación y procesamiento de la información hasta construir el conocimiento. Debe ser un participante activo en la construcción de su propio aprendizaje, ello lo conducirá a pensar y reflexionar en la actividad de manera metacognitivos, autorregulada y autoevaluando la pertinencia de sus acciones en interacción con sus iguales de forma solidaria y respetuosa.

La tarea de aprendizaje debe exigirle al estudiante, deberá esforzar su pensamiento al realizar acciones intelectuales de indagación, predicción y crear tareas productivas en todas las etapas de la actividad. Al realizar un ejercicio el educando debe concientizar las acciones, y los procedimientos a realizar para la búsqueda del qué aprender, qué utilidad tiene lo aprendido, para qué le sirve mediante la problematización al trabajar en grupo donde socializan sus ideas, opiniones, consensuan y proponen la solución al problema planteado lo que potencia la comunicación oral y el aprendizaje significativo.

En ese sentido, Fullan y Langworthy (2014), precisa que el docente y el estudiante deben ser colaboradores donde todos aprenden y enseñan en los diferentes momentos del proceso educativo. El estudiante explora y construye su conocimiento a través de la orientación y el diálogo con otros compañeros donde socializan ideas, identifican sus necesidades, investigan y resuelven conflictos donde ponen a prueba sus saberes en todos los sentidos. Desde esta posición, el educando se convierte en un agente reflexivo, eficaz y consciente de su propia formación profesional que le permita tener una experiencia de un aprendizaje enriquecedor y real que fortalezca su confianza a medida que no dependa de 
límites que dificulten su proceso.

El rol del grupo. El grupo lo integran un conjunto de estudiantes que construyen su propia identidad alcanzando niveles superiores de autonomía funcional producto de la interrelación con sus iguales en un ambiente cuyas condiciones motivan la actuación individual y colectiva mediante trabajos grupales, colaborativos y formativos (Castellanos et al. (2007, 2007).

Para que el estudiante alcance autonomía a niveles sobresalientes es necesario que interactúe con los demás en contextos que fomenten su accionar autónomo y verdadero; visto desde un enfoque histórico- cultural. Al respecto Castellanos $(2002,2007)$, estima que el aprendizaje en forma grupal es un proceso de interrelación e influencia mutua que permite el descubrimiento gradual de las propias potencialidades y limitaciones del estudiante. Precisamente en la comunicación generada entre los participantes que lo conforman cumplimiento de las normas y funciones orientando la interiorización de los contenidos.

Los estudios significan que la actividad grupal da la oportunidad a los educandos socializar las ideas, relacionarse con sus compañeros y debatir sobre el contenido propiciando una apropiación eficiente, producir conocimientos y reconstruir las experiencias en un diálogo y ayuda mutua que modifica y mejora las destrezas sociales en el plano individual y grupal. El docente incentiva la realización de las actividades en colectivo, asignándoles roles a los estudiantes que favorezcan el desenvolvimiento de la personalidad y en el autocontrol para lograr el desarrollo satisfactorio de la actividad.

Otro aspecto es la forma de organización de la clase Sobre las formas de organizar la clase, Ortiz (2012), Addine (2013) y Rico et al (2013), afirman que, de la interrelación entre los protagonistas de la clase, deviene en un accionar integral continua donde los componentes didácticos y los personales cumplen una labor esencial en el proceso enseñanza -aprendizaje al garantizar el cumplimiento de los objetivos propuestos. Es necesario planificar el proceso de la clase de forma interactiva entre el profesor - alumno, potenciarlos con actividades que promuevan el pensamiento y las habilidades en el trabajo colaborativo.

Los métodos dialógicos y colaborativos se sugieren con el propósito de estimular la asimilación consciente de los estudiantes desde sus experiencias y saberse previos, fortalecer la expresión de ideas y fluidez comunicativa de manera permanente en el aula mediante actividades grupales y en parejas para incidir en el desarrollo de las habilidades interpersonales y reflexivas de los estudiantes a partir de la tarea de aprendizaje. En ello desempeña una función o rol excepcional el docente siempre que cumpla con las exigencias de la actividad de aprendizaje. 
Exigencias de la actividad del aprendizaje en el proceso de enseñanza- aprendizaje.Las actividades planteadas permiten que los educandos interactúen con su contexto, así como la autoevaluación de los conocimientos adquiridos, ya que son propicios para fortalecer los procesos de aprendizaje a través de la generación de interés y motivación de las capacidades para apropiarse de los conocimientos impartidos en las sesiones de clase.

Por su parte, se espera que el educando ponga en práctica los conocimientos de la parte conceptual, procedimental y actitudinal en su formación integral, mostrando un cambio progresivo en su personalidad y en la mejora de los procesos cognitivos, metacognitivos y comunicativos en los distintos espacios y contextos de actuación. (Vygotsky, 1989; Márquez, 1999; González, 2008; Ortiz, 2008; Rímac y Velàzquez,2017 y Mora, 2017).

En cuanto a las falencias observadas durante toda la investigación, se determinó que es necesario que los docentes eleven su preparación profesional a fin de poder asumir un rol eficiente en las metodologías al conducir el proceso de enseñanza - aprendizaje, puesto que deben identificar las necesidades del grupo, los objetivos a cumplir y las actividades de aprendizaje que contribuyan con el desarrollo de la comunicación oral y escrita de los estudiantes desde su contexto sociocultural.

Los objetivos planteados en la investigación proponen que el docente planifique, organicé y dirija el proceso de enseñanza - aprendizaje de manera creativa, puesto que es el encargado de diseñar el sistema de clases a partir de las exigencias donde integre los métodos y actividades de aprendizaje como premisa principal en la generación del conocimiento y en la formación integral de la personalidad de los educandos, ya que esta es la base de las esferas del ser humano, para lograr un óptimo aprendizaje.

El diagnóstico pedagógico dio a conocer la situación real de los estudiantes, siendo un factor importante en las propuestas planteadas, logrando una adecuada orientación de las fortalezas y debilidades de cada uno de los estudiantes, razón por la cual permite plantear y diseñar una estrategia didáctica que abarque todas las falencia en el desarrollo del conocimiento, siendo una herramienta muy útil que permita la integración de los fundamentos conceptuales, procedimentales y actitudinales en los diversos niveles del conocimiento de manera individual y colaborativo.

El docente es el encargado de plantear desafíos y conflictos cognitivos que estimulen las capacidades de los estudiantes, desarrollando una serie de habilidades en diversos niveles 
cognitivos, metacognitivos, así como sensoriales y extrasensoriales a partir de la actividad de aprendizaje.

La actividad o tarea de aprendizajes un proceso mediante el cual el estudiante interactúa con el objeto, el medio que le rodea y otros sujetos incidiendo en él, transformando y al mismo tiempo recibiendo influencias que en mayor o menor medida también transforman al propio sujeto al respecto Márquez (1999), González (2008), Zilberstein y Silvestre (2011), y Rico et. al (2013).

Para su realización es necesario la participación eficaz del educando en aras de promover su autonomía cognoscitiva, regulación y sistematización de sí mismo al tener conciencia de los errores que comete en esta etapa ejecutoria, llevándolo a reflexionar sobre su praxis interactiva concebida en el proceso lógico de apropiación del idioma meta que guiado por las exigencias didácticas generales y metodológicas particulares del docente impulsa la asimilación de la oralidad desarrolladora y continua en el aula como respuesta al desarrollo reproductivo alcanzado en un entorno sociocultural (González , 2008).

Durante la planificación de la tarea comunicativa, el docente debe considerar los niveles de desempeño de manera que responda a los objetivos rectores de la enseñanzaaprendizaje a fin de desarrollar las destrezas orales de la lengua.

En este contexto la tarea comunicativa fundamenta su accionar desde un enfoque didáctico de la lengua sopesándose como un medio real que fortalezca y desarrolle plenitud la competencia oral del educando. A este respecto Ortiz (2008), reconoce a la tarea comunicativa como una herramienta pragmática que antepone la descontextualización del lenguaje oral en los distintos momentos de la actividad propiciando la formación integral particular al cual el estudiante aspira llegar, por lo que se pueden tomar como referentes para acondicionar los contenidos a la asignatura de inglés II en la carrera de Negocios Internacionales.

En resumen, las tareas deben permitirle al estudiante tomar conciencia de su aprendizaje y poder comunicarse libremente en un clima de cooperación, respecto y ayuda mutua para potenciar el desarrollo de las capacidades, habilidades y competencias progresivamente. Ello exige que los estudiantes se expresen y comuniquen sus ideas en la lengua español, a través de situaciones cotidianas a fin de potenciar las habilidades comunicativas.

Desarrollar las habilidades comunicativas en la clase requiere orientar al estudiante en los distintos momentos de la actividad de aprendizaje para que el educando tenga éxito en el 
qué, cómo hacerla y cómo aplicar lo aprendido en la solución de problemas idiomáticos. A continuación, se presentan algunos ejemplos de la tarea de aprendizaje.

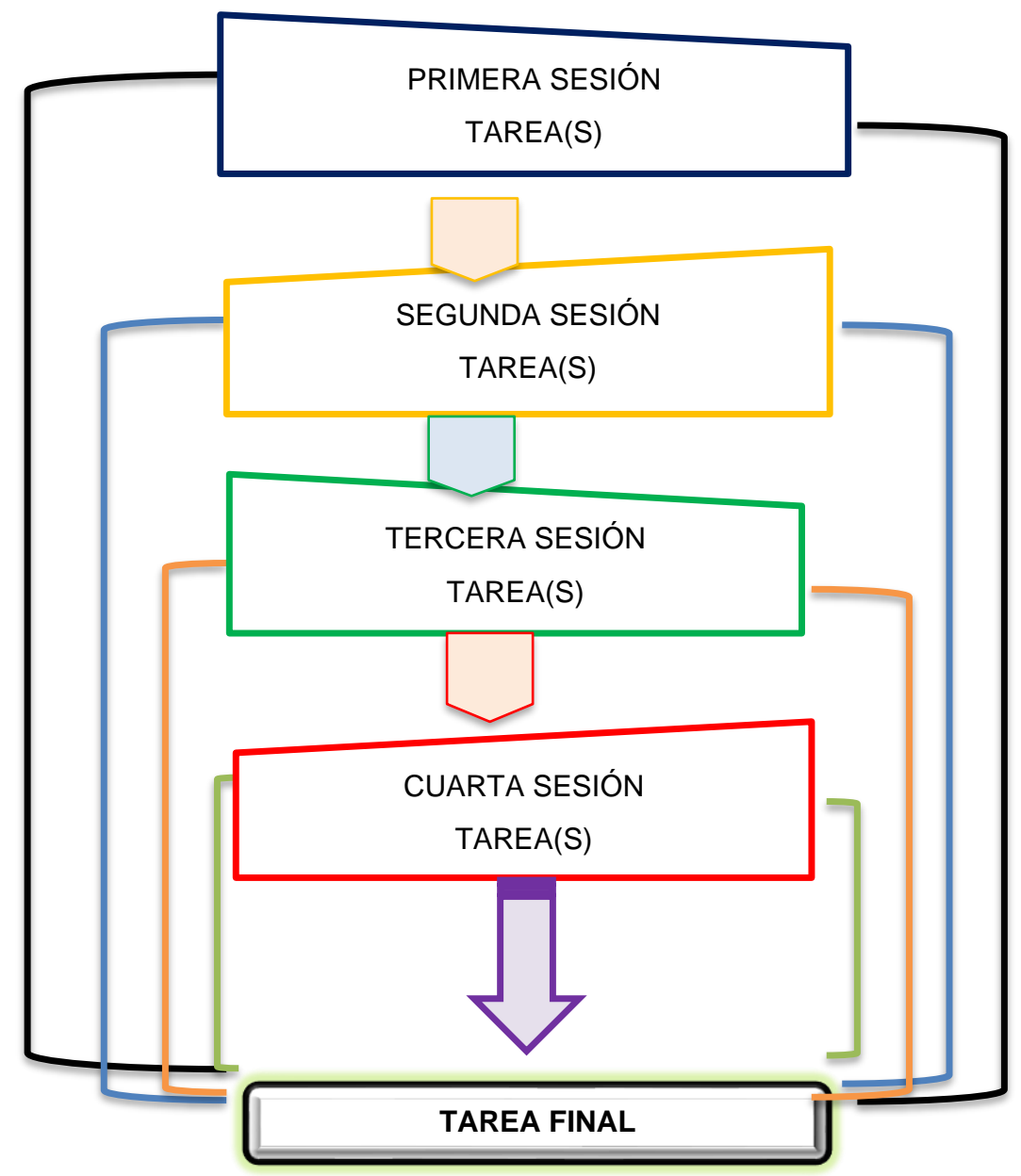

Figura 4. Estructura de una unidad didáctica a través del enfoque por tareas

Fuente. Estaire (1990).

\section{Ejemplo de tareas de aprendizaje}

Tarea 1: Escribir un relato corto (doce líneas como máximo) sobre cómo sería vivir en una época donde no exista la imprenta ni la escritura

Se empieza por insertar el tema de trabajo, la temática del proyecto a realizar, sus objetivos y cuál será la tarea final.

Luego se procederá al desarrollo de la sesión invitando a los educandos a observar un video sobre Gutenberg y la creación de la imprenta para establecer diálogo agrupándolos en parejas y tríos y brainstorming lo experimentado; captando las ideas sobresalientes en un organizador visual de su elección. 
Seguido se le facilita un texto impreso que aporta nuevos elementos informativos del tema y se establece un sistema de preguntas para destacar su significado social y cultural. Al responder se produce un diálogo que refleja la asimilación del contenido por los estudiantes.

Con esta actividad se incentivan los procesos lógicos mentales como la observación, la escucha, la comprensión, producir las ideas, frases u oraciones a los estudiantes y desarrollar la lengua meta en la que el educando pone en práctica sus conocimientos de forma grupal e individual y se favorece la comunicación oral.

Tarea 2: En grupos, crear un discurso sobre las habilidades de un diseñador gráfico en el desarrollo de la producción gráfico.

Se inicia la actividad con un repaso del contenido tratado en el ejercicio anterior a través de un cuestionario donde activan los saberes adquiridos. Luego se continúa con el desarrollo de las habilidades de un diseñador gráfico.

A continuación, se proyecta un vídeo referente donde se observa los procedimientos desarrollados en la industria gráfica y las complejas funciones que un diseñador realiza en el área de producción gráfica.

Este tipo de ejercicio estimula la escucha, la comprensión e impulsa el interés y la motivación en los estudiantes por conocer, indagar, investigar, aprender y valorar y la cultura gráfica. De esa manera se ha creado una situación comunicativa que tiene como objetivo rector el desarrollo de la comunicación oral en los estudiantes, pues se prepara en grupo y posteriormente exponen ante el plenario de la clase su producto y una vez concluida deberán responder a las preguntas y opiniones de sus compañeros y autoevaluarse a partir de los indicadores establecidos.

Tarea 3: En grupos deben elaborar una descripción sobre la experimentación en diversos formatos de impresión.

En la introducción de esta actividad se plantea a los estudiantes nombrar diversos formatos de impresión que hayan empleado anteriormente en la realización de trabajos.

Al finalizar la dinámica previa se facilita una ficha de descripción técnica para que los estudiantes elaboren las características de cada formato empleado, indicando sus beneficios y adecuado empleo. Por último, los grupos se organizan para comprar los materiales de impresión.

Tarea 4: Role play, cliente y diseñador en la creación de una pieza gráfica.

El docente puede comenzar explicando sobre la actualización de las aplicaciones de diseño gráfico y realiza la siguiente pregunta: ¿Para qué sirve las actualizaciones de diseño 
gráfico?; ¿Cuáles son las aplicaciones que han utilizado para el desarrollo de piezas gráficas?; ¿Qué importancia tiene asumir nuevos retos en el diseño gráfico?, entre otras preguntas que pueden surgir en la interacción comunicativa. Luego se reúnen por equipos y leerán una materia informativa a fin de que debatan entre todos. El docente desempeña su rol como guía, conductor y regulador de la actividad para cumplir la tarea. Con el objeto de reforzar las habilidades de los estudiantes y concientizarlos en el interés de conocer nuevas aplicaciones de diseño gráfico.

En la segunda parte de la sesión se realiza la tarea final, consistente en establecer un diálogo sobre una situación cotidiana, entre un cliente y un diseñador donde deben emplear sus habilidades gráficas para impresionar al cliente por sus destrezas y creatividad. Al presenciar la situación comunicativa, el docente escucha y reformula otras interrogantes vinculadas con el fin de estimular la comunicación oral. Para la realización de la actividad es necesario que el docente proponga un sistema de preguntas relacionadas con el tema objeto de estudio de tal manera que los estudiantes de orienten por ellas y compruebe cómo por su nivel de preparación cómo excluyen o rechazan aquellas que no forman parte del tema a tratar.

Tarea 5: Realizar un afiche publicitario.

Se continúan de forma coherente con una actividad que responde al objetivo iniciado en la actividad anterior, la producción de material gráfico. Como tarea deberán analizar y realizar en equipo, la elaboración de un afiche publicitario donde cubran las necesidades del cliente. En este sentido el educador entregará a cada grupo una lista de características que los estudiantes tienen que leer el material y comentan entre toda la información, los pasos a seguir en cada procedimiento, lo que expresan las imágenes y otros detalles. Con ello se estimula la inquietud por hacerlo bien, la curiosidad por el proceso de aprendizaje aplicando sus destrezas para lograr tal propósito comunicativo.

Finalmente exponen a nivel de plenaria cómo procedieron en cada momento en la elaboración de los distintos elementos integrados en el afiche publicitario para alcanzar el objetivo propuesto.

\section{Orientaciones metodológicas para la aplicación del método problémico}

El aprendizaje consciente el estudiante lo demuestra cuando utiliza, valora y le da importancia a lo aprendido. Lograrlo significa que el docente debe orientarlos suficientemente a través de un conjunto de preguntas contradictorias. Al respecto Álvarez de Zayas (1999) señala que problematizar el contenido de la clase empodera al estudiante de 
la relación de la escuela con la vida. Es a partir de los conflictos y su libración que el estudiante tiene la oportunidad de desarrollar sus capacidades y actitudes comunicativas en la clase (Pérez, 2015y Moreno y Velázquez, 2017).

La estrategia propuesta canaliza la enseñanza problémica y heurística de manera integral en el estudio de los niveles de la lengua como un todo integral y no como una selección de las partes u objetivos para que mejore la comunicación interactiva con sus compañeros en el aula; es decir, que a través del oído fonemático y el hablar perciben y asimilan el contenido, potenciando el conocimiento y el desarrollado de la competencia comunicativa oral. Para ello es necesario destacar la relevancia de la participación activa, coherente y la fluidez en las ideas y disposición de corrección (Rey, 2014).

En la figura siguiente se muestra cómo ha de programarse una unidad didáctica a través de una secuenciación docente de seis pasos ya sea en solitario o en conjunción con los alumnos.

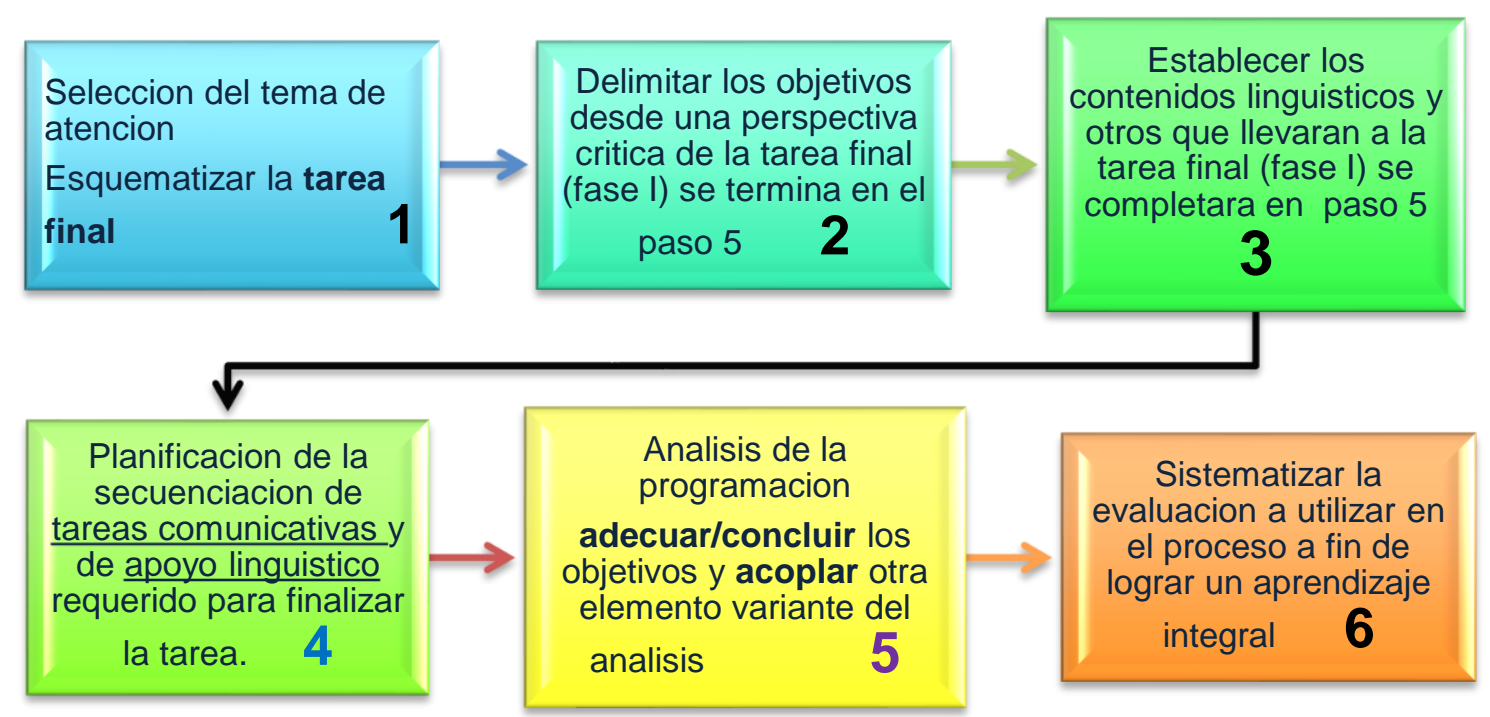

Figura 5. Secuenciación de una unidad didáctica desde este enfoque.

Nota: Adaptado para la programación por tareas (Estaire, 1990).

La perspectiva de la clase comprende un conjunto de actividades que parten del método comunicativo y colaborativo en la realización de la tarea y lograr del aprendizaje esperado en los estudiantes. Estas se pueden organizar de la siguiente manera:

Selección del tema y tarea final. Orientada a las necesidades, inquietudes, intereses y destrezas de los alumnos impulsando su desarrollo en el proceso de aprendizaje. 
Delimitación de objetivos Es necesario establecer objetivos consecuentes al estado actual en que se encuentra el estudiante abordado desde la concreción de actividades para alcanzar el cumplimiento de la tarea final.

Determinar los contenidos, habilidades, valores y las acciones que fomentan el interés y necesidades del estudiante hacia la generación de conocimientos, destrezas y valores que se desarrollara a lo largo del contenido en la asignatura.

Presentación de la tarea guía al educando a través del desarrollo de actividades comunicativas a alcanzar la tarea final teniendo en cuenta los momentos, los recursos a utilizar y la interconectividad entre ellas.

Fortalecer la estructura cognitiva, instrumental y emocional, el docente brinda la oportunidad experiencial de desarrollar los conocimientos, habilidades y valores

Accionar de los estudiantes Desempeño actitudinal, procedimental y cognitivo del educando en las actividades y tareas que lo llevara a analizar- modelar- crear soluciones al cuestionamiento planteado.

Concluir y amoldar los pasos previos El estudiante diseña y revisa la solución haciendo las modificaciones necesarias paso por paso para que finalmente sea socializado y debatido sobre ello.

Incorporar la evaluación como parte del proceso de aplicación de las herramientas evaluadoras que verifiquen distintos aspectos de lo aprendido remarcando la autoevaluación consciente de los fallos realizados en la programación por parte de cada estudiante.

Estos elementos evidencian lo complejo que puede ser llevar a cabo los procedimientos metodológicos con efectividad; pues el proceso lógico seguido permite el desarrollo de las capacidades comunicativas.

\section{Desarrollo e implementación de la propuesta}

\section{Secuencia metodológica de la estrategia diseñada para la clase}

El desarrollo de los momentos de la sesión, deben integrar una serie de actividades destinadas a facilitar la asimilación activa y consciente del aprendizaje por los educandos. La sesión de clase organizada y planificada según la secuencia lógica debe asegurar la apropiación objetiva de los conocimientos relacionados con los saberes previos (Silvestre y Zilberstein, 2002; Castellanos et al. 2007; Pimienta 2012; Addine, 2013 y Tobón, 2013).

Dentro del rol del docente se aplica métodos y procedimientos que promueven la competencia comunicativa, interactuando con la reestructuración del proceder didáctico caracterizada por la lógica en el aprendizaje consiente del educando. Dichas características 
permiten enriquecer el aprendizaje individual y grupal de los propios estudiantes como del docente. La secuencia metodológica está divida en tres momentos: el inicio, el desarrollo y el cierre.

Al inicio de clase: se orienta. a captar el interés del educando, a través de la recopilación de los saberes previos y el estableciendo de los objetivos a desarrollar en la sesión, presentando una situación problémica que propicie el diálogo entre los educandos y el docente, que a su vez creará expectativas sobre los nuevos conocimientos a adquirir.

\section{Por ejemplo}

En la sesión se presenta la dinámica "Conexiones forzadas", a través de imágenes presentadas en una diapositiva, donde se realiza la siguiente interrogante: ¿Qué palabra podemos inventar de la siguiente conexión?, donde los estudiantes emiten sus respuestas interactuando con sus compañeros de manera dinámica.

Desarrollo de la sesión, una vez estimulado el interés y la motivación como resultado de la exploración de los saberes previos se logra una problematización dialógica entre los estudiantes y el docente. Se le da tratamiento a la información fundamental a través de variados ejemplos en el que se aplica un sistema de preguntas heurísticas que ayudará a los estudiantes a asimilar y comprender el tema de la clase. Para ello se utilizarán diversos recursos didácticos que favorecen la observación, comprensión, el análisis de la información presentada, la producción del nuevo saber y su aplicación en la solución de las tareas de diseño. El docente cumple la función de orientador y guiar el proceso educativo durante el desarrollo de las actividades, valiéndose de criterios de aplicación evaluación formativa al trabajar individual y grupales donde debe observar el comportamiento de cada educando, cómo actúan y socialicen a partir del diálogo a fin de construir un conocimiento consciente entre todos.

Ejemplo $\mathbf{N}^{\circ}{ }^{1}$, La situación problémica se presenta desde la perspectiva de una casuística referente al contenido temático de la sesión.

Tema: Conociendo el origen de la escritura en el mundo antiguo.

Se presenta el video del caso de: "Johannes Gutenberg y la imprenta".

Una vez observado el video se procede a realizar un sistema de preguntas dialécticas a los estudiantes:

¿Crees que el caso presentado es relevante para la sociedad?, ¿Crees que la idea de Gutenberg revolucionó la producción gráfica?, ¿Cómo Gutenberg generó la idea de una imprenta?, ¿Qué tipo de ideas puede desarrollar una persona creativa?, ¿A qué llamamos una persona creativa?, ¿Recuerdas cómo tú aprendiste a escribir?, ¿Será importante conocer sobre 
los fundamentos teóricos de la escritura? ¿Qué cualidades son necesarias para potenciar nuestra creatividad?, ¿Qué relación hay entre creatividad y la producción gráfica?

Luego de ello el docente procede a explicar con detalle los contenidos de la sesión, donde se emplean imágenes y esquemas gráficos que permitan la transferencia de conocimiento, seguido de ello el docente formula las siguientes interrogantes: ¿La producción gráfica se influencio por la creación de la imprenta?, ¿Consideran importante la imprenta en el desarrollo de la sociedad? ¿Qué dificultades se presentaría si no existiera la imprenta?

A través de esas preguntas, se plantea una situación dialógica entre los estudiantes y el docente, la cual debe ser fluida y enriquecida por las diversas opiniones y perspectivas de los participantes.

Seguido se orienta a los estudiantes a unirse en equipos de 3 para trabajar la actividad planteada donde se promueve las habilidades investigativas, para ello se establece los criterios de evaluación, planteados en una coevaluación: Les entrega un texto con la información sobre qué es la producción gráfica, el impacto de la imprenta y las diversas perspectivas sobre el diseño gráfico.

Se les indica los procedimientos a seguir, solicitando que subrayen y realicen un organizar visual de su preferencia resaltando los aspectos claves. Mientras trabajan colaborativamente, el docente observa los avances de la actividad, ofreciendo su ayuda en todo momento. Al concluir la actividad se indica que los estudiantes compartan su información y el producto de su aprendizaje, así mismo los grupos expondrán sus organizadores visuales; luego de ello los compañeros de clase formulan preguntas y se organizan para otorgar una evaluación al grupo expositor. Al finalizar el docente interviene para felicitar el desempeño de los estudiantes, y proporcionar sugerencias sobre posibles mejoras como parte de la retroalimentación.

Ejemplo N. 2 Tema: Desarrollando mis habilidades en la Producción Gráfica. Se inicia mencionando la siguiente frase "La producción gráfica es mucho más que conocer los procesos de impresión" Se escuchan las respuestas.

¿Qué opinión te merece?, ¿Consideras que tienes las habilidades para desarrollar la producción gráfica?, ¿Crees que la producción gráfica complementará en tu desarrollo profesional?, ¿Qué habilidades necesitamos para desarrollar la producción gráfica?

Se establece una situación comunicativa y dialógica entre los educandos y los docentes, donde se intercambian opiniones y perspectivas donde se respetan los puntos de vistas de cada estudiante. 
Luego se procede a formar equipos de trabajos para realizar la investigación; para ello se establecen los indicadores que se evaluarán en la autoevaluación y coevaluación. Luego se les entrega material sobre las habilidades artísticas, producción gráfica, desenvolvimiento profesional.

Como se evidencia en los ejemplos anteriores, el rol que cumple el docente es vital en la orientación, estimulación por el aprendizaje, motivación e incentivar el juicio crítico, analítico y valorativo del estudiante. Las actividades planteadas son propicias para desarrollar las competencias, capacidades y habilidades de los estudiantes, potenciando el lado cognitivo, afectivo y emocional dentro de un clima de asertividad escolar.

Por otra parte, el tipo de actividades planteadas permite la socialización, interacción y el diálogo entre los educandos que se reflejará en el desarrollo de las habilidades interpersonales y colaborativas, necesarias para comprender las opiniones de los demás y así mismo fortalecer sus relaciones integrales.

La propuesta planteada de la secuencia metodológica brinda la posibilidad de fomentar el del pensamiento crítico -reflexivo, así como elaborar y formular hipótesis de casos, asumiendo una actitud proactiva frente al desarrollo de las habilidades socioculturales presentes en la competencia comunicativa (Cruz y Velázquez, 2016).

En la parte del cierre de la sesión: se debe lograr que el estudiante comprenda los objetivos del autorreflexión, metacognición y autoevaluación. Por ello el docente planifica la sesión de clase para obtener la comprensión de los conocimientos, y la aplicación de todas sus habilidades y capacidades. Permite que el educando desarrolle su competencia comunicativa oral, el aprendizaje significativo y su aplicación en el contexto que lo rodea.

En esta etapa se implementan diversas formas de evaluación para medir el aprendizaje de los estudiantes como: la heteroevaluación, coevaluación y autoevaluación. Resaltando el uso de valores que fortalecen las actitudes de los educandos frente a su aprendizaje como: la reflexión, constancia y autorregulación (Castellanos et al.,2007; González, 2008; Rico et al., 2013 y De Corte, 2015).

La propuesta comprende dos sesiones de aprendizaje que sirven como guía a los docentes para la realización de las clases (Anexo 16). Asimismo, se proponen tres instrumentos de evaluación (Anexo 17), que favorecen la objetividad del desarrollo de la evaluación formativa en la sesión de clase. 


\section{Propuesta de talleres teórico práctico para la capacitación a los docentes}

En cuanto a la preparación del nivel teórico y metodológico de los docentes se propone la realización de talleres teóricos prácticos, organizados en tres jornadas pedagógicas que se concretarán durante el periodo vacacional de febrero. Se debe priorizar y realizar las coordinaciones con la dirección académica para su cumplimento.

El taller pedagógico como forma de organización de la superación o capacitación de los docentes desde su puesto de trabajo, le permite profundizar en los enfoques teóricos, analizar, debatir y autor reflexionar sobre esos argumentos, las características del estudiantado, las del contexto y los factores prácticos que intervienen en el proceso de enseñanza - aprendizaje, identificar los métodos, las metodologías activas como refieren, Zegarra, y Velázquez (2017),para lograr una formación integral de los educandos para la vida.

Para la adecuada ejecución del taller se considera la secuencialidad necesaria para generar la motivación del docente, partiendo de una situación comunicativas, empleando recursos didácticos que permitan explorar los saberes previos. En este aspecto los docentes analizan en los talleres, comparten y reflexionan y auto reflexiona sobre sus fortalezas y las necesidades presentes en el proceso de aprendizaje y se toman acuerdos para mejorar la dirección de su desempeño pedagógico en el aula.

Las actividades se proponen desde el trabajo colaborativo conjugándolo con la experiencia. Para ello deben seleccionarse diversos materiales teóricos y didácticos; orientar con claridad las tareas específicas a realizar a partir del debate, la discusión, asumir posiciones y toma de acuerdos al resolver los ejercicios. El producto de la actividad cada equipo debe exponer en la sesión plenaria ante sus compañeros con el fin que todos, expresen sus ideas, sugieran, proponga nuevas tareas sobre cómo ellos lo realizan y llegar a conclusiones. Al final, elaboran como producto diversos organizadores visuales seguido de una exposición del trabajo elaborado. Esta actividad permite exponer los hallazgos a los otros equipos para compartir la información recopilada, así como aclarar posibles dudas.

A continuación, se propone el plan temático a desarrollar en los talleres de capacitación docente a fin de mejorar el desempeño de los docentes al dirigir las clases evidenciadas en el diagnóstico de campo: 
Tabla 2

Talleres de capacitación docente.

\begin{tabular}{|c|c|c|c|}
\hline Título del taller & Objetivos & Campo temático & Actividades \\
\hline $\begin{array}{l}\text { Fundamentos de la } \\
\text { estrategia didáctica. }\end{array}$ & $\begin{array}{l}\text { Valorar los fundamentos de la } \\
\text { didáctica y su aplicación en el } \\
\text { proceso de enseñanza- } \\
\text { aprendizaje. }\end{array}$ & $\begin{array}{l}\text { Estrategia didáctica } \\
\text { Proceso de enseñanza- } \\
\text { aprendizaje. }\end{array}$ & $\begin{array}{l}\text { Organizador } \\
\text { visual }\end{array}$ \\
\hline $\begin{array}{l}\text { El enfoque cognitivo y } \\
\text { comunicacional en la } \\
\text { asignatura Producción } \\
\text { Gráfica }\end{array}$ & $\begin{array}{l}\text { Proporcionar a los docentes los } \\
\text { sustentos teóricos que orientan el } \\
\text { desarrollo de aprendizajes desde } \\
\text { lo cognitivo y comunicacional en } \\
\text { los estudiantes de la asignatura } \\
\text { de Producción Gráfica. }\end{array}$ & $\begin{array}{l}\text { Enfoque cognitivo } \\
\text { Enfoque comunicacional } \\
\text { Competencias de la } \\
\text { asignatura de Producción } \\
\text { Gráfica. }\end{array}$ & $\begin{array}{l}\text { Organizador } \\
\text { visual } \\
\text { Unidad } \\
\text { Didáctica }\end{array}$ \\
\hline $\begin{array}{l}\text { Las habilidades } \\
\text { socioculturales } \\
\text { desarrolladas en la } \\
\text { asignatura de } \\
\text { Producción Gráfica. }\end{array}$ & $\begin{array}{l}\text { Orientar al desarrollo de las } \\
\text { habilidades socioculturales en el } \\
\text { proceso de enseñanza- } \\
\text { aprendizaje de la asignatura de } \\
\text { Producción Gráfica }\end{array}$ & $\begin{array}{l}\text { Habilidades } \\
\text { socioculturales } \\
\text { Estrategias de enseñanza- } \\
\text { aprendizaje. }\end{array}$ & $\begin{array}{l}\text { Organizador } \\
\text { visual } \\
\text { Sesión de } \\
\text { Aprendizaje }\end{array}$ \\
\hline
\end{tabular}

Fuente: Elaboración propia (2019).

Las actividades planteadas contribuyen en el fortalecimiento de los conocimientos, el buen desarrollo de la comunicación asertiva y a su vez potencia las capacidades y habilidades de los docentes.

En las últimas dos sesiones, se plantea que los docentes elaboren una unidad didáctica y una sesión de aprendizaje que sirva como referente para el desarrollo de sus sesiones cotidianas, así mismo se busca que asimilen todos los conocimientos brindados en el taller. De esta manera se mejora el desempeño docente en cuanto a la organización, planificación de las actividades (Díaz y Hernández, 2010; Velázquez, 2014 y Addine, Recarey, Fuxà y Fernández, 2015).

\section{Sugerencias para la implementación de la propuesta en la práctica pedagógica}

Se implemente diversos objetivos dentro de la propuesta metodológica que se dan de manera secuencial dentro de la práctica:

Primero convocar a una reunión con la comunidad pedagógica donde se da a conocer todos los fundamentos teóricos, didácticos y metodológicos que conforman la estructura de la 
propuesta didáctica en el proceso de enseñanza - aprendizaje en el área curricular de Producción Gráfica dirigida a los estudiantes de IV ciclo de Educación Superior.

Segundo los docentes responsables de la disciplina referida, analizan y verifican que la propuesta guarde una relación con los elementos normativos del área de estudio. Es primordial valorar los diversos aspectos legales que fundamentan la propuesta planteada; la Ley de Institutos y Escuelas de Educación superior, las indicaciones del Currículo Nacional referidas a la asignatura de Producción Gráfica y su adecuada contribución integral de los educandos.

Tercero, se establece la forma de distribuir los contenidos y el fortalecimiento de las habilidades y capacidades necesarias para el buen desempeño del proceso de aprendizaje, la aplicación de sistemas de métodos y evaluaciones formativas. De igual manera se orienta siempre a una excelente organización, planificación y dosificación de las unidades y sesiones de aprendizaje.

Seguido de la fundamentación teórica y didáctica recopilada de la investigación, así como el análisis de diversos referentes teóricos sistematizados como base de la propuesta integrando un enfoque cognitivo, comunicacional y sociocultural, que permiten contribuir al desarrollo de las habilidades y capacidades de los estudiantes a partir de una adecuada función del docente como facilitador.

La unidad didáctica presentada se dosificó como parte de la estrategia didáctica modelada como primer aporte por ser una exigencia didáctica para la planificación de las clases, se modelaron dos sesiones de aprendizaje a modo de ejemplificar y situaciones de aprendizaje que orientan al docente para su tratamiento: Se argumentan de manera integral los intereses y necesidades del educando en el tratamiento didáctico de la competencia comunicativa oral tanto en el componente cognitivo, las habilidades comunicativas, socioculturales y actitudinales que se concreta en el proceso de enseñanza- aprendizaje en el área curricular de Producción Gráfica. Se incluye los instrumentos de la evaluación formativa, con indicadores a controlar en el desempeño respecto a cada una de las actividades y los logros esperados en las distintas actividades a realizar por los educandos en la sesión de clase.

\section{Validación de la estrategia didáctica propuesta}

Para lograr el proceso de validación de la pertinencia de la estrategia didáctica modelada como producto general de la investigación en su aspecto externo e interno, se usó el método de juicio de expertos. Este método según precisan Escobar y Cuervo (2008) y Cerezal y Fiallo (2016), se caracteriza por reunir un conjunto de requisitos para su aplicación. 
Se diseñaron dos rúbricas con diez ítems cada una, a fin de evaluar la propuesta tanto en el plano cual como el cuantitativo. Entre los requisitos establecidos para la elección de los especialistas o expertos de plantearon: poseer grado académico de Maestro o Doctor en Educación, título de post grado en la especialidad, acumular quince años de experiencia o más en la práctica docente o ejercer la dirección académica en una institución de educación universitarias.

\section{Características de los expertos}

Los tres especialistas que dieron fe de la validación de la estrategia didáctica modelada como producto teórico- práctico desatacan porque ser docentes que acumulan en su haber el grado académico y científico requerido, la experiencia en el ejercicio profesional, la autoridad y prestigio profesional integral para evaluar la propuesta. En la siguiente tabla se presenta la relación de los expertos que participaron en el proceso de validación del producto de la investigación.

Tabla 3

Relación de los expertos que validaron la estrategia propuesta

\begin{tabular}{|c|c|c|c|c|}
\hline $\begin{array}{l}\text { Nombres y } \\
\text { Apellidos }\end{array}$ & Grado académico & $\begin{array}{c}\text { Especialidad } \\
\text { profesional }\end{array}$ & Ocupación & $\begin{array}{c}\text { Años de } \\
\text { experiencia }\end{array}$ \\
\hline $\begin{array}{l}\text { Aldo Alfonso } \\
\text { López Kitano }\end{array}$ & $\begin{array}{l}\text { Magister en Educación } \\
\text { e Investigador. }\end{array}$ & Docencia & $\begin{array}{c}\text { Docente del Instituto } \\
\text { Superior CIMA'S }\end{array}$ & 22 años \\
\hline $\begin{array}{c}\text { Fernando Goñi } \\
\text { Cruz }\end{array}$ & $\begin{array}{l}\text { Doctor en Ciencias de } \\
\text { la Educación. }\end{array}$ & $\begin{array}{l}\text { Licenciado en } \\
\text { Educación }\end{array}$ & $\begin{array}{l}\text { Docente y asesor de tesis } \\
\text { de la Universidad San } \\
\text { Ignacio de Loyola }\end{array}$ & 20 años \\
\hline $\begin{array}{c}\text { Hernán Gerardo } \\
\text { Flores } \\
\text { Valdiviezo }\end{array}$ & $\begin{array}{l}\text { Magister } \\
\text { Administración } \\
\text { Gerencia social. }\end{array}$ & Sociólogo & $\begin{array}{l}\text { Docencia y asesor de tesis } \\
\text { de la Universidad San } \\
\text { Ignacio de Loyola }\end{array}$ & 40 años \\
\hline
\end{tabular}

Fuente: Elaboración propia (2019).

\section{Validación interna y externa de la estrategia didáctica por criterio de expertos}

El proceso de validación de la propuesta, exigió la existencia de dos rúbricas de evaluación: una orientada a la evaluación interna del producto, o sea al contenido tratado y la otra rúbrica para la validar lo externo, concerniente a la forma de expresión y las vías de aplicación de la estrategia didáctica propuesta en la práctica pedagógica sustentada en diez criterios de orden cualitativo y cuantitativo.

En el aspecto cuantitativo los especialistas emitieron su juicio evaluativo atendiendo a los 
siguientes criterios: deficiente (puntaje 1), bajo (puntaje 2), regular (puntaje 3), buena (puntaje 4) y muy bien (puntaje 5).

Tabla 4

Tabla de Valoración

\begin{tabular}{ll}
\hline \multicolumn{3}{c}{ Valoración } \\
\hline Deficiente & $\mathbf{0 - 2 5}$ \\
Baja & $25-50$ \\
Regular & $51-70$ \\
Buena & $71-85$ \\
Muy Buena & $86-100$ \\
\hline
\end{tabular}

Fuente: Documentos de elaboración de tesis USIL (2018).

Al analizar el resultado conclusivo de cada rúbrica, se debía alcanzar una puntuación total de cincuenta puntos, que al sumarse las dos hacen un total de cien puntos.

Los expertos al analizar el aspecto cualitativo de la estrategia didáctica diseñada, debía ejercer una apreciación crítica - valorativa general del modelo examinado a partir de las siguientes dimensiones: positivos, negativos y sugerencias.

En resumen, el especialista en el aspecto interno, evalúa el contenido del modelo presentado a partir de los indicadores establecidos: factibilidad de la aplicación del resultado presentado; claridad de los fundamentos para ser aplicado por otros; posibilidad del producto de extenderse a otros contextos semejantes; correspondencia con las necesidades sociales e individuales; congruencia entre el resultado y el objetivo fijado; novedad en el uso de conceptos y procedimientos; contiene propósitos basados en los fundamentos educativos, curriculares y pedagógicos detallados, precisos y efectivos; la propuesta está contextualizada a la realidad en estudio; presenta objetivos claros, posibles de alcanza y contiene un plan de acción de lo general a lo particular.

Similar proceder se exigió para la validar el aspecto interno de la propuesta. Para ello se utilizó una rúbrica con los indicadores precisos, el puntaje, la escala de valoración correspondiente y el cierre final a través de las dimensiones: positivos, negativos y sugerencias pertinentes. Para ese efecto debían señalar: claridad, objetividad, actualidad, organización, suficiencia, intencionalidad, consistencia, (coherencia, metodología y pertinencia.

Al final se presenta la sumatoria total de los resultados otorgados por los expertos a la estrategia didáctica propuesta como resultado del proceso de validación interna y externa del producto de la investigación presentado. 
Tabla 5

Resultados de la validación integral por e los especialistas

\begin{tabular}{|c|c|c|c|c|c|}
\hline $\mathbf{N}^{\circ}$ & Especialista & $\begin{array}{c}\text { Grado } \\
\text { Académico }\end{array}$ & $\begin{array}{l}\text { Validación } \\
\text { Interna }\end{array}$ & $\begin{array}{l}\text { Validación } \\
\text { Externa }\end{array}$ & $\begin{array}{l}\text { Sumatoria } \\
\text { Valorativa }\end{array}$ \\
\hline 01 & $\begin{array}{l}\text { Aldo Alfonso } \\
\text { López Kitano }\end{array}$ & Magister & 50 & 50 & 100 \\
\hline 02 & $\begin{array}{l}\text { Fernando Goñi } \\
\text { Cruz }\end{array}$ & Doctor & 48 & 41 & 84 \\
\hline 03 & $\begin{array}{l}\text { Hernán Gerardo } \\
\text { Flores Valdiviezo }\end{array}$ & Magister & 41 & 49 & 90 \\
\hline & & & & Total & 274 \\
\hline
\end{tabular}

Fuente: Fichas de validación interna y externa USIL (2019).

Resultados finales del promedio de la valoración otorgada por los expertos al modelo teórico presentado consistente en una estrategia didáctica para contribuir

Tabla 6

Resultado de la valoración interna y externa por criterio de expertos

\begin{tabular}{ccc}
\hline Sumatoria de Valoración Total & Promedio de Valoración & Valoración \\
\hline 274 & 92 & Muy bien
\end{tabular}

Fuente: Fichas de validación interna y externa USIL (2019).

La estrategia didáctica propuesta es validada con la categoría de Muy Bien por los especialistas que actuaron como expertos. Los mismos añaden que los fundamentos científicos, didácticos y práctica son integrales y acreditan que el producto resultante del proceso investigativo es novedoso, exigente y contribuye a la orientación y empoderamiento de los docentes a fin de asumir un rol eficiente al conducir el proceso de enseñanza- aprendizaje y estimular el desarrollo de la competencia comunicativa oral en los estudiantes del V ciclo de la carrera de Diseño Gráfica.

En los argumentos valorativos planteados por los especialistas se enfatiza que dados los argumentos que sostienen la propuesta en el tratamiento a la comunicación, la secuencialidad didáctica, los métodos de enseñanza que sistematiza y las actividades de aprendizaje que expone, puede ser aplicada a otras áreas curriculares de la carrera, a fin de potenciar el desarrollo de la competencia y las habilidades comunicativas como un aporte que enriquecerá la práctica pedagógica universitaria de los docentes de la especialidad. 


\section{Conclusiones}

Al concluir el proceso investigativo mediante la sistematización de los referentes científicos, analizar los resultados del diagnóstico de campo y modelar la estrategia didáctica propuesta para contribuir a la transformación del problema objeto de estudio se formulan las siguientes conclusiones generales.

\section{Primera}

Se cumplió con el objetivo general de la investigación al modelarse la estrategia didáctica para contribuir al desarrollo de la competencia comunicativa oral en los estudiantes del V ciclo de la asignatura Producción Gráfica de la carrera de Diseño Gráfica de un instituto superior privado de Lima.

\section{Segunda}

Se sistematizaron como parte del cumplimiento de la primera tarea científica, las categorías y subcategorías apriorísticas relacionadas con el aprendizaje, la competencia comunicativa oral y la estrategia didáctica desde una perspectiva holística que permitió comprender los diversos enfoques teóricos y didácticos que contribuyen a lograr un aprendizaje consciente y autorregulado que facilita la construcción del conocimiento y el desarrollo de la competencia comunicativa oral en los profesionales en formación.

\section{Tercera}

Se cumplió la tarea científica sobre el diagnóstico o trabajo de campo a partir del diseño, validación y aplicación de las técnicas e instrumentos de recojo, procesamiento y triangulación de la información que permitió identificar las categorías emergentes sustantivas y las que inciden en el problema científico en el proceso de enseñanza- aprendizaje de la asignatura Producción Gráfica sobre la competencia comunicativa oral en los estudiantes de un instituto superior privado de Lima. 


\section{Cuarta}

La modelación de la estrategia didáctica respondió a la tercera tarea científica a partir de considerar los criterios teóricos, prácticos y metodológicos que sirvieron de base a la propuesta para contribuir al desarrollo de la competencia comunicativa oral en los estudiantes del V ciclo de la asignatura Producción Gráfica, en la que los educandos asumen un rol protagónico a partir de la aplicación de los métodos activos e investigativos que inciden en la formación integral de los profesionales.

\section{Quinta}

Se cumplió con la cuarta tarea científica orientada a partir de la validación por los especialistas de la efectividad de la estrategia didáctica modelada como producto de la investigación. Enfatizan que los argumentos teóricos, didácticos y prácticos 'que posee el producto acreditan su aplicación en el proceso de enseñanza - aprendizaje donde el docente asuma el rol de mediador y aplique el conjunto de métodos propuestos a fin de que los educandos sean protagonistas en el desarrollo de la competencia comunicativa oral. 


\section{Recomendaciones}

\section{Primera}

Analizar el producto de la investigación con los directivos de la institución, a fin de considerar su posible aplicación en la práctica pedagógica de la disciplina Producción Gráfica. y en otras disciplinas curriculares, ciclos o facultades como una alternativa pedagógica innovadora que orienta al docente al dirigir el proceso de enseñanza- aprendizaje desde una dinámica reflexiva que inciden en la apropiación consciente del aprendizaje y el desarrollo de la competencia comunicativa oral en los estudiantes.

\section{Segunda}

Validar el impacto de la aplicación en la práctica docente de la estrategia didáctica modelada, con el objetivo de comprobar su efectividad en la transformación de los estudiantes en el desarrollo de los conocimientos y la competencia comunicativa oral tratado desde la enseñanza -aprendizaje de la disciplina Producción Gráfica.

\section{Tercera}

Presentar los resultados de la investigación en los distintos eventos científicos programados, a fin de dar a conocer sus resultados, continuar la investigación en otras aristas de la problemática estudiada, con el propósito de aportar a la solución de los problemas de la práctica pedagógica. 


\section{Referencias}

Addine, F. (2013) La didáctica general y su enseñanza en la Educación Superior Pedagógica. Aportes e impactos. La Habana: Pueblo y Educación, 9-27.

Addine Recarey Fuxà M. y Fernández S. (2015). Didáctica, teoría y práctica. La Habana: Pueblo y Educación.

Álvarez de Zayas, C. (2016). Didáctica General. La Escuela en la Vida. Décima Edición. Bolivia.

Álvarez, P. (1999). Desarrollo de la competencia comunicativa oral. Santiago de Chile.

Anijovich, R. y Mora, S. (2010). Estrategias de enseñanza. Otra mirada al quehacer en el aula. La Habana.

Austin, J. (1982). Como hacer cosas con palabras. Barcelona. Paidós.

Ausubel, D. (1983). Teoría del aprendizaje significativo. Un punto de vista cognoscitivo. México D.F:Trillas.

Bahamón, M., Vianchá, M., Alarcón, L. y Bohórquez, C. (2013). Estilos y estrategias de aprendizaje relacionados con el logro académico en estudiantes universitarios. Pensamiento Psicológico. Bogotá: Universidad de Boyacá.

Bisquerra, R. (2009). Educación para la ciudadanía. Madrid: Síntesis.

Bixio, C. (2010). El oficio de educar. Argentina.

Canale, M. y Swain, M. (1981). Bases teóricas de los enfoques comunicativos para la enseñanza de idiomas. Lingüística Aplicada, 1. 1-47.

Cassany, D. (2009). Taller de textos: leer, escribir y comentar en el aula. Barcelona Buenos Aires. Paidós.

Cassany, D. (2010). En_línea: leer y escribir en la red. Barcelona: Anagrama.

Cassany, D. (2013). Tras las líneas. Sobre la lectura contemporánea. Barcelona: Anagrama.

Cassany, D. (2016). Taller de textos: leer, escribir y comentar en el aula, 2a Edición. Barcelona Buenos Aires. Paidós.

Castellanos, D., Reinoso, C. y García, C. (2007). Para promover un aprendizaje desarrollador. La Habana: Colección de proyectos. 
Castellanos, S. (2002). Aprender y Enseñar en la Escuela Cap. 2. Ed. Pueblo y Educación. La Habana. pp. 20-5

Cerezal, J. y Fiallo, J. (2016). Cómo investigar en pedagogía. La Habana: Pueblo y Educación.

Chomsky, N. (1960). Aspectos de la Teoría de la Sintaxis. MIT Press. New York

Chomsky, N. (1972). Languague and mind. New York

Chomsky, N. (1974). Conditions on trasformations. New York

Chomsky, N. (1995). Estructuras sintácticas. México DF (México): Editorial Siglo XXI.

Cisterna, F. (2005). Categorización y triangulación como procesos de validación del conocimiento. España: Grau.

Comisión Económica para América Latina y el Caribe (Cepal, 2015). Desarrollo de la competencia comunicativa. México

Cot, J. (2000). “Hacia una descripción pedagógica de la competencia pragmática de los hablantes nativos de lengua inglesa". Madrid, Edelsa,

Crispín, M. y Esquivel M. (2011). Aprendizaje Autónomo, orientaciones para la docencia, Aprendizaje Autónomo (pp. 49-65). México.

Cruz, O. y Velázquez, M. (2016) Metodología innovadora para ejercicios físicos. Revista de Educación, Argentina, 7(9), 317335. http://fh.mdp.edu.ar/revistas/index.php/r_educ/article/view/1915.

Cruzata, A. (2007). Estrategia didáctica para el tratamiento a la competencia literaria. Ciudad de la Habana.

De La Corte, G. (2015). Enseñar y aprender con nuevos métodos (la revolución cultural de la era electrónica). Barcelona.

De la Torre, P. (2002). Estrategias de enseñanza. Medellín.

Del Risco, R. (2008). La competencia comunicativa oral en el proceso de enseñanzaaprendizaje del idioma español como segunda lengua. (Tesis de maestría). Universidad de Granada, España.1

Díaz Barriga, F. (2010). Estrategias docentes para un aprendizaje significativo una interpretación constructivista. México: 1 McGraw-Hill Interamericana Editores 
Díaz, F. y Hernández, G. (2010) Estrategias docentes para un aprendizaje significativo, 2a Edición. México: Mc Graw Hill. $\quad$ didáctica y evaluación. Bogotá, Colombia: Editorial Ecoe.

Domínguez, A. (2010). Construcción de los objetos del lenguaje. Madrid.

Domínguez, G. y Sevillano, M. (2013). Competencia comunicativa, investigación e interculturalidad. Madrid.

Domínguez, R. (2015). Estrategias didácticas y el rendimiento académico de los estudiantes de educación secundaria de las instituciones educativas del distrito de Taurija, La Libertad - 2013 (Tesis de maestría). Universidad Nacional de Educación Enrique Guzmán y Valle, La Libertad, Perú.

Ennis, R. (2011). The Nature of Critical Thinking: An Outline of Critical Thinking Dipositions And Abilities. Recuperado de faculty.education.ilinois.edu.

Feo, R. (2010). Orientaciones básicas para el diseño de una estrategia didáctica. España.

Fingermann, L. (2012). Formas de sociabilidad en torno a una experiencia de microcrédito. VII Jornadas de Sociología de la UNLP. Argentina.

Forgas, J. (2006). Diseño curricular por competencias: una alternativa para La formación de un técnico competente. Curso 14 Pedagogía. Ciudad de La Habana. Editorial Pueblo y educación.

Freire P. (2017). Pedagogía de la autonomía: saberes necesarios para la práctica educativa. Argentina. Sigloveintiuno.

Fullan, M. y Langworthy, M. (2014). “Towards a New End: New Pedagogies for Deep Learning". Tomado de: http://www.newpedagogies.org/

Gagné, R. (1965). Conditions of Learning. New York.

García M; y Huamán R. (2017), La imaginación escrita. Universidad Peruana de Ciencias Aplicadas. Lima.

González, J. et. al (2008). Tuning - América Latina: Reflexiones y perspectivas de la Educación Superior en América Latina. Revista Iberoamericana de Educación.

Guerrero, Y. (2017). Estrategias activas interdisciplinarias para fortalecer las habilidades comunicativas en los estudiantes del VII ciclo, especialidad Primaria, de formación 
magisterial del IESPP Rafael Hoyos Rubio de la provincia de San Ignacio, 2014 (Tesis de maestría). Universidad Nacional de Cajamarca, Perú.

Hernández, R., Fernández, C. y Baptista, P. (2006). Metodología de la investigación. Cuarta Edición. México: Mc Graw Hill.

Hernández, R., Fernández, C. y Baptista, P. (2014). Metodología de la investigación. Sexta Edición. México: Mc Graw Hill.

Hilgard, E. (1979). Teorías del Aprendizaje. México: Trillas.

Hymes, D. (1971). Competencia comunicativa, Ed- J. Pride and J. Holmes, EE.UU.

Instituto Nacional de Estadística e Informática (2017). Estadística de habitantes en Lima Región. Lima.

Jaramillo, A. (2009). La competencia comunicativa oral en el proceso docente educativo CESDE(Tesis de maestría). Universidad de Caldas, Colombia.

La Nuez, M. y Fernández, E. (2003) Material docente del curso básico de Metodología de la Investigación Educativa. Maestría en Educación. La Habana: Instituto Pedagógico Latinoamericano y caribeño. Cátedra Unesco.

Lara, A. (2013). Las competencias comunicativas y creativas, que utilizan los docentes para la enseñanza-aprendizaje de TIC, en estudiantes de cuarto grado de Primaria(Tesis de maestría). Tecnológico de Monterrey, México.

Ley General de Educación para los Instituto Nº 28044 (2005). Ministerio de Educación. Perú

Lomas, C. y Tusón A. (2012) Lengua, cultura y sociedad. Una mirada sociolingüística a la enseñanza de la lengua", en Textos de didáctica de la lengua y la literatura, 60:77-91

Lomas, C. y Tusón, A. (2012). Pensamiento narrativo y educación. Oviedo.

Loor, B. (2015). Desarrollo del habla como competencia social del bachiller. Transformación, 11(3), 114-122. Recuperado el 16 de febrero de 2016, de http://transformación.reduc.edu.cu/index.php/transformacion/article/view/167/152

López, M. (2008). Comunicaciones interpersonales efectivas en el trabajo directivo. Ruidos y barreras en la comunicación. Imagen corporativa del siglo XXI, Buenos Aires, La Crujia Ediciones. 
Maingueneau, D. (1984). Elementos de la lingüística para el discurso literario. Valencia.

Mandojana, N. (1970) "The long-term benefits of organizational resilience through sustainable business practices”, Strategic Management Journal, 37 (8), pp. 1615-1631.

Manglares \& Mejía, (2011). Las estrategias didácticas tienen un alto grado de dificultad. Fin de la enseñanza.

Márquez, P. (1999). Concepciones sobre el aprendizaje. Recuperado de http://www.peremarques.net/aprendiz.htm

Martínez, A. y Bonachea, O. (2002). ¿Estrategia de enseñanza o estrategia de aprendizaje? Revista Valera, 3-6, Argentina

Martínez, G. (2010). El Espacio Europeo de Educación Superior (EEES) y nuevo rol del estudiante Universitario. Cuadernos de Educación y Desarrollo, 2(16). Recuperado de http://www.eumed.net/rev/ced/16/jamg.htm

Martínez, H. y Ávila, E. (2011). Metodología de la investigación. México

McClelland, D. (1973). Testing for Competence Rather Than for "Intelligence”. Cambrige.

Méndez, J. (2013). Fortalecimiento de las competencias comunicativas de los estudiantes de grado noveno mediante la producción escrita de historias de vida(Tesis de maestría).Tecnológico de Monterrey, México.

Mercer, N. (2013). The social brain, language, and goal-directed collective thinking: A social conception of cognition and its implications for understanding how we think, teach, and learn. EducationalPsychologist, 48(3), 148-168. doi: https://doi.org/10.1080/00461520.2013.804394

Ministerio de Educación. (2016). Diseño Curricular Nacional. Lima

Ministerio de Educación. (2017). Programa Curricular Nacional. Lima

Mora, F. (2017). Neuroeducación: Solo se puede aprender aquello que se ama. Madrid: Alianza Editorial.

Moreno W. y Velázquez, M. (2017) Estrategia didáctica para desarrollar el pensamiento crítico. Revista Iberoamericana sobre Calidad, Eficacia y Cambio en Educación REICE, 2017,5(2), 53-73. https://doi.org/10.15366/reice2017.15.2.00315.

Morín, E., (2011). Los siete saberes necesarios para la educación, París, Francia: Unesco. 
Muñoz, H. y Pagés, T. (1991). La innovación como competencia docente en la universidad: Innovación orientada a la mejora de aprendizaje. Aloma 34(1), 33-43. doi: http://revistaaloma.net/index.php/aloma/article/view/282

Nava, M. (2015). Estrategia didáctica orientada a la construcción de conceptos científicos en física. Doctorado en Ciencias de la Educación. Universidad Rafael Belloso Chacín. Venezuela.

Neira, M. et al. (2018). La competencia comunicativa en el Grado de Maestro/a en Educación Infantil y Primaria. Una propuesta de criterios de desempeño como referencia-marco para su análisis y evaluación. España.

Neyra, M.y Ferreira, B. (2011). La competencia comunicativa en el grado de maestro de infantil y primaria. Una propuesta de criterios de desempeño como instrumento para su análisis y evaluación. España

Niño, Víctor (2008). Competencias en la comunicación. Hacia las prácticas del discurso. Bogotá. Ecoe Ediciones.

Organización de las Naciones Unidas para la Educación, la Ciencia y la Cultura (Unesco, (2015). Hacia las sociedades del conocimiento. Francia.

Ortega, I. (2000). Alfabetización Tecnológica y el desarrollo regional. Universidad de Salamanca. España

Ortiz, A. (2012). Didáctica problematizadora y aprendizaje basado en problemas. Cali, Colombia: Litoral.

Ortiz, P. (2008). Educación y formación de la personalidad. Universidad de Ciencias y Humanidades, Lima.

Pedraza, T. (2016). Programa de estrategias didácticas cognitivas para desarrollar la competencia comunicativa en los estudiantes de educación Secundaria de la I.E "Fe y alegría 69 San Viador” de Cutervo, 2016. Universidad Cesar Vallejo, Cutervo, Perú.

Peña, P. (2014). Aplicación sistemática de estrategias didácticas de historia, geografía y economía por los docentes de la educación básica regular (Tesis de maestría). Universidad de Piura.

Peñaloza, W. (2003). Los propósitos de la educación. Lima: Fondo Editorial del Pedagógico San Marcos.

Perdomo, J. y Lorence, J. (2003). Aproximaciones al estudio de las estrategias como resultado 
científico. Villa Clara. Centro de Estudios de Ciencias Pedagógicas. Universidad Pedagógica Félix Varela Morales. Material Digital pág.2 y 5

Pérez, L. (2015). Competencia comunicativa en la labor pedagógica. Madrid.

Piaget, J. (1981). La teoría de Piaget. Infancia y Aprendizaje. Ediciones Morata. 4(2), 12-54.

Pimienta, J. (2012). Estrategias de enseñanza - aprendizaje. Docencia universitaria basada en competencias. Naucalpan de Juárez, México: Pearson Educación.

Real Academia Española. (2014). Diccionario de la Lengua Española, (21 a ed.). Madrid, España

Recarey, S. (2004). Didáctica. Teoría y práctica. La Habana: Ed: Pueblo y Educación

Reyzábal, M. (2012). Las competencias comunicativas y lingüísticas, clave para la calidad educativa. Revista Iberoamericana sobre Calidad, Eficacia y Cambio en Educación, 10(4), 63-77.

Rico, L. et al (2013), “Análisis didáctico y metodología de investigación”. Granada

Rico, P., Santos, E. y Martín, V. (2013). Enseñanza- aprendizaje desarrollador escuela primaria. Teoría y práctica. La Habana: Pueblo y Educación.

Rímac D. Velázquez M. (2017). Estrategias innovadoras para contribuir al pensamiento crítico de los estudiantes.Rev. Educación Argentina- Scielo, http://fh.mdp.edu.ar/revistas/index.php/r_educ

Rivera, G. (2016). Desarrollo del enfoque comunicativo y el aprendizaje del idioma inglés en los estudiantes de la Universidad Jaime Bausate y Meza, 2016 (Tesis de maestría). Universidad Inca Garcilazo de la Vega, Perú.

Roldán, E. (2002). “Sobre la Ortología”. Documentos Lingüísticos y Literarios. España

Roméu A. (2009). Aplicación del Enfoque Comunicativo en la Escuela Media: Comprensión, Análisis y Construcción de textos. Material Impreso, IPLAC, La Habana.

Roméu, A. (2007). El enfoque cognitivo, comunicativo y sociocultural en la enseñanza de la lengua y la literatura. La Habana: Pueblo y Educación.

Rosano, A. (2011). Metáfora y poesía como instrumento para la comunicación intercultural en el aula ELE. Universidad de Santiago de Compostela. España

Sales, L. (2007). La enseñanza-aprendizaje en la construcción de textos. Ciudad de La Habana. 
Saussure, N. (1980). Actuación del hablante. Francia

Sergeeva, M.et al (2018). Psychological and pedagogical support for the social worker's professional development. Espacios, 39(2), 26.

Silvestre, M. y Zilberstein, J. (2011). Hacia una didáctica desarrolladora. México: CEDEI.

La Habana: Pueblo y Educación.

Superintendencia Nacional de Educación Superior Universitaria (Sunedu, 2017). Estándares de calidad. Lima.

Tobón, S. (2009). Formación basada en competencias: pensamiento complejo, diseño curricular y didáctica. Bogotá: Ecoe.

Tobón, S. (2010). Formación basada en competencias. Pensamiento complejo, diseño curricular y didáctica. Bogotá. Ecoe.

Tobón, S. (2013). Formación basada en competencias: pensamiento complejo, diseño curricular y didáctica, 2da Edición. Bogotá: Ecoe.

Van Dijk, T. (2001). Estructuras y funciones del discurso. Una introducción interdisciplinaria a la lingüística del texto y a los estudios del discurso. México siglo XXI ediciones.

Vargas, G. (2014). Las competencias comunicativas como estrategia pedagógica para favorecer el aprendizaje significativo en los estudiantes de Primaria (Tesis de maestría). Corporación Universitaria Minuto de Dios, México.

Velazco, M. y Mosquera, F. (2010). Estrategias Didácticas para el Aprendizaje Colaborativo. PAIEP. Consultado el 15 de agosto de 2018, en: http://acreditacion.udistrital.edu.co/flexibilidad/estrategias_didacticas_aprendizaje_col aborativo.pdf

Velázquez, M. (2014). Estrategia para enseñar y aprender la Lengua Española en la Escuela. Lima. Fondo Editorial del Pedagógico San Marcos.

Velázquez, M. (2017). Estrategia didáctica para la construcción de textos escritos en los estudiantes de Primaria. Florida. Pontifica Universidad Católica Americana.

Vygotski, L. (1989). El desarrollo de los procesos psicológicos superiores. Barcelona: Crítica-Grijalbo.

Vygotsky, L. (1979). Pensamiento y Lenguaje. El desarrollo de los procesos Psicológicossuperioresy la socialización. La Habana. Pueblo y educación. 
Zegarra, R. y Velázquez, M. (2017). El coaching: una forma para fortalecer el profesionalismo del docente en el aula. Páginas de educación. Uruguay: Universidad Católica del Uruguay. doi: https://doi.org/10.22235/pe.v9i2.1294. 


\section{Anexos}

\section{ANEXO 01}

\section{Matriz metodológica}

Estrategia Didáctica para el desarrollo de la competencia comunicativa oral de los estudiantes.

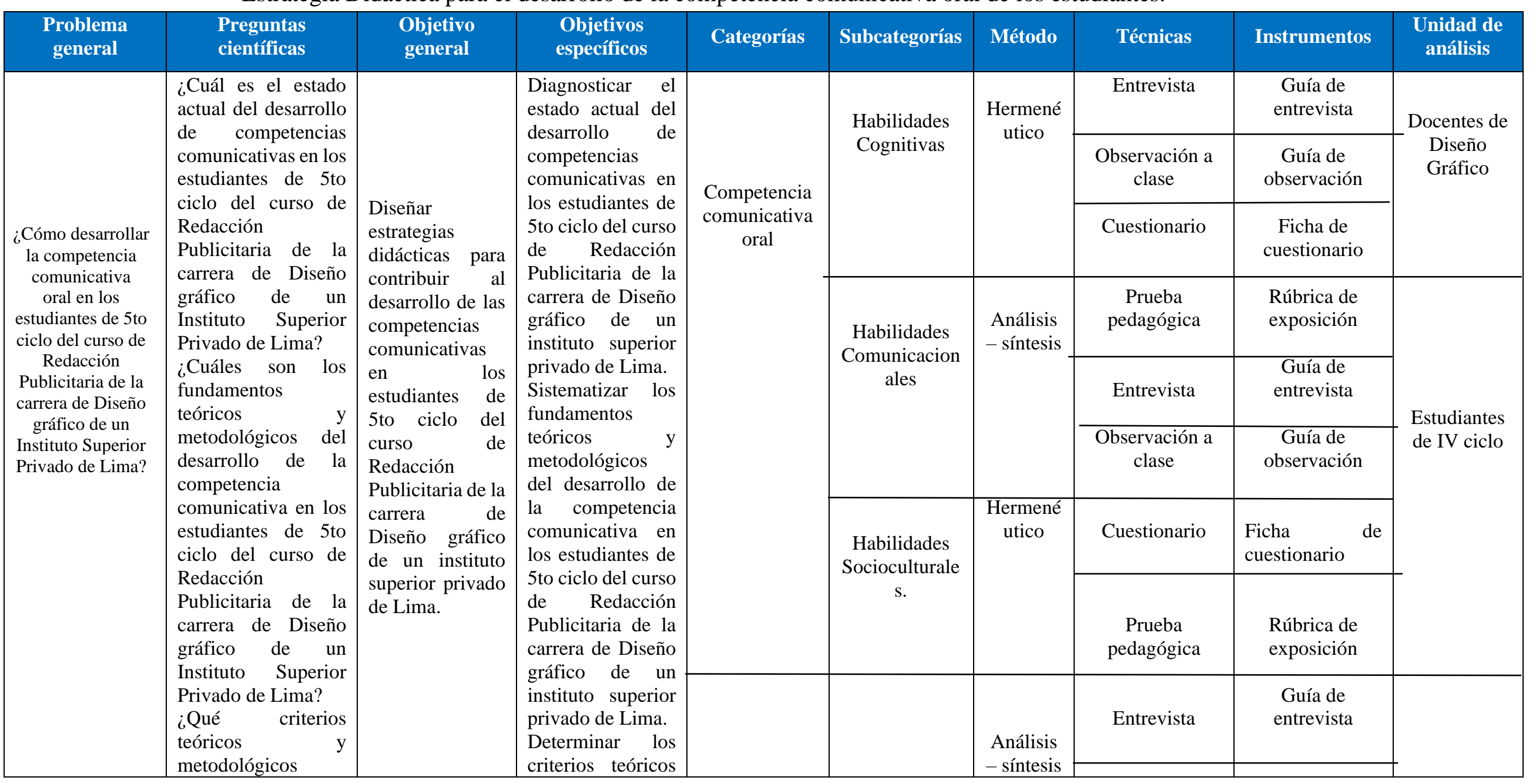




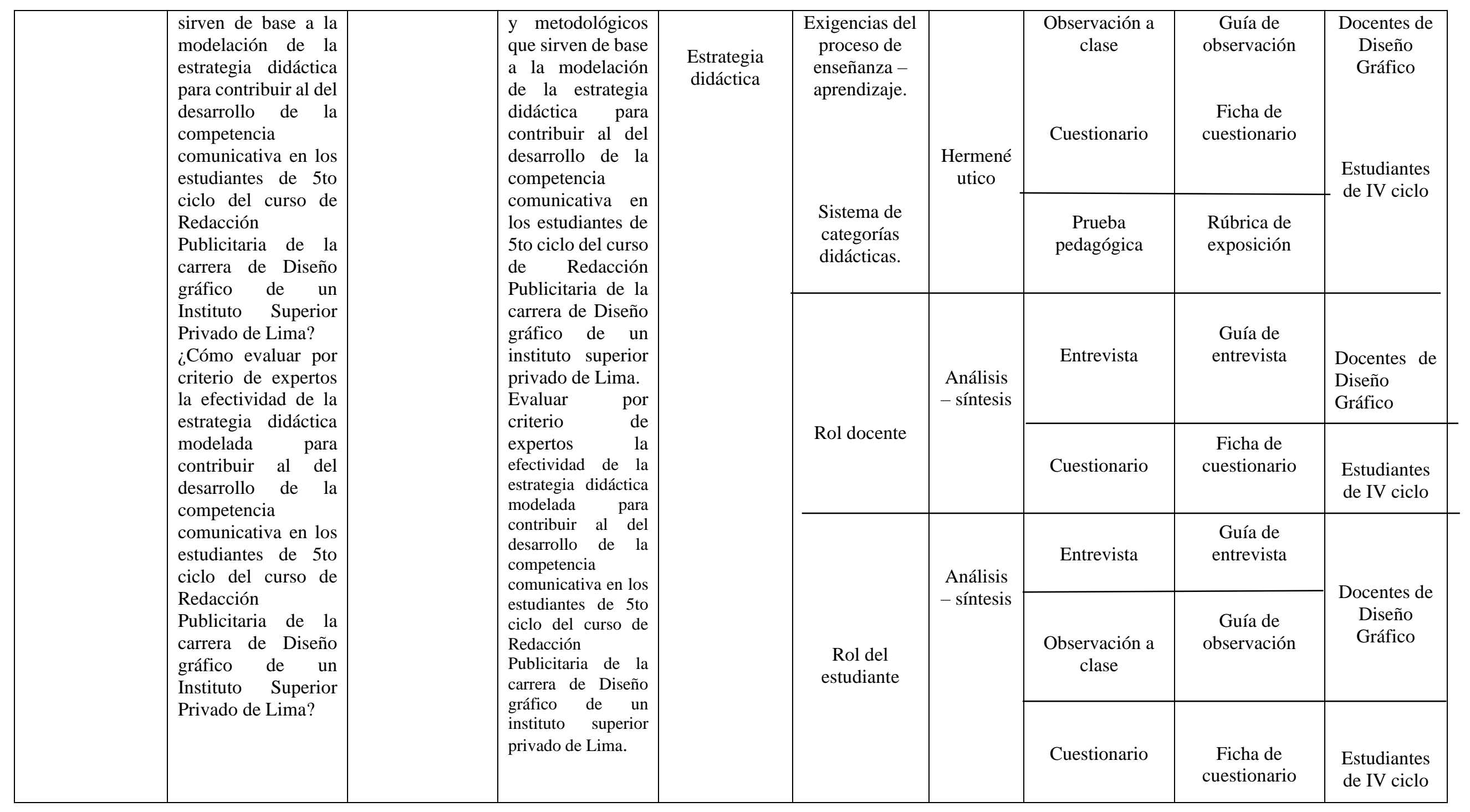




\section{ANEXO 02}

\section{Matriz metodológica}

Estrategia didáctica para desarrollar la competencia comunicativa oral en los estudiantes de IV ciclo de Diseño Gráfico de un instituto superior de Lima.

\begin{tabular}{|c|c|c|c|c|c|c|c|c|}
\hline \multirow[b]{2}{*}{$\begin{array}{l}\text { PROBLEMA DE } \\
\text { INVESTIGACIÓN }\end{array}$} & \multirow[b]{2}{*}{$\begin{array}{l}\text { OBJETIVO } \\
\text { GENERAL }\end{array}$} & \multirow[b]{2}{*}{ CATEGORÍAS } & \multirow[b]{2}{*}{ SUBCATEGORÍAS } & \multicolumn{5}{|c|}{ INSTRUMENTOS } \\
\hline & & & & INDICADORES & $\begin{array}{l}\text { ENTREVISTA A } \\
\text { DOCENTES }\end{array}$ & $\begin{array}{c}\text { CUESTIONARIO } \\
\text { A } \\
\text { ESTUDIANTES }\end{array}$ & $\begin{array}{c}\text { PRUEBA } \\
\text { PEDAGÓGICA } \\
\text { PARA } \\
\text { ESTUDIANTES } \\
\end{array}$ & $\begin{array}{l}\text { OBSERVACIÓN A } \\
\text { CLASE }\end{array}$ \\
\hline \multirow{3}{*}{$\begin{array}{c}\text { ¿Cómo } \\
\text { desarrollar la } \\
\text { competencia } \\
\text { comunicativa } \\
\text { oral en los } \\
\text { estudiantes de } \\
\text { IV ciclo de la } \\
\text { disciplina de } \\
\text { Producción } \\
\text { Gráfica de la } \\
\text { carrera de } \\
\text { Diseño gráfico } \\
\text { de un Instituto } \\
\text { Superior } \\
\text { Privado de } \\
\text { Lima? }\end{array}$} & \multirow{3}{*}{$\begin{array}{c}\text { Diseñar una } \\
\text { estrategia } \\
\text { didáctica } \\
\text { para } \\
\text { contribuir al } \\
\text { desarrollo de } \\
\text { la } \\
\text { competencia } \\
\text { comunicativa } \\
\text { oral en los } \\
\text { estudiantes } \\
\text { de IV ciclo } \\
\text { de la } \\
\text { disciplina de } \\
\text { Producción } \\
\text { Gráfica de la } \\
\text { carrera de } \\
\text { Diseño } \\
\text { Gráfico de } \\
\text { un Instituto } \\
\text { Superior }\end{array}$} & \multirow{3}{*}{$\begin{array}{l}\text { Competencia } \\
\text { comunicativa } \\
\text { oral } \\
\text { La competencia } \\
\text { comunicativa es la } \\
\text { configuración } \\
\text { psicológica que } \\
\text { integra diversos } \\
\text { componentes } \\
\text { cognitivos, meta } \\
\text { cognitivo, } \\
\text { motivacionales y } \\
\text { cualidades, Romeú } \\
\text { (2007). }\end{array}$} & \multirow{3}{*}{$\begin{array}{l}\text { Habilidades cognitivas } \\
\text { Consisten en la asimilación de } \\
\text { un sistema complejo cuyas } \\
\text { operaciones son las encargadas } \\
\text { de organizar la información } \\
\text { obtenida. }\end{array}$} & $\begin{array}{l}\text { Explica los } \\
\text { fundamentosteóricos } \\
\text { de la comunicación. }\end{array}$ & $\begin{array}{l}\text { ¿Cuáles son } \\
\text { los } \\
\text { fundamentos } \\
\text { teóricos de la } \\
\text { comunicación? }\end{array}$ & $\begin{array}{|lr|}\text { El docente } \\
\text { utiliza autores } \\
\text { que sustenten el } \\
\text { análisis del } \\
\text { contenido } \\
\text { visual. } \\
\end{array}$ & & \\
\hline & & & & $\begin{array}{l}\text { Diferencia la } \\
\text { intención } \\
\text { comunicativa y la } \\
\text { finalidad del autor. }\end{array}$ & $\begin{array}{|lr|}\text { ¿Qué } & \\
\text { diferencias } & \\
\text { encuentra } & \\
\text { entre } & \text { la } \\
\text { intención } & \\
\text { comunicativa } \\
\text { con r ra } \\
\text { finalidad del } \\
\text { autor? }\end{array}$ & $\begin{array}{l}\text { Identificode } \\
\text { forma clara } \\
\text { cuál es el } \\
\text { mensaje de los } \\
\text { contenidos } \\
\text { vistos en clase. }\end{array}$ & $\begin{array}{l}\text { El mensaje } \\
\text { comunicativo de } \\
\text { la pieza gráfica es } \\
\text { claro y coherente. }\end{array}$ & \\
\hline & & & & $\begin{array}{lr}\text { Caracteriza } & \text { los } \\
\text { procedimientos } & \mathrm{y} \\
\text { habilidades } & \\
\text { cognitivas } & \mathrm{y} \\
\text { metacognitivas. } & \end{array}$ & & 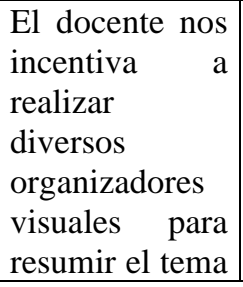 & $\begin{array}{l}\text { Presentación de la } \\
\text { información de } \\
\text { manera original y } \\
\text { de r fácil } \\
\text { entendimiento. }\end{array}$ & $\begin{array}{l}\text { Durante el desarrollo } \\
\text { del proceso de } \\
\text { aprendizaje se aplica } \\
\text { estrategias cognitivas } \\
\text { y metacognitivas. }\end{array}$ \\
\hline
\end{tabular}




\begin{tabular}{|c|c|c|c|c|c|}
\hline & & & $\begin{array}{l}\text { trabajado en } \\
\text { clase. }\end{array}$ & & \\
\hline \multirow{3}{*}{$\begin{array}{l}\text { Habilidadescomunicacionales } \\
\text { Integración de los procesos } \\
\text { lingüísticos que se establecen a } \\
\text { lo largo de la vida humana, } \\
\text { donde se tiene como objetivo la } \\
\text { participación efectiva y } \\
\text { dinámica con los ámbitos } \\
\text { sociales que nos rodean. }\end{array}$} & $\begin{array}{ll}\text { Caracteriza } & \text { los } \\
\text { medios } & \\
\text { comunicativos, } & \\
\text { verbales y } & \text { no } \\
\text { verbales } & \end{array}$ & & $\begin{array}{l}\text { Identifico el } \\
\text { uso de la } \\
\text { comunicación } \\
\text { verbal y/o no } \\
\text { verbal en las } \\
\text { publicidades } \\
\text { mostradas por } \\
\text { el docente. } \\
\end{array}$ & $\begin{array}{l}\text { Presentación } \\
\text { efectiva } \\
\text { evidenciada en la } \\
\text { postura corporal y } \\
\text { el manejo de la } \\
\text { audiencia. }\end{array}$ & \\
\hline & $\begin{array}{lr}\text { Argumenta } & \text { los } \\
\text { distintos tipos } & \text { de } \\
\text { textos orales. } & \end{array}$ & $\begin{array}{l}\text { ¿Cómo } \\
\text { clasifica las } \\
\text { formas } \\
\text { elocutivas en } \\
\text { el proceso } \\
\text { comunicativo? }\end{array}$ & $\begin{array}{l}\text { Mi expresión } \\
\text { oral en una } \\
\text { exposición es } \\
\text { clara, coherente } \\
\text { y precisa. }\end{array}$ & $\begin{array}{lr}\text { Utiliza } & \text { un } \\
\text { lenguaje } & \\
\text { apropiado } & \text { con } \\
\text { corrección } & \\
\text { sintáctica } & \text { y } \\
\text { gramatical. } & \end{array}$ & $\begin{array}{lr}\text { El docente emplea } \\
\text { una adecuada forma } \\
\text { elocutiva con los } \\
\text { estudiantes } & \text { para } \\
\text { vincular } & \text { el } \\
\text { conocimiento previo } \\
\text { con el tema de la } \\
\text { sesión. }\end{array}$ \\
\hline & $\begin{array}{l}\text { Maneja los diversos } \\
\text { estilos de } \\
\text { comunicación. }\end{array}$ & & $\begin{array}{l}\text { Identifico el } \\
\text { tipo de lenguaje } \\
\text { empleado en } \\
\text { las } \\
\text { publicidades } \\
\text { que se analiza } \\
\text { en clase. }\end{array}$ & $\begin{array}{l}\text { Emplea } \\
\text { vocabulario } \\
\text { formal y técnico } \\
\text { para } \\
\text { presentación del } \\
\text { proyecto. }\end{array}$ & \\
\hline $\begin{array}{l}\text { Habilidades socioculturales } \\
\text { Definidas como el estudio de la } \\
\text { conducta y su aplicación en la } \\
\text { resolución de problemas de } \\
\text { contexto social de manera } \\
\text { efectiva. }\end{array}$ & $\begin{array}{l}\text { Identifica la cultura } \\
\text { y la sociedad en su } \\
\text { dimensión semiótica } \\
\text { y discursiva. }\end{array}$ & $\begin{array}{l}\text { ¿Qué } \\
\text { característica } \\
\text { de la cultura y } \\
\text { la sociedad } \\
\text { peruana } \\
\text { manifiesta en } \\
\text { la } \\
\text { comunicación } \\
\text { oral o } \\
\text { discursiva? }\end{array}$ & $\begin{array}{lr}\text { El docente } & \text { me } \\
\text { motiva } & \mathrm{a} \\
\text { indagar } & \mathrm{y} \\
\text { analizar } & \mathrm{mi} \\
\text { contexto para } \\
\text { extraer } \\
\text { características } \\
\text { del público } \\
\text { objetivo. }\end{array}$ & $\begin{array}{l}\text { Integra } \\
\text { características del } \\
\text { contexto en la } \\
\text { construcción del } \\
\text { mensaje } \\
\text { publicitario. }\end{array}$ & \\
\hline
\end{tabular}




\begin{tabular}{|c|c|c|c|c|c|c|}
\hline & & $\begin{array}{|lr|}\text { Conoce } & \text { las } \\
\text { relaciones } & \text { entre } \\
\text { participantes, } & \text { a } \\
\text { partir de r r sus } \\
\text { intenciones y } & \text { la } \\
\text { clase, grupo social o } \\
\text { instituciones a r las } \\
\text { que pertenecen }\end{array}$ & $\begin{array}{|lrr|}\text { ¿Cómo es } & \text { el } \\
\text { desarrollo } & \\
\text { discursivo } & \text { de } \\
\text { sus estudiantes } \\
\text { según r r el } \\
\text { estatus rocial } \\
\text { de su familia? } \\
\end{array}$ & $\begin{array}{ll}\text { El docente } \\
\text { propone } & \\
\text { actividades } & \text { de } \\
\text { aprendizaje } & \text { en } \\
\text { equipo. } & \end{array}$ & & $\begin{array}{l}\text { El docente identifica } \\
\text { las necesidades de los } \\
\text { estudiantes a través de } \\
\text { un diálogo } \\
\text { participativo. }\end{array}$ \\
\hline & & $\begin{array}{l}\text { Valora la influencia } \\
\text { del contexto en lo } \\
\text { que dice el hablante. }\end{array}$ & & $\begin{array}{l}\text { Mi lenguaje es } \\
\text { el adecuado } \\
\text { para } \\
\text { expresarme en } \\
\text { el aula de clase. }\end{array}$ & $\begin{array}{|lrr|}\text { El vocabulario } \\
\text { empleado en } & \text { las } \\
\text { piezas } & \text { gráficas } \\
\text { corresponde } & \text { al } \\
\text { contexto de } & \text { la } \\
\text { investigación. }\end{array}$ & $\begin{array}{l}\text { La sesión de clase y } \\
\text { las actividades de } \\
\text { aprendizaje se basan } \\
\text { en el análisis del } \\
\text { contexto } \\
\text { estudiante. }\end{array}$ \\
\hline \multirow{3}{*}{$\begin{array}{c}\text { Estrategia } \\
\text { didáctica } \\
\text { La estrategia } \\
\text { didáctica como un } \\
\text { modelo, } \\
\text { compuesto por } \\
\text { métodos, } \\
\text { procedimientos, } \\
\text { técnicas y } \\
\text { actividades a } \\
\text { través de los } \\
\text { cuales el docente } \\
\text { y los estudiantes } \\
\text { organizan las } \\
\text { acciones de } \\
\text { manera consciente } \\
\text { para construir y } \\
\text { lograr metas } \\
\text { previstas e } \\
\text { imprevistas en el } \\
\text { proceso enseñanza }\end{array}$} & \multirow{2}{*}{$\begin{array}{l}\text { Exigencias del proceso } \\
\text { Enseñanza- Aprendizaje } \\
\text { Es un proceso donde tanto la } \\
\text { enseñanza como el aprendizaje } \\
\text { se basan en una educación } \\
\text { desarrolladora } \\
\text { caracteriza que por se una } \\
\text { comunicación y actividad } \\
\text { intencionales, cuyo accionar } \\
\text { didáctico genera estrategias de } \\
\text { aprendizajes para el desarrollo } \\
\text { de la personalidad integral. }\end{array}$} & \begin{tabular}{|lr} 
Aplica de & manera \\
coherente & las \\
categorías & \\
didácticas. & \\
\end{tabular} & 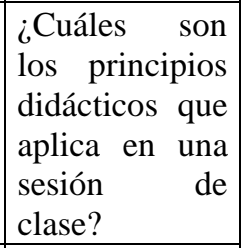 & $\begin{array}{l}\text { El docente } \\
\text { emplea } \\
\text { estrategias } \\
\text { didácticas en la } \\
\text { sesión de clase. }\end{array}$ & & \\
\hline & & $\begin{array}{|lr|} & \\
\text { Aplica } & \text { el } \\
\text { diagnóstico } & y \\
\text { caracteriza el grupo. } & \\
\end{array}$ & $\begin{array}{|lr|}\text { ¿Realiza } & \text { un } \\
\text { análisis } & \text { de } \\
\text { diagnóstico } & \\
\text { durante } & \mathrm{el} \\
\text { desarrollo } & \mathrm{de} \\
\text { una sesión } & \mathrm{de} \\
\text { clase? } & \\
\end{array}$ & 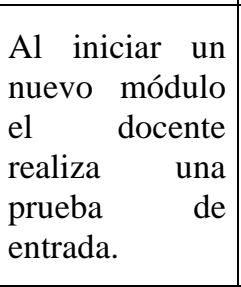 & & \\
\hline & $\begin{array}{l}\text { Sistema de categorías } \\
\text { didácticas } \\
\text { Definido como la organización } \\
\text { de los medios de enseñanza } \\
\text { presentes en las sesiones de } \\
\text { clase donde el docente plantea } \\
\text { objetivos y metas concretas }\end{array}$ & $\begin{array}{l}\text { Organiza el } \\
\text { aprendizaje a partir } \\
\text { de los métodos } \\
\text { heurísticos, } \\
\text { comunicativo, } \\
\text { creativo } \\
\text { investigativo. }\end{array}$ & & $\begin{array}{l}\text { El docente } \\
\text { incentiva en la } \\
\text { búsqueda de } \\
\text { nueva } \\
\text { información } \\
\text { adicional a la } \\
\text { presentada en } \\
\text { clase. }\end{array}$ & & \\
\hline
\end{tabular}




\begin{tabular}{|c|c|c|c|c|c|c|}
\hline \multirow[t]{5}{*}{$\begin{array}{c}\text { - aprendizaje, } \\
\text { adaptándose a las } \\
\text { necesidades de los } \\
\text { participantes de } \\
\text { manera } \\
\text { significativa, Feo } \\
\text { (2010). }\end{array}$} & $\begin{array}{l}\text { para lograr un aprendizaje } \\
\text { significativo. }\end{array}$ & $\begin{array}{l}\text { Orienta la actividad } \\
\text { de aprendizaje según } \\
\text { la necesidad del } \\
\text { estudiante. }\end{array}$ & $\begin{array}{l}\text { ¿Cómo adapta } \\
\text { las actividades } \\
\text { de aprendizaje } \\
\text { según las } \\
\text { necesidades } \\
\text { del estudiante? }\end{array}$ & $\begin{array}{l}\text { El docente } \\
\text { analiza las } \\
\text { necesidades de } \\
\text { aprendizaje de } \\
\text { todos } \quad \text { mis } \\
\text { compañeros } \\
\text { para incluirlo } \\
\text { dentro de las } \\
\text { sesiones de } \\
\text { clases. }\end{array}$ & & $\begin{array}{l}\text { Adapta las } \\
\text { actividades de } \\
\text { aprendizaje según las } \\
\text { necesidades del grupo } \\
\text { estudiantil. }\end{array}$ \\
\hline & \multirow{2}{*}{$\begin{array}{l}\text { Rol del docente } \\
\text { Debe tener maestría pedagógica } \\
\text { y dominio de su especialidad y } \\
\text { aplicar métodos que potencien } \\
\text { el protagonismo de los } \\
\text { estudiantes en el proceso de } \\
\text { enseñanza- aprendizaje para } \\
\text { alcanzar los objetivos } \\
\text { instructivos y formativos en los } \\
\text { estudiantes de forma integral. }\end{array}$} & $\begin{array}{l}\text { Demuestra ser un } \\
\text { mediador eficaz que } \\
\text { dominar el } \\
\text { contenido y atiende } \\
\text { la diversidad del } \\
\text { grupo. }\end{array}$ & $\mid \begin{array}{lr}\text { ¿Cuál es } & \text { su } \\
\text { preparación } & \\
\text { previa } & \text { para } \\
\text { desarrollar } & \text { una } \\
\text { sesión } & \text { de } \\
\text { clase? } & \end{array}$ & \begin{tabular}{|lr} 
El docente \\
domina los \\
temas de las \\
sesiones & de \\
clases de la \\
asignatura \\
Producción \\
Gráfica & \\
\end{tabular} & & $\begin{array}{l}\text { El docente demuestra } \\
\text { dominio del tema } \\
\text { logrando } \\
\text { participación activa } \\
\text { de los estudiantes. }\end{array}$ \\
\hline & & $\begin{array}{l}\text { Organiza el } \\
\text { aprendizaje desde la } \\
\text { zona de desarrollo } \\
\text { próximo. }\end{array}$ & & $\begin{array}{lr}\text { Durante la } \\
\text { sesión de clase } \\
\text { el docente } \\
\text { monitorea } \\
\text { vigila } \\
\text { creación la de } \\
\text { nuevos } \\
\text { conocimientos. } \\
\end{array}$ & & $\begin{array}{l}\text { Realiza una } \\
\text { retroalimentación de } \\
\text { la sesión de } \\
\text { aprendizaje, así como } \\
\text { la resolución de dudas } \\
\text { de los estudiantes. }\end{array}$ \\
\hline & \multirow{2}{*}{$\begin{array}{l}\text { Rol del estudiante } \\
\text { Asume una actitud en la clase } \\
\text { que lo hace protagónico, activo, } \\
\text { problematizador, dialógico, } \\
\text { colaborativo e interactivo que } \\
\text { investiga y construye el } \\
\text { conocimiento y desarrolla } \\
\text { habilidades que le permiten } \\
\text { transformar sus formas de } \\
\text { pensar, hacer y sentir al actuar. }\end{array}$} & $\begin{array}{lr}\text { Demuestra } & \text { ser } \\
\text { responsable } & y \\
\text { consciente de su } \\
\text { propio aprendizaje. }\end{array}$ & & $\begin{array}{lr}\text { Comprendo } & \text { de } \\
\text { manera } & \\
\text { consciente } & \text { los } \\
\text { contenidos } & \text { que } \\
\text { brinda } & \text { el } \\
\text { docenter } & \end{array}$ & $\begin{array}{lr}\text { Presenta } & \text { la } \\
\text { información } & \text { de } \\
\text { manera } & \\
\text { organizada } & \text { con } \\
\text { puntualidad } & \text { y } \\
\text { responsabilidad. }\end{array}$ & $\begin{array}{l}\text { Los estudiantes } \\
\text { realizan las } \\
\text { actividades } \\
\text { encomendadas por el } \\
\text { docente con un alto } \\
\text { nivel de } \\
\text { responsabilidad, }\end{array}$ \\
\hline & & $\begin{array}{l}\text { Resuelv0e tareas de } \\
\text { aprendizaje } \\
\text { individual y en } \\
\text { colaboración de } \\
\text { manera significativa. }\end{array}$ & $\begin{array}{|lr|}\text { ¿Qué } & \text { criterios } \\
\text { aplica } & \text { para } \\
\text { determinar } & \text { el } \\
\text { trabajo } & \\
\text { individual } & y \\
\end{array}$ & $\begin{array}{l}\text { Resuelvo las } \\
\text { actividades } \\
\text { encomendadas } \\
\text { por el docente } \\
\text { reconociendo } \\
\end{array}$ & & $\begin{array}{l}\text { El producto obtenido } \\
\text { en la tarea de } \\
\text { aprendizaje } \\
\text { encomendada por el }\end{array}$ \\
\hline
\end{tabular}




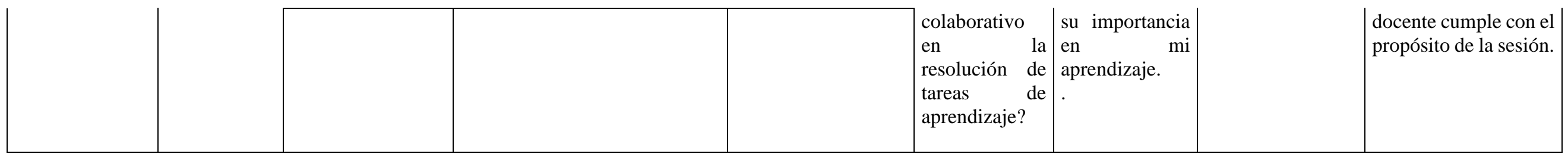




\section{ANEXO 03 \\ Guía de entrevista a los docentes}

\section{Datos informativos:}

\section{Entrevistador:}

\section{Lugar y Fecha:}

\section{Duración:}

OBJETIVO: Conocer la preparación teórica y didáctica que poseen los docentes en torno a las estrategias didácticas para desarrollar la competencia comunicativa oral en los estudiantes de IV ciclo de Diseño Gráfico de un Instituto Superior de Lima.

Cuestionario:

¿Cuáles son los fundamentos teóricos de la comunicación?

¿Qué diferencias encuentra entre la intención comunicativa con la finalidad del autor?

¿Cómo clasifica las formas elocutivas en el proceso comunicativo?

¿Qué característica de la cultura y la sociedad peruana manifiesta en la comunicación oral o discursiva?

¿Cómo es el desarrollo discursivo de sus estudiantes según el estatus social de su familia?

¿Cuáles son los principios didácticos que aplica en una sesión de clase?

¿Realiza un análisis de diagnóstico durante el desarrollo de una sesión de clase?

¿Cómo adapta las actividades de aprendizaje según las necesidades del estudiante?

¿Cuál es su preparación previa para desarrollar una sesión de clase?

¿Qué criterios aplica para determinar el trabajo individual y colaborativo en la resolución de tareas de aprendizaje? 


\section{ANEXO 04}

\section{Guía de observación a clase}

\section{Datos Generales:}

Curso:

Fecha

Total de Alumnos

\section{Nombre del observador}

\section{Tiempo total de observación}

El documento que se proporciona a continuación incluye aspectos y situaciones de la competencia comunicativa oral organizadas para la observación entre colegas. El diseño propone un espacio de interacción entre iguales (peer coaching) para: reflexionar, sistematizar y dar soluciones de aquellos aspectos que favorecen la implementación de la estrategia en el salón de clases.

\begin{tabular}{|c|c|c|c|}
\hline ASPECTOS A OBSERVAR & SI & NO & OBSERVACIÓN \\
\hline Motivación y orientación hacia los objetivos. & & & \\
\hline $\begin{array}{l}\text { El docente emplea una adecuada forma elocutiva con los estudiantes para vincular } \\
\text { el conocimiento previo con eltema de la sesión. }\end{array}$ & & & \\
\hline $\begin{array}{l}\text { El docente identifica las necesidades de los estudiantes a través de un diálogo } \\
\text { participativo }\end{array}$ & & & \\
\hline Desarrollo del proceso de enseñanza - aprendizaje & & & \\
\hline $\begin{array}{l}\text { El docente demuestra dominio del tema logrando la participación activa del } \\
\text { estudiante. }\end{array}$ & & & \\
\hline Adapta las actividades de aprendizaje según las necesidades del grupo estudiantil. & & & \\
\hline $\begin{array}{l}\text { Durante el desarrollo del proceso de aprendizaje se aplica estrategias cognitivas y } \\
\text { metacognitivas. }\end{array}$ & & & \\
\hline $\begin{array}{l}\text { La sesión de clase y las actividades de aprendizaje se basan en el análisis del } \\
\text { contexto del estudiante }\end{array}$ & & & \\
\hline $\begin{array}{l}\text { Los estudiantes realizan las actividades encomendadas por el docente con un alto } \\
\text { nivel de responsabilidad. }\end{array}$ & & & \\
\hline Conclusiones de la clase & & & \\
\hline $\begin{array}{l}\text { El producto obtenido en la tarea de aprendizaje encomendada por el docente } \\
\text { cumple con el propósito de la sesión. }\end{array}$ & & & \\
\hline $\begin{array}{l}\text { Realiza una retroalimentación de la sesión de aprendizaje, así como la resolución } \\
\text { de dudas de los estudiantes. }\end{array}$ & & & \\
\hline
\end{tabular}


ANEXO 05

Encuesta a estudiantes

\section{DATOS GENERALES:}

Curso:

Edad: ___ Sexo: Femenino () Masculino () Fecha:

OBJETIVO:Conocer el nivel de satisfacción de los estudiantes de IV ciclo de Diseño Gráfico en el desarrollo deestrategias didácticas y la competencia comunicativa oral en la asignatura de Producción Gráficade un Instituto Superior de Lima.

Instrucciones:Estimado estudiante, como parte de una investigación necesitamos que colabores con tu opinión respecto a los contenidos de las asignaturas de producción gráfica y de la forma como los docentes dirigen la sesión de clase. Para ello te pedimos que leas atentamente el siguiente cuestionario para responder con sinceridad las siguientes preguntas.

\section{Cuestionario:}

\begin{tabular}{|c|c|c|c|c|c|c|}
\hline $\mathbf{N}^{\circ}$ & Ítems & $\begin{array}{l}\text { 巳 } \\
\text { 至 }\end{array}$ & 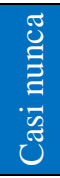 & $\begin{array}{l}\mathscr{8} \\
0 \\
\otimes \\
\varangle\end{array}$ & $\overline{\tilde{J}}$ & : \\
\hline 1 & El docente utiliza autores que sustenten el análisis del contenido visual. & & & & & \\
\hline 2 & Identifico de forma clara cuál es el mensaje de los contenidos vistos en clase. & & & & & \\
\hline 3 & $\begin{array}{l}\text { El docente nos incentiva a realizar diversos organizadores visuales para resumir el tema trabajado } \\
\text { en clase. }\end{array}$ & & & & & \\
\hline 4 & $\begin{array}{l}\text { Identifico el uso de la comunicación verbal y/o no verbal en las publicidades mostradas por el } \\
\text { docente. }\end{array}$ & & & & & \\
\hline 5 & Mi expresión oral en una exposición es clara, coherente y precisa. & & & & & \\
\hline 6 & Identifico el tipo de lenguaje empleado en las publicidades que se analiza en clase. & & & & & \\
\hline 7 & $\begin{array}{l}\text { El docente me motiva a indagar y analizar mi contexto para extraer características del público } \\
\text { objetivo. }\end{array}$ & & & & & \\
\hline 8 & El docente propone actividades de aprendizaje en equipo. & & & & & \\
\hline 9 & Mi lenguaje es el adecuado para expresarme en el aula de clase. & & & & & \\
\hline 10 & El docente emplea estrategias didácticas en la sesión de clase. & & & & & \\
\hline 11 & Al iniciar un nuevo módulo el docente realiza una prueba de entrada. & & & & & \\
\hline 12 & El docente realiza una retroalimentación al finalizar la sesión de clase. & & & & & \\
\hline 13 & La docente incentiva en la búsqueda de nueva información adicional a la presentada en clase. & & & & & \\
\hline 14 & $\begin{array}{l}\text { El docente analiza las necesidades de aprendizaje de todos mis compañeros para incluirlo dentro } \\
\text { de las sesiones de clases. }\end{array}$ & & & & & \\
\hline 15 & El docente domina los temas de las sesiones de clases de la asignatura Producción Gráfica & & & & & \\
\hline 16 & Durante la sesión de clase el docente monitorea o vigila la creación de nuevos conocimientos. & & & & & \\
\hline 17 & Comprendo de manera consciente los contenidos que brinda el docente. & & & & & \\
\hline 18 & $\begin{array}{l}\text { Resuelvo las actividades encomendadas por el docente reconociendo su importancia en mi } \\
\text { aprendizaje. }\end{array}$ & & & & & \\
\hline
\end{tabular}




\section{ANEXO 06 \\ Prueba pedagógica para estudiantes}

\section{Datos generales:}

\section{Asignatura: Producción Gráfica Ciclo: IV Código: 34002}

Edad: Sexo: Femenino ( ) Masculino ( )

Fecha:

OBJETIVO: Comprobar el nivel de competencia comunicativa oral que desarrolla el curso de Producción Gráfica que llevan los estudiantes del IV ciclo de una institución educativa privada de Lima.

INSTRUCCIONES: Como parte de la metodología de clase, se planteó una exposición anticipada del curso, para la cual se realizó una rúbrica de exposición en la cual se muestra los ítems a observar según los requerimientos de la investigación.

\section{Datos del proyecto final}

PROYECTO: “Campaña en redes sociales”

TEMA: Marketing Online / Facebook

\section{Objetivos del proyecto:}

Incursión del estudiante en el mundo digital a través de la creación de piezas gráficas dirigidas a un segmento seleccionado.

\section{Instrucciones:}

Trabajo individual

Entrega de imágenes en HD, formato AI y PDF

Tiempo de exposición de 20 minutos.

\section{Presentación:}

Creación de un correo corporativo

Estructura: nombresapellidos@gmail.com

Creación de un Fan Page

Diseñar una foto de perfil - Logotipo.

Diseñar una foto de portada- Alusiva a su personalidad.

Diseñar 4 publicaciones

Publicación sobre el perfil profesional del estudiante

Áreas de interés y dominio

Manejo de herramientas digitales

Portafolio digital.

Promocionar en FB y gestionar los contenidos. 


\section{ANEXO 07}

Validación instrumentos: experto 1

USWL

Br. Josselyn Lara Escalante
Macstria en Educación con

CERTIFICADO DE VALIDEZ DE CONTENIDO DE LA GUIA DE OBSERVACIÓN A CLASE

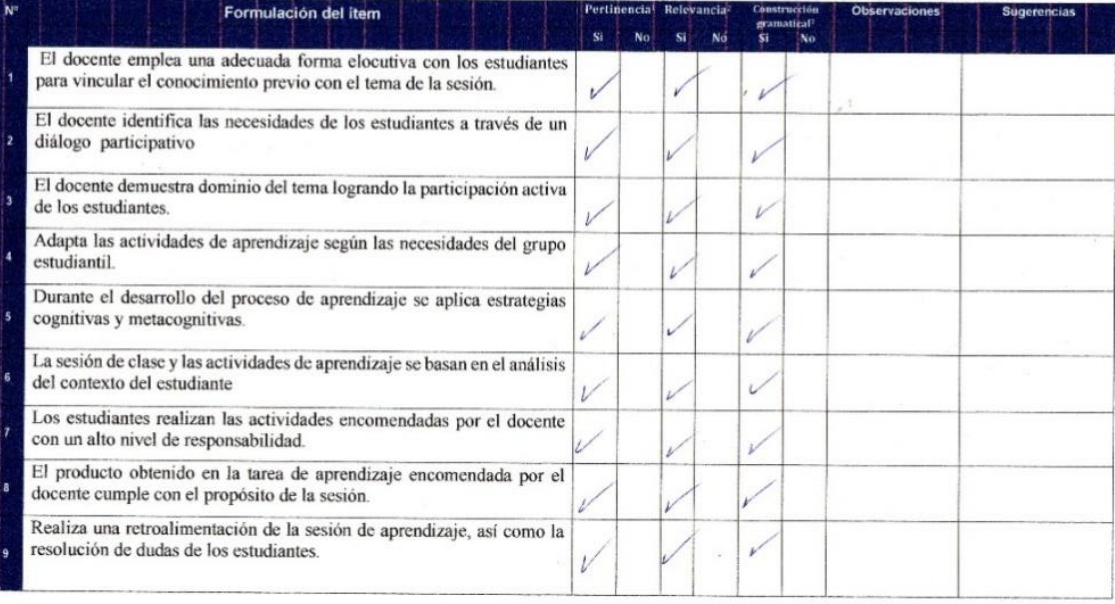

U.

Br. Josselyn Lara Escalante Maestría en Educación con
mención en Docencia Superior.

OPINIÓN DE APLICABILIDAD DE LA GUIA DE OBSERVACIÓN:

observaciones (precisar si hay suficiencia)

Opinión de aplicabilidad: Aplicable [ ] Aplicable después de corregir $V]$ No aplicable [ ]

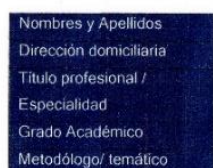

Maria Teresa llerrera Montoya
Av. Ricardo Palma 636 Sanjeoquin Bellewise

Lic Educauión

Mg Psicopedagogia

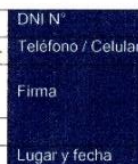

25600207

96094883

7 mung

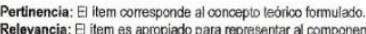

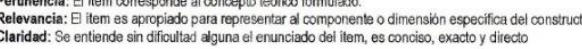

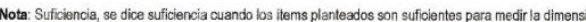

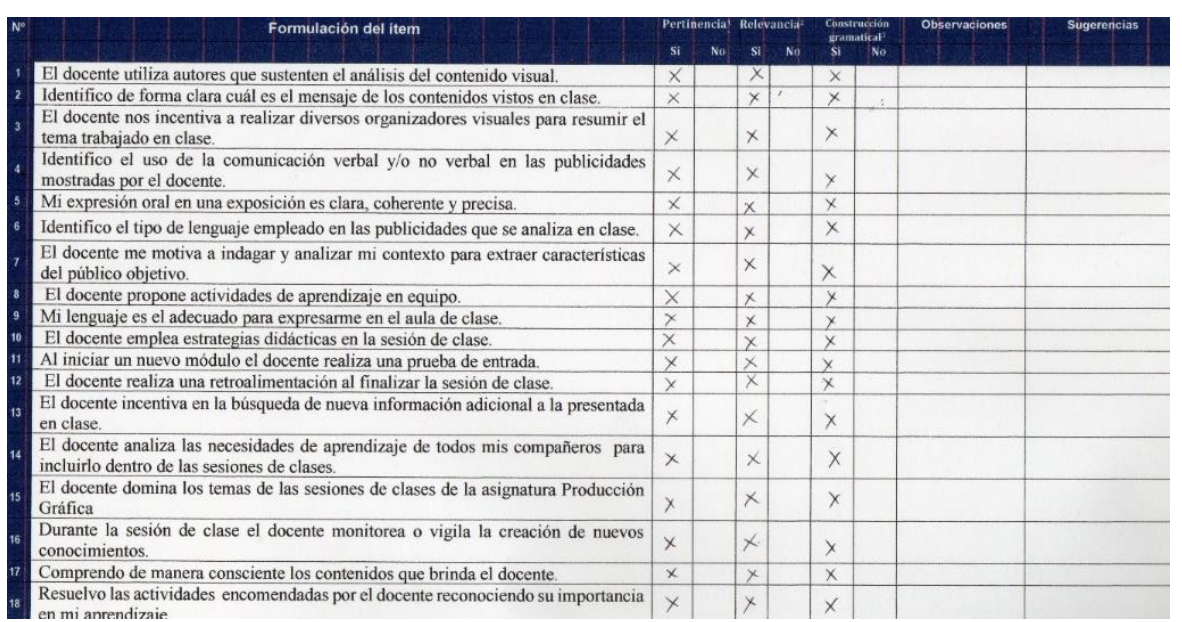

USTL UNIVERSIDAD

Br. Josselyn Lara Escalante Maestria en Educación co

OPINION DE APLICABILIDAD DEL CUESTIONARIO:

observaciones (precisar si hay suficiencia):

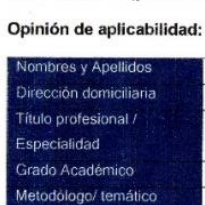

Aplicable [ ] Aplicable después de corregir [ $[$ ' 1

Maria Tembaltemera Monroye

W. Ricardo Palma Gas6 San beoquin Belllowista

Lic Educacion'

Mg Psicopedagogia

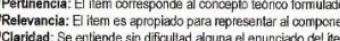

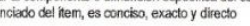

Nota: Suffienolia, se dire 


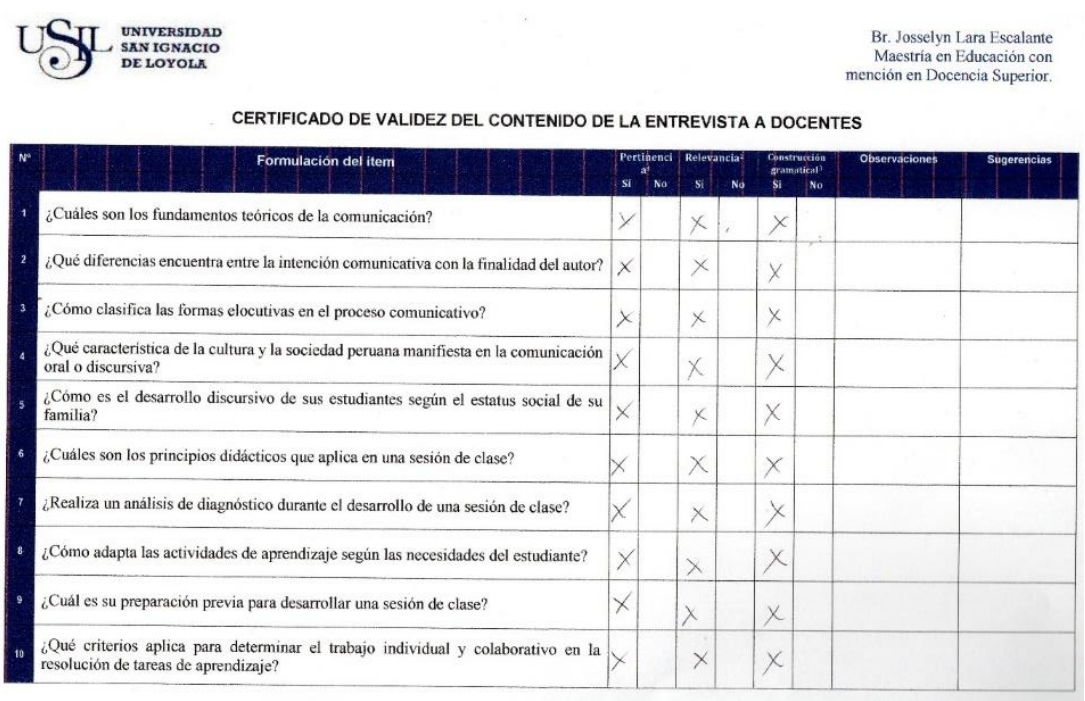

\begin{tabular}{ll|l|l|l|l|l|l}
\multicolumn{1}{c}{ Formulación del item } & & \\
\hline
\end{tabular}

UST

Br. Josselyn Lara Escalante Maestría en Educación co mención en Docencia Superior
OPINIÓN DE APLICABILIDAD DE LA ENTREVISTA:

Observaciones (procisar si hay surcioncia:

Opinión de aplicabilidad: Aplicable [ ] Aplicable después de corregir [ [ 1 ] No aplicable [ ]

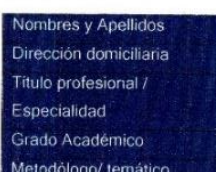

Maria Terwa lierrera Montoya

Av. Ricardo Palma 636 San foaquín Bellavibis

Lic Educación

ing Pricopedagogia

Pertinencia: El item correspondica al conceppl teorico tormulade

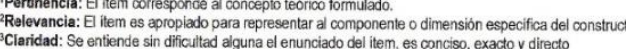

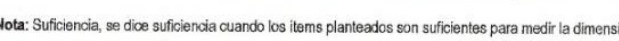

USyL

Br. Josselyn Lara Escalante Maestria en Educación con
mención en Docencia Superior

\section{OPINIÓN DE APLICABILIDAD DE LA PRUEBA}

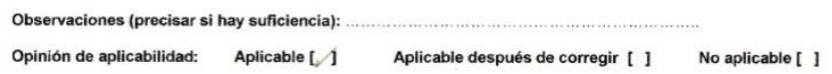

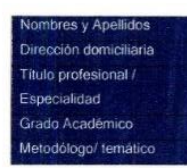

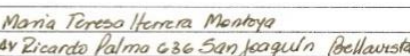

av Ricardo Palmo C36 Sanjoaquern Bellawista

$$
\text { Lie Educación }
$$

Mg Psicopedagogín

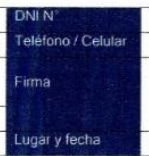

600207

960948887

Tume

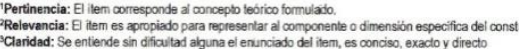




\section{ANEXO 08}

\section{VALIDACIÓN INSTRUMENTOS: EXPERTO 2}

U.

CERTIFICADO DE VALIDEZ DEL CONTENIDO DE LA ENTREVISTA A DOCENTES
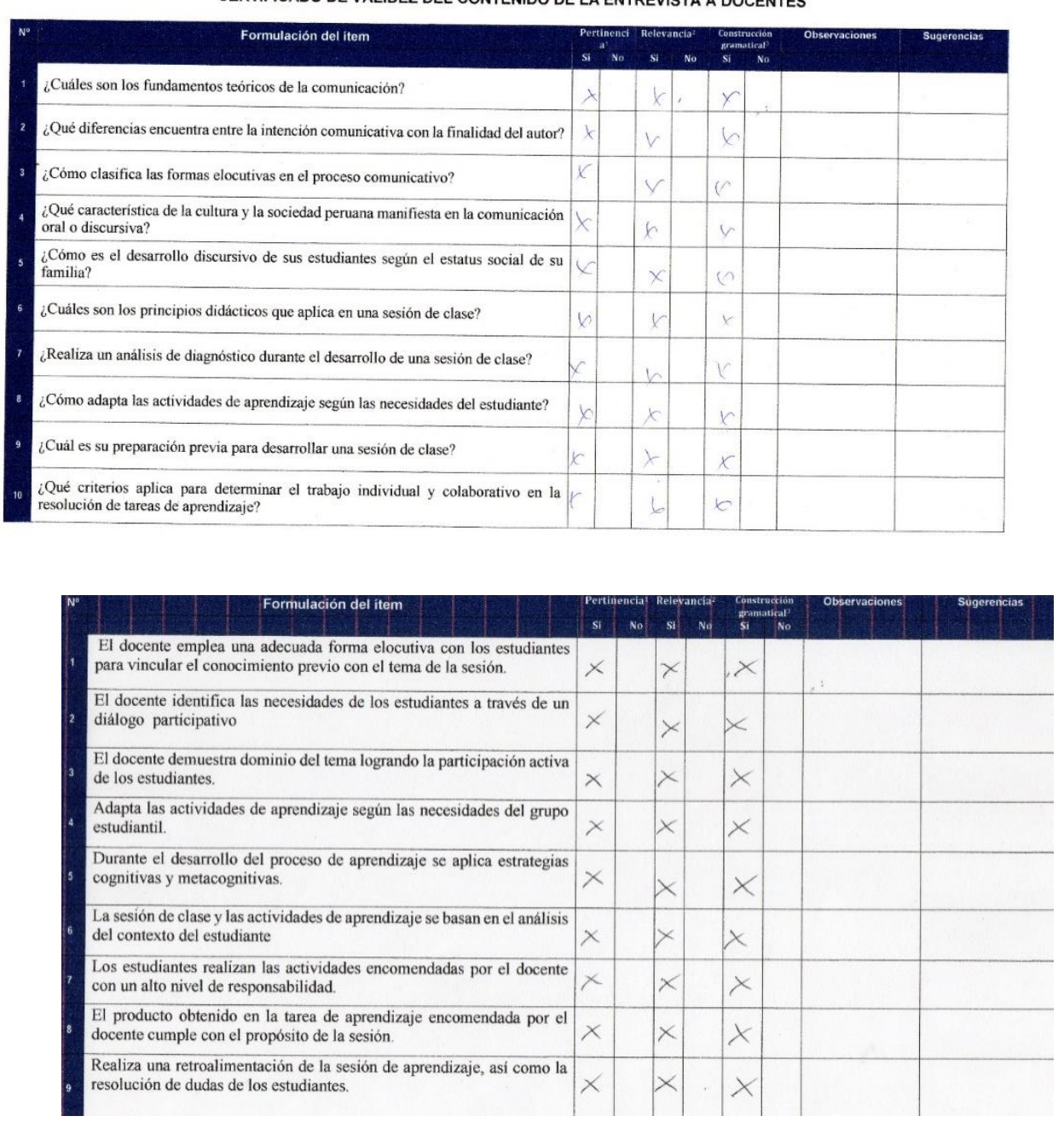

UDL

Br. Josselyn Lara Escalante Maestría en Educación con
nención en Docencia Superior.

OPINIÓN DE APLICABILIDAD DE LA ENTREVISTA:

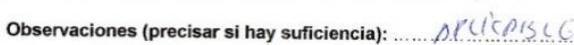

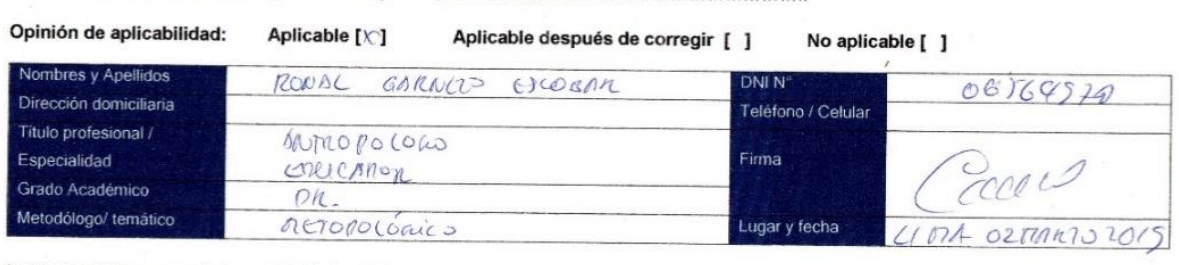

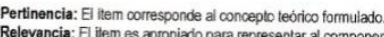

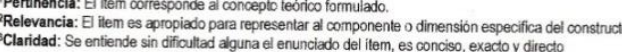

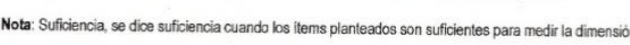

\section{U.}

Br. Josselyn Lara Escalante Maestria en Educación con
naion en Docencia Superior.

OPINIÓN DE APLICABILIDAD DE LA GUIA DE OBSERVACIÓN:

Observaciones (preciser si hay SUCDech:

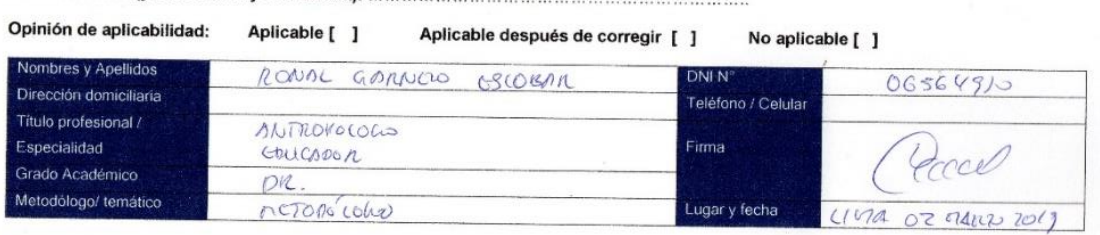

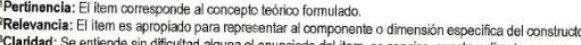

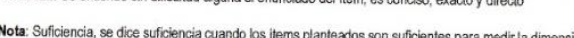


CERTIFICADO DE VALIDEZ DE CONTENDO DEL CUESTIONARIO TOMADO A ESTUDIANTES

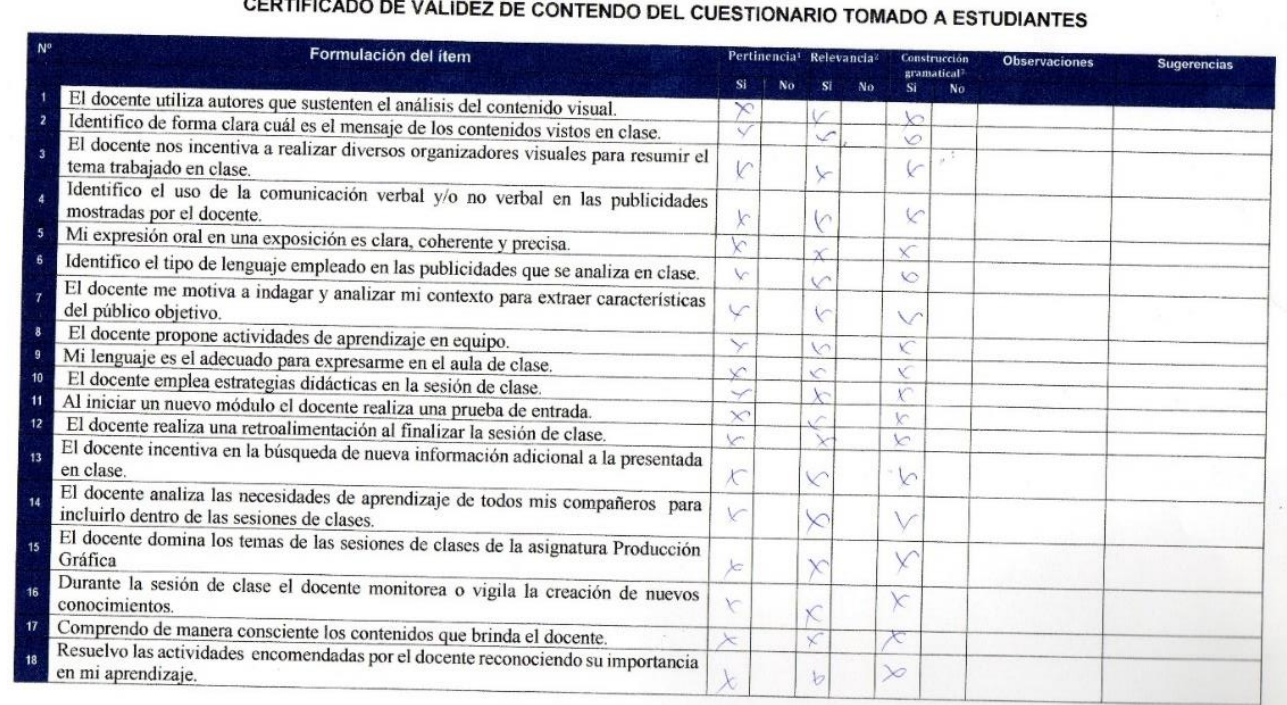

\section{USTH}

Br. Josselyn Lara Escalante Maestria en Educación con
ención en Docencia Superior

CERTIFICADO DE VALIDEZ DE CONTENDO DE LA PRUEBA PEDAGÓGICA A ESTUDIANTES

\begin{tabular}{|c|c|c|c|c|c|c|}
\hline Formulación del item & si & No si & 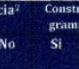 & & & \\
\hline $\begin{array}{l}\text { Presentación de la información de manera original y de fácil } \\
\text { entendimiento }\end{array}$ & $x$ & $x$ & $x$ & & $\therefore$ & \\
\hline $\begin{array}{l}\text { Presentación efectiva evidenciada en la postura corporal y el manejo de } \\
\text { la audiencia. }\end{array}$ & $x$ & $x$ & $x$ & & & \\
\hline $\begin{array}{l}\text { Emplea un vocabulario formal y técnico para la presentación del } \\
\text { proyecto. }\end{array}$ & $x$ & $x$ & $y$ & & & \\
\hline El mensaje comunicativo de la pieza gráfica es claro y coherente & $x$ & $x$ & Y & & & \\
\hline Utiliza un lenguaje apropiado con corrección sintáctica y gramatical. & $x$ & $y$ & $x$ & & & \\
\hline $\begin{array}{l}\text { Integra características del contexto en la construcción del mensaje } \\
\text { publicitario. }\end{array}$ & $x$ & $x$ & $x$ & & & \\
\hline $\begin{array}{l}\text { El vocabulario empleado en las piezas gráficas corresponde al contexto } \\
\text { de la investigación. }\end{array}$ & $x$ & $x$ & $x$ & & & \\
\hline $\begin{array}{l}\text { Presenta la información de manera organizada con puntualidad y } \\
\text { responsabilidad. }\end{array}$ & $y$ & $y$ & V & & & \\
\hline
\end{tabular}

\section{USY}

Br. Josselyn Lara Escalar ención en Docencia Superi

OPINIÓN DE APLICABILIDAD DEL CUESTIONARIO:

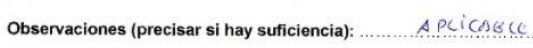

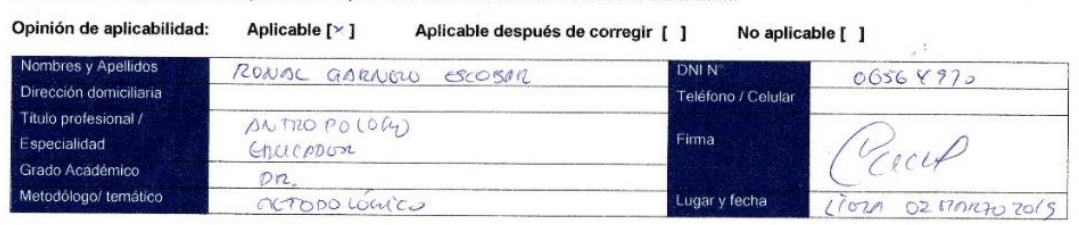

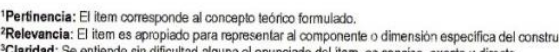

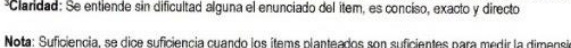

U.

Br. Josselyn Lara Escalante Maestría en Educación co

OPINIÓN DE APLICABILIDAD DEL CUESTIONARIO:

Observaciones (precisar si hay suficiencia): ........ ApCicsesc

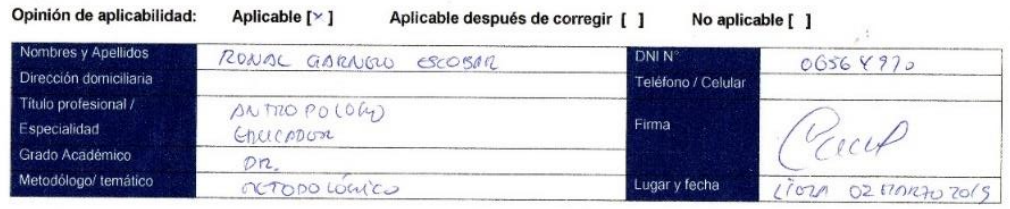

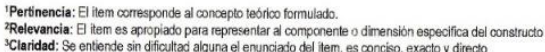

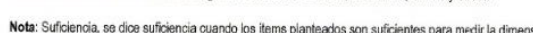




\section{ANEXO 09}

\section{VALIDACIÓN INSTRUMENTOS: EXPERTO 3}

\section{USTL}

Br. Josselyn Lara Escalante

Macstria en Educación con
mencioi n en Docencia Superior.

CERTIFICADO DE VALIDEZ DEL CONTENIDO DE LA ENTREVISTA A DOCENTES

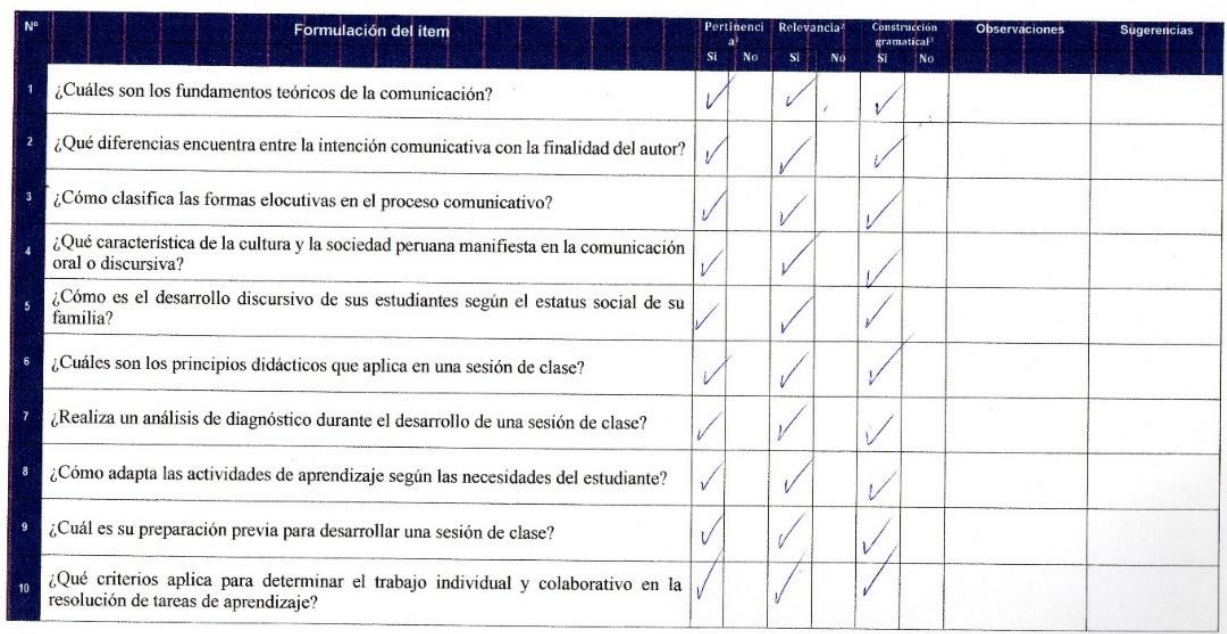

USWL

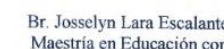
mención en Docencia Superior

CERTIFICADO DE VALIDEZ DE CONTENIDO DE LA GUIA DE OBSERVACIÓN A CLASE

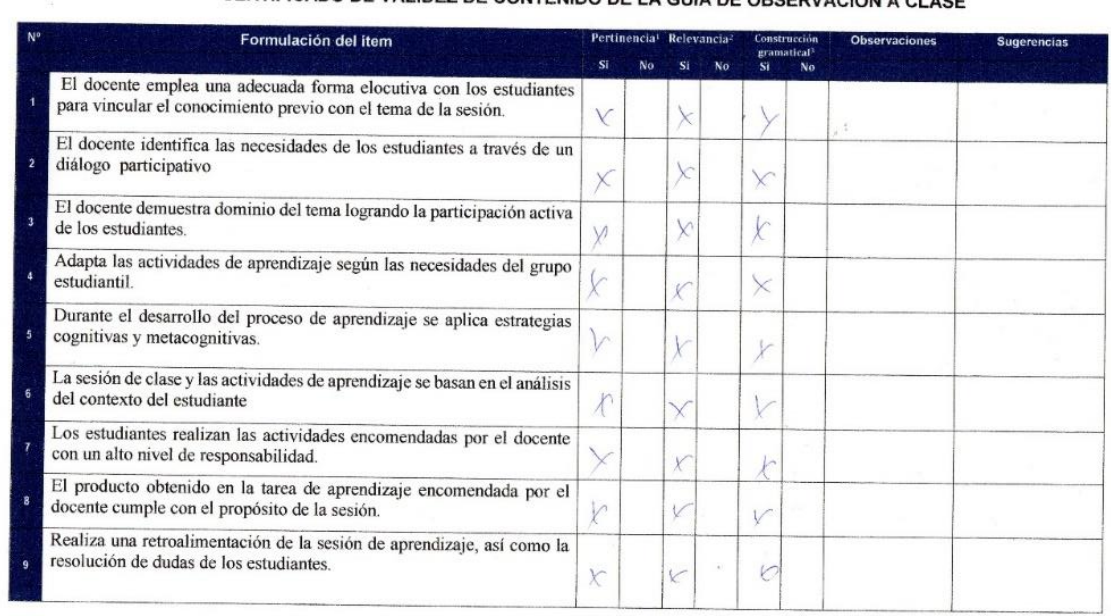

USW

Br. Josselyn Lara Escalante Maestria en Educación con
mención en Docencia Superior.

OPINIÓN DE APLICABILIDAD DE LA ENTREVISTA:

Observaciones (precisar si hay sufficiencia): . SI HAY SuriciencitA

Opinión de aplicabilidad: Aplicable $[\because] \quad$ Aplicable después de corregir [ ] No aplicable [ ]

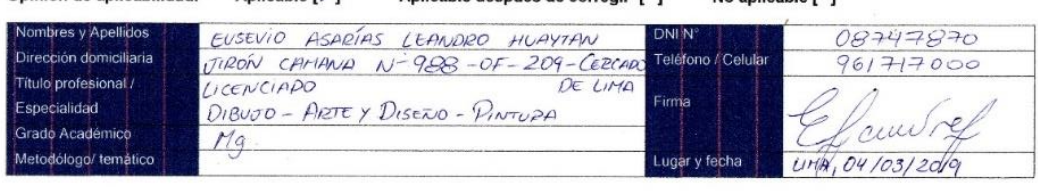

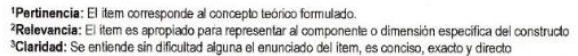

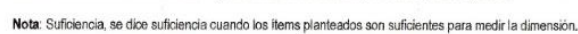

OPINIÓN DE APLICABILIDAD DE LA GUIA DE OBSERVACIÓN:

Observaciones (precisar si hay suficiencia): Si HAY SUFiCEEUCiD

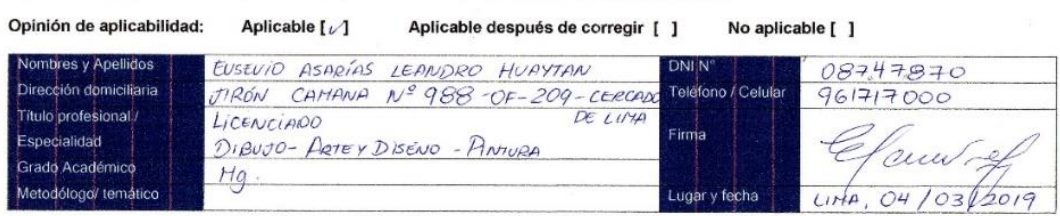

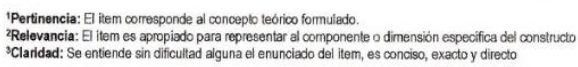

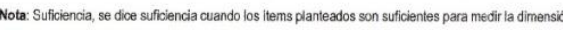




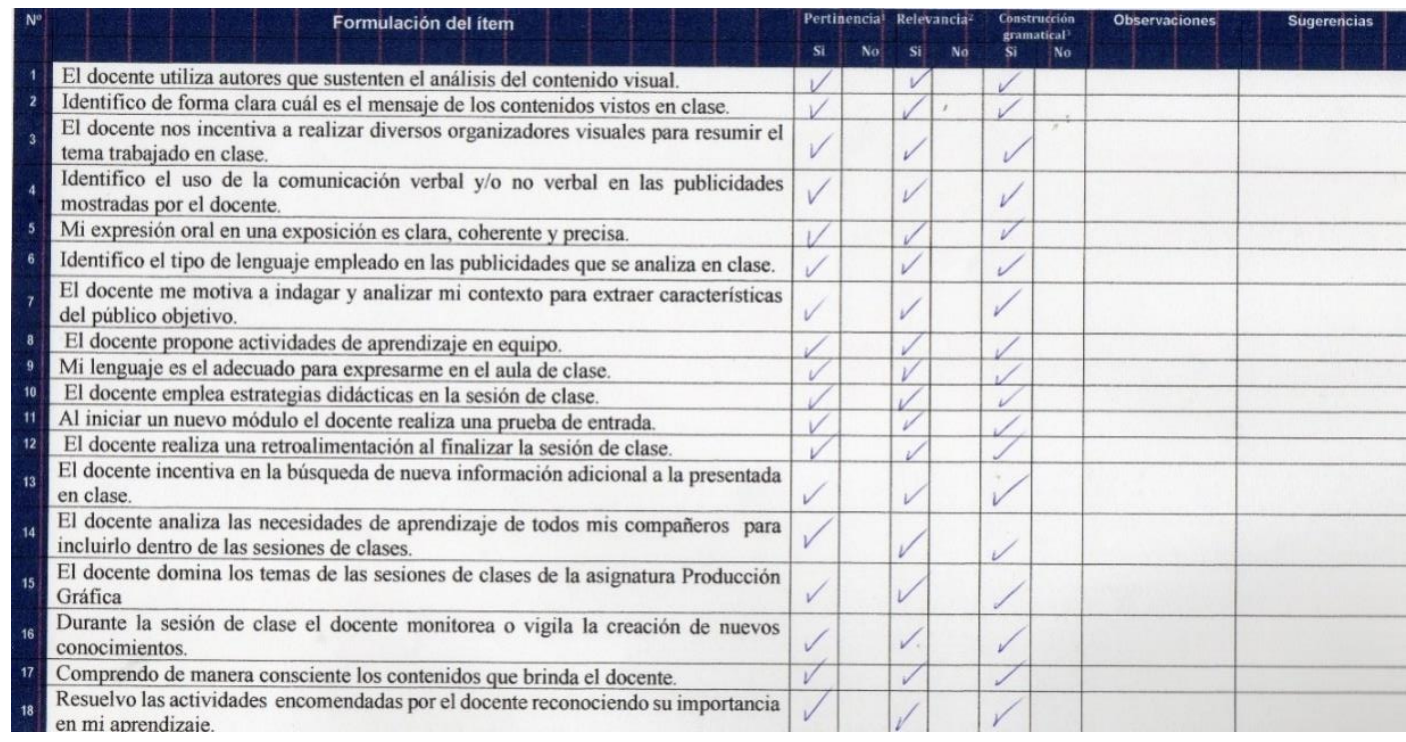

Formulación del item

\begin{tabular}{l} 
1. $\begin{array}{l}\text { Presentación de la información de manera original y de fácil } \\
\text { entendimiento }\end{array}$ \\
\hline $\begin{array}{l}\text { Presentación efectiva evidenciada en la postura corporal y el manejo de } \\
\text { la audiencia. }\end{array}$ \\
\hline $\begin{array}{l}\text { Emplea un vocabulario formal y técnico para la presentación del } \\
\text { proyecto. }\end{array}$
\end{tabular}

\section{USLY}

Br. Josselyn Lara Escalante mención en Docencia Superior.

OPINIÓN DE APLICABILIDAD DEL CUESTIONARIO

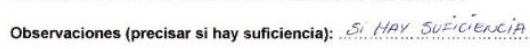

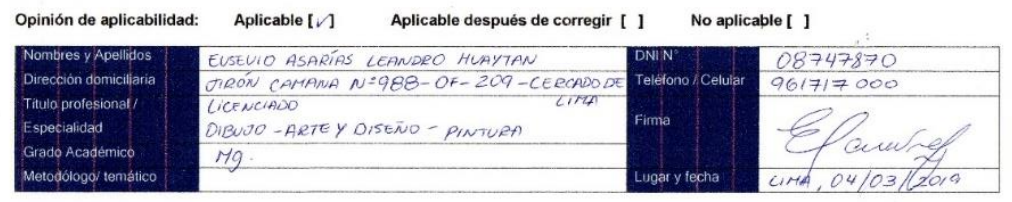

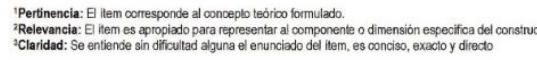

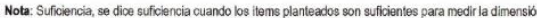

STL

Br. Josselyn Lara Escalante Maestria en Educación con
mención en Docencia Superior

\section{OPINIÓN DE APLICABILIDAD DE LA PRUEBA:}

Observaciones (precisar si hay sufficiencia): ....... HAY SUficlauciA

Opinión de aplicabilidad: Aplicable $[r] \quad$ Aplicable después de corregir []$\quad$ No aplicable [ ]
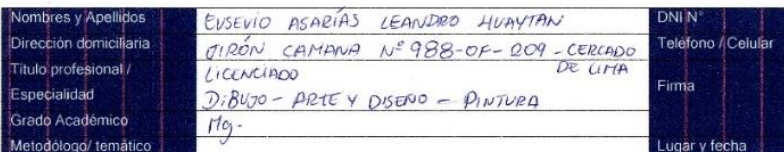

$\frac{08747870}{961717000}$

Elcounref

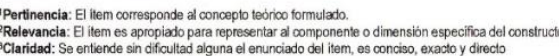

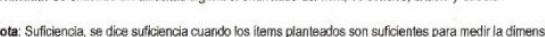


ANEXO 10

MATRIZ DE REDUCCIÓN DE DATOS: GUÍA DE OBSERVACIÓN

\begin{tabular}{|c|c|c|c|c|}
\hline $\begin{array}{c}\text { MOMENTOS DE LA } \\
\text { SESIÓN }\end{array}$ & INDICADORES & $\begin{array}{l}\text { REGISTRO DE } \\
\text { OBSERVACIÓN }\end{array}$ & $\begin{array}{l}\text { CONCEPTUALIZA } \\
\text { CIÓN }\end{array}$ & $\begin{array}{c}\text { CÓDIG } \\
0\end{array}$ \\
\hline \multirow{5}{*}{$\begin{array}{l}\text { I. Motivación } \\
\text { orientación hacia } \\
\text { objetivos }\end{array}$} & \multirow{2}{*}{$\begin{array}{l}\text { El docente emplea una } \\
\text { adecuada forma } \\
\text { elocutiva con los } \\
\text { estudiantes para vincular } \\
\text { el conocimiento previo } \\
\text { con el tema de la sesión }\end{array}$} & \multirow{2}{*}{$\begin{array}{l}\text { El docente ingresa y saluda a los } \\
\text { estudiantes, a lo cual muy pocos } \\
\text { estudiantes le prestan atención, } \\
\text { así mismo el docente no emplea } \\
\text { un tono de voz elevado, coloca la } \\
\text { diapositiva e inicia la clase } \\
\text { leyendo el título de la sesión de } \\
\text { clase. }\end{array}$} & $\begin{array}{l}\text { Bajo nivel de } \\
\text { atención. }\end{array}$ & GO1 \\
\hline & & & $\begin{array}{l}\text { Inadecuado empleo } \\
\text { del tono de voz. }\end{array}$ & $\mathrm{GO} 2$ \\
\hline & \multirow{3}{*}{$\begin{array}{l}\text { El docente identifica las } \\
\text { necesidades de los } \\
\text { estudiantes a través de un } \\
\text { diálogo participativo. }\end{array}$} & \multirow{3}{*}{$\begin{array}{l}\text { El docente explica las } \\
\text { diapositivas sin pausa, los } \\
\text { estudiantes están distraídos, } \\
\text { otros estudiantes llegan tarde e } \\
\text { ingresan sin pedir permiso. El } \\
\text { docente sigue explicando sin } \\
\text { realizar alguna pregunta para } \\
\text { promover su interés. }\end{array}$} & $\begin{array}{l}\text { Falta de normas } \\
\text { comunicativas. }\end{array}$ & GO3 \\
\hline & & & Falta de motivación & GO4 \\
\hline & & & Falta de interés & GO5 \\
\hline \multirow[t]{9}{*}{$\begin{array}{l}\text { II. Desarrollo del } \\
\text { proceso de enseñanza - } \\
\text { aprendizaje }\end{array}$} & \multirow{2}{*}{$\begin{array}{l}\text { El docente demuestra } \\
\text { dominio del tema } \\
\text { logrando la participación } \\
\text { activa del estudiante. }\end{array}$} & \multirow{2}{*}{$\begin{array}{l}\text { El docente lee la diapositiva, el } \\
\text { cual está cargada con demasiada } \\
\text { información que no genera } \\
\text { ningún tipo de motivación por el } \\
\text { aprendizaje de los estudiantes, } \\
\text { no utiliza materiales didácticos. }\end{array}$} & $\begin{array}{l}\text { Falta de metodología } \\
\text { docente. }\end{array}$ & GO6 \\
\hline & & & $\begin{array}{l}\text { Mal empleo de } \\
\text { material didáctico. }\end{array}$ & GO7 \\
\hline & \multirow{3}{*}{$\begin{array}{l}\text { Adapta las actividades de } \\
\text { aprendizaje según las } \\
\text { necesidades del grupo } \\
\text { estudiantil. }\end{array}$} & \multirow{3}{*}{$\begin{array}{l}\text { El tema de la sesión de clase está } \\
\text { basado en el silabo que es creado } \\
\text { por el propio docente, razón por } \\
\text { la cual no está basado en las } \\
\text { necesidades de los estudiantes, si } \\
\text { no en el criterio del docente. Se } \\
\text { puede observar que los } \\
\text { estudiantes no tienen interés por } \\
\text { el tema de clase ya que cada uno } \\
\text { está concentrado en sus } \\
\text { celulares, computadoras, } \\
\text { conversando con amigos. }\end{array}$} & Estructura curricular. & GO8 \\
\hline & & & $\begin{array}{l}\text { Falencia } \\
\text { institucional en la } \\
\text { supervisión de los } \\
\text { sílabos. }\end{array}$ & GO9 \\
\hline & & & Falta de interés. & GO10 \\
\hline & \multirow{4}{*}{$\begin{array}{l}\text { Durante el desarrollo del } \\
\text { proceso de aprendizaje } \\
\text { se aplica estrategias } \\
\text { cognitivas } \\
\text { metacognitivas. }\end{array}$} & \multirow{4}{*}{$\begin{array}{l}\text { El docente explica toda la sesión } \\
\text { de manera seria y lineal, al } \\
\text { finalizar realiza una actividad sin } \\
\text { mostrar un ejemplo como guía, } \\
\text { los estudiantes empiezan a } \\
\text { cuestionar al docente ya que no } \\
\text { comprendieron cual es la } \\
\text { finalidad de la actividad, así } \\
\text { mismo el docente no brinda las } \\
\text { referencias adecuadas para la } \\
\text { búsqueda de información razón } \\
\text { por la cual se puede visualizar } \\
\text { que los estudiantes ingresan a } \\
\text { páginas poco confiables para } \\
\text { realizar sus piezas gráficas. }\end{array}$} & $\begin{array}{l}\text { Docente subjetivo } \\
\text { impositivo. }\end{array}$ & GO11 \\
\hline & & & $\begin{array}{l}\text { Falta de modelaje de } \\
\text { actividades. }\end{array}$ & GO12 \\
\hline & & & $\begin{array}{l}\text { Opinión de los } \\
\text { estudiantes. }\end{array}$ & GO13 \\
\hline & & & $\begin{array}{l}\text { Falta de referencias } \\
\text { bibliográficas. }\end{array}$ & GO14 \\
\hline
\end{tabular}




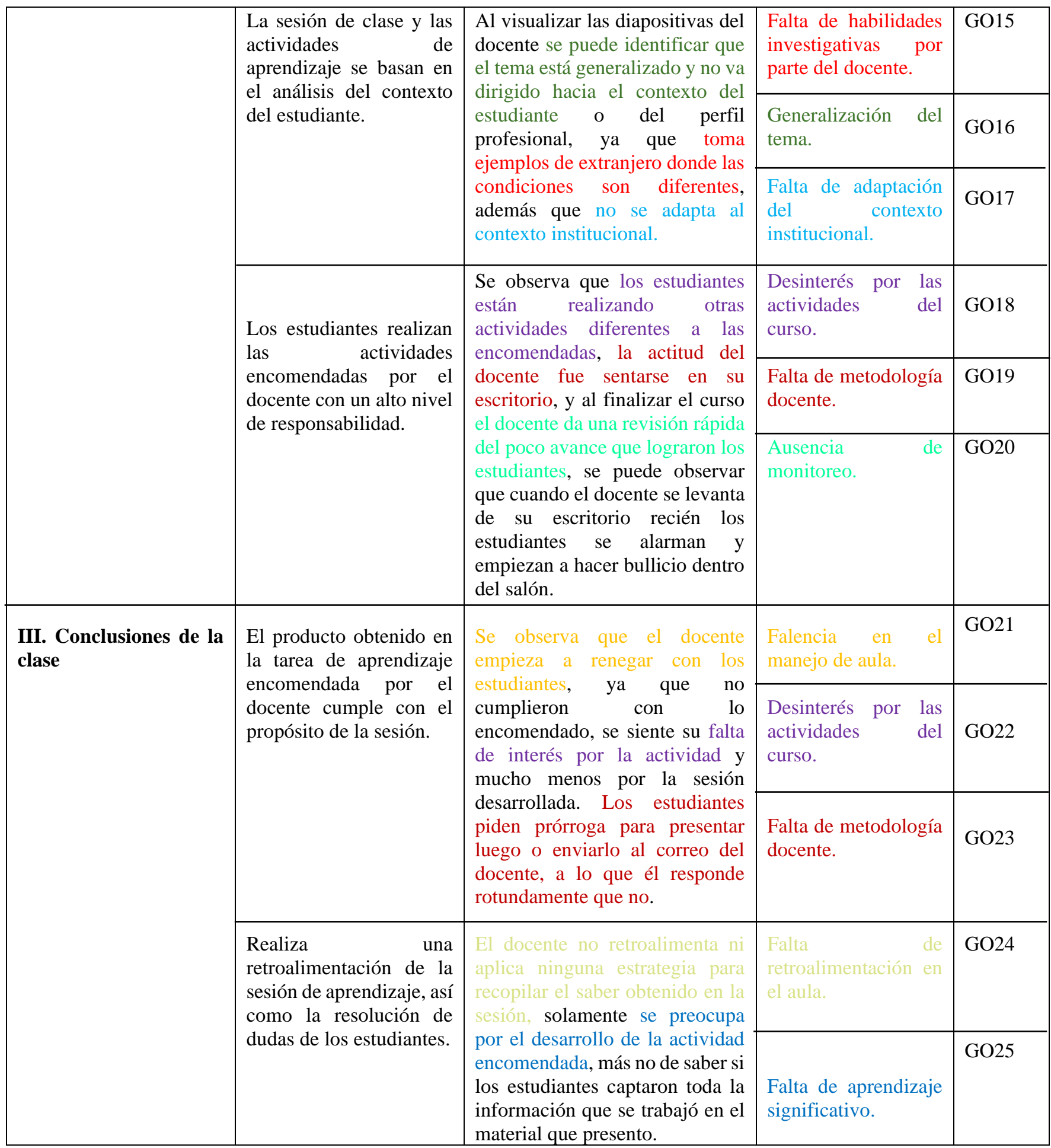


ANEXO 11

MATRIZ DE REDUCCIÓN DE DATOS: ENTREVISTA SEMI ESTRUCTURADA A

DOCENTE

\begin{tabular}{|c|c|c|c|c|}
\hline $\mathbf{N}^{\circ}$ & PREGUNTAS Y RESPUESTAS & $\begin{array}{c}\text { FRASES } \\
\text { CODIFICADAS }\end{array}$ & $\begin{array}{l}\text { POSIBLES } \\
\text { CATEGORÍAS } \\
\text { EMERGENTES }\end{array}$ & $\begin{array}{l}\text { ASIGNACIÓN } \\
\text { DE CÓDIGO }\end{array}$ \\
\hline \multirow{4}{*}{$\begin{array}{l}\text { ITEM } \\
1\end{array}$} & Entrevista $\mathrm{N}^{\circ}$ 1: DOCENTE 1 & & & \\
\hline & \multirow{2}{*}{$\begin{array}{l}\text { E: ¿Cuáles son los fundamentos teóricos de la } \\
\text { comunicación? } \\
\text { D: Comprendo que, el ser humano a lo largo de su existencia } \\
\text { siempre ha buscado comunicarse, llevar un mensaje de un lugar } \\
\text { a otro, desde la existencia de pinturas en las piedras, creación } \\
\text { de la rueda, evolución de la escritura, aparición de medios de } \\
\text { comunicación, lanzamiento del internet, entre otros. } \\
\text { Actualmente la búsqueda es constante, porque el ser humano } \\
\text { busca trascender a través de la historia, dejar un legado o para } \\
\text { algunos casos un hito (punto de partida) para que otros logren } \\
\text { concretar lo que en un principio se dio como inicio. }\end{array}$} & $\begin{array}{l}\text { El ser humano a lo } \\
\text { largo de su existencia } \\
\text { siempre ha buscado } \\
\text { comunicarse. }\end{array}$ & $\begin{array}{l}\text { Expresión } \\
\text { comunicativa. }\end{array}$ & ED1 \\
\hline & & $\begin{array}{l}\text { El ser humano busca } \\
\text { trascender a través de } \\
\text { la historia. }\end{array}$ & $\begin{array}{l}\text { La comunicación } \\
\text { humana. }\end{array}$ & ED2 \\
\hline & $\begin{array}{l}\text { E: ¿Qué diferencias encuentra entre la intención } \\
\text { comunicativa con la finalidad del autor? } \\
\text { D: Entiendo que la intención comunicativa es el preámbulo al }\end{array}$ & $\begin{array}{l}\text { Es el preámbulo al } \\
\text { objetivo concreto de } \\
\text { lo que se quiere emitir } \\
\text { como mensaje }\end{array}$ & $\begin{array}{lr}\text { Saberes revios } \\
\text { asociados } & \text { al } \\
\text { mensaje final. }\end{array}$ & ED3 \\
\hline $\begin{array}{l}\text { ITEM } \\
2\end{array}$ & $\begin{array}{l}\text { éste a su vez deberá estar plenamente vinculado con la finalidad } \\
\text { del autor (a dónde pretende llegar o qué pretende explicar), } \\
\text { aunque muchas veces la intención comunicativa desvía el } \\
\text { objetivo concreto del mensaje, puesto que si no está bien } \\
\text { definido conlleva a que desarrollen diferentes } \\
\text { conceptualizaciones o 'ideas falsas'. }\end{array}$ & $\begin{array}{l}\text { La intención } \\
\text { comunicativa desvía } \\
\text { el objetivo concreto } \\
\text { del mensaje }\end{array}$ & $\begin{array}{l}\text { Desviación de la } \\
\text { intención } \\
\text { comunicativa. }\end{array}$ & ED4 \\
\hline \multirow[t]{2}{*}{$\begin{array}{l}\text { ITEM } \\
3\end{array}$} & \multirow{2}{*}{$\begin{array}{l}\text { E: ¿Cómo clasifica las formas elocutivas en el proceso } \\
\text { comunicativo? } \\
\text { D: Supongo que las formas elocutivas son la forma de } \\
\text { expresarse, ya sea oral o verbal, pero más allá de ese tema no } \\
\text { manejo el concepto. }\end{array}$} & $\begin{array}{l}\text { Las formas elocutivas } \\
\text { son la forma de } \\
\text { expresarse. }\end{array}$ & $\begin{array}{l}\text { Expresión } \\
\text { comunicativa }\end{array}$ & ED5 \\
\hline & & $\begin{array}{l}\text { No manejo el } \\
\text { concepto. }\end{array}$ & $\begin{array}{l}\text { Desconocimiento de } \\
\text { las formas } \\
\text { elocutivas. }\end{array}$ & ED6 \\
\hline \multirow[t]{4}{*}{$\begin{array}{l}\text { ITEM } \\
4\end{array}$} & \multirow{2}{*}{$\begin{array}{l}\text { E: ¿Qué característica de la cultura y la sociedad peruana } \\
\text { manifiesta en la comunicación oral o discursiva? } \\
\text { D: En diferentes ocasiones, se inicia el diálogo sobre } \\
\text { referencias de personas con éxito y en consecuencia se propone } \\
\text { a modo de referencia para lo que se espera obtener como } \\
\text { resultado de vida, sensibilizar sobre los buenos hábitos que los } \\
\text { jóvenes deben practicar día a día depende para generar una } \\
\text { generación de profesionales innovadores con propuestas de } \\
\text { solución y sean referentes para otros jóvenes también. }\end{array}$} & $\begin{array}{l}\text { Sensibilizar sobre los } \\
\text { buenos hábitos que } \\
\text { los jóvenes deben } \\
\text { practicar día a día. }\end{array}$ & $\begin{array}{l}\text { Dialogo como } \\
\text { sensibilización. }\end{array}$ & ED7 \\
\hline & & $\begin{array}{l}\text { Referentes para otros } \\
\text { jóvenes también. }\end{array}$ & $\begin{array}{l}\text { Modelo a seguir } \\
\text { para los estudiantes. }\end{array}$ & ED8 \\
\hline & \multirow{2}{*}{$\begin{array}{l}\text { E: ¿Cómo es el desarrollo discursivo de sus estudiantes } \\
\text { según el estatus social de su familia? } \\
\text { D: No acostumbro a intercambiar diálogo sobre temas } \\
\text { personales con los estudiantes, lo que tengo entendido es que la } \\
\text { mayoría trabaja durante el día y con ello solventan sus estudios } \\
\text { en el horario nocturno. Por otro lado, de alguna manera } \\
\text { siempre se conlleva a la reflexión sobre asuntos coyunturales } \\
\text { en el aspecto social, sobre la integridad personal (crecer a }\end{array}$} & $\begin{array}{l}\text { No acostumbro a } \\
\text { intercambiar diálogo } \\
\text { sobre temas } \\
\text { personales con los } \\
\text { estudiantes }\end{array}$ & $\begin{array}{l}\text { Abstención de } \\
\text { diálogos personales. }\end{array}$ & ED9 \\
\hline & & $\begin{array}{l}\text { Siempre se conlleva a } \\
\text { la reflexión sobre }\end{array}$ & $\begin{array}{l}\text { Reflexión de temas } \\
\text { coyunturales de la } \\
\text { sociedad. }\end{array}$ & ED10 \\
\hline
\end{tabular}




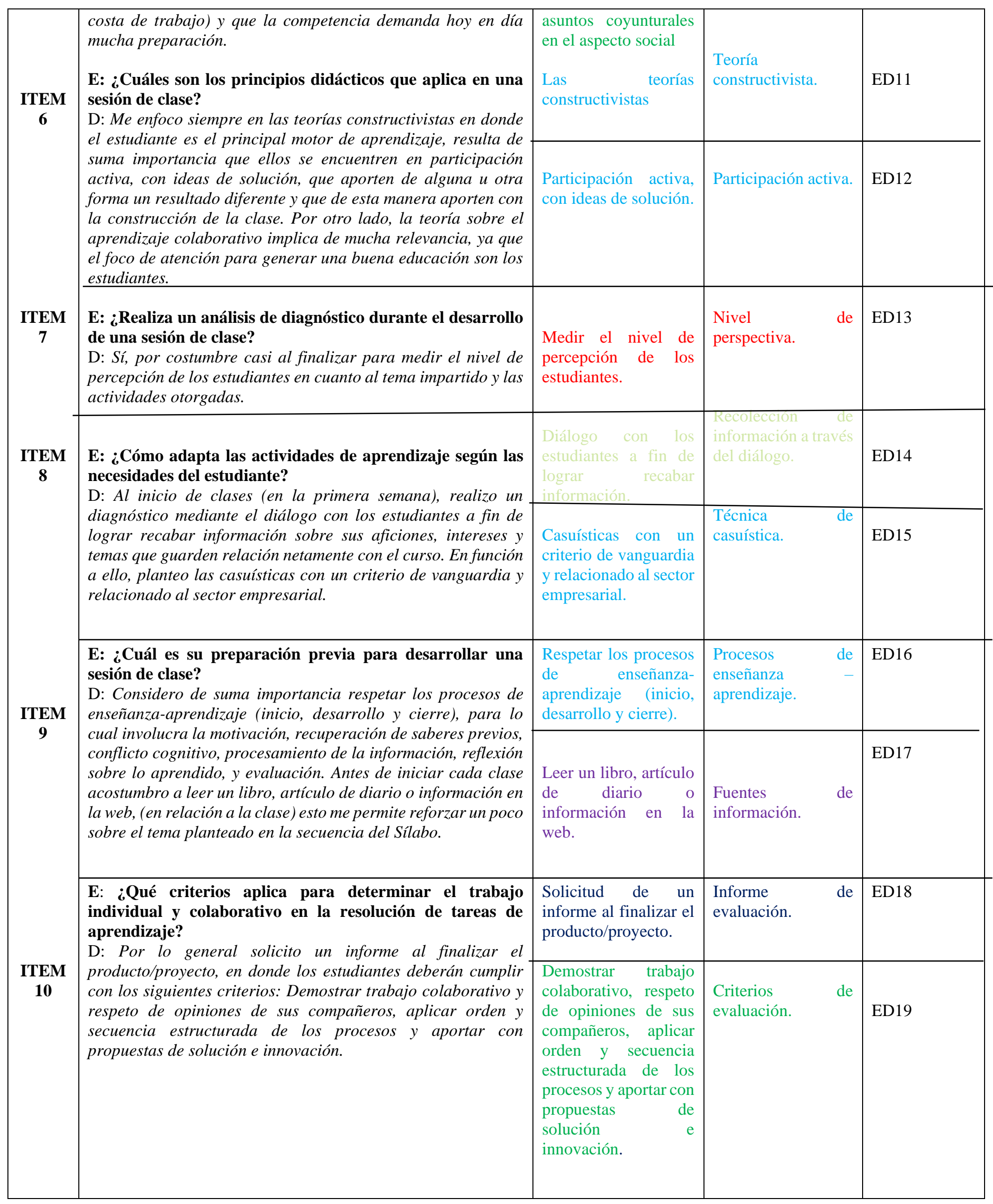




\begin{tabular}{|c|c|c|c|c|}
\hline \multirow{2}{*}{$\begin{array}{l}\text { ITEM } \\
1\end{array}$} & Entrevista $\mathrm{N}^{\circ}$ 2: DOCENTE 2 & $\begin{array}{l}\text { Los fundamentos } \\
\text { teóricos en sí no los } \\
\text { domino mucho. }\end{array}$ & $\begin{array}{l}\text { Desconocimiento de } \\
\text { los fundamentos } \\
\text { teóricos. }\end{array}$ & ED20 \\
\hline & $\begin{array}{l}\text { E: ¿Cuáles son los fundamentos teóricos de la } \\
\text { comunicación? } \\
\text { D: Bueno los fundamentos teóricos en sí no los domino mucho, } \\
\text { pero creo que debería aprender más sobre el tema. }\end{array}$ & $\begin{array}{l}\text { Debería aprender más } \\
\text { sobre el tema. }\end{array}$ & Autoaprendizaje. & $\mathrm{ED} 21$ \\
\hline \multirow[b]{2}{*}{$\begin{array}{l}\text { ITEM } \\
\quad 2\end{array}$} & \multirow{2}{*}{$\begin{array}{l}\text { E: ¿Qué diferencias encuentra entre la intención } \\
\text { comunicativa con la finalidad del autor? } \\
\text { D: La intención comunicativa es lo que uno puede interpretar } \\
\text { de manera subjetiva, y la finalidad del autor es el objetivo en sí } \\
\text { con el cuál se maneja el mensaje. }\end{array}$} & $\begin{array}{l}\text { Uno puede interpretar } \\
\text { de manera subjetiva. }\end{array}$ & $\begin{array}{l}\text { Interpretación } \\
\text { subjetiva } \\
\text { mensaje. }\end{array}$ & ED22 \\
\hline & & $\begin{array}{l}\text { Finalidad del autor es } \\
\text { el objetivo en sí con el } \\
\text { cuál se maneja el } \\
\text { mensaje. }\end{array}$ & $\begin{array}{l}\text { Objetivo } \\
\text { mensaje. }\end{array}$ & ED23 \\
\hline $\begin{array}{l}\text { ITEM } \\
3\end{array}$ & $\begin{array}{l}\text { E: ¿Cómo clasifica las formas elocutivas en el proceso } \\
\text { comunicativo? } \\
\text { D: No lo sé, no estoy enterado de ese tema. }\end{array}$ & $\begin{array}{l}\text { Desconocimiento de } \\
\text { las formas elocutivas. }\end{array}$ & $\begin{array}{l}\text { Desconocimiento de } \\
\text { las formas } \\
\text { elocutivas. }\end{array}$ & ED24 \\
\hline \multirow[t]{2}{*}{$\begin{array}{l}\text { ITEM } \\
4\end{array}$} & \multirow{2}{*}{$\begin{array}{l}\text { E: ¿Qué característica de la cultura y la sociedad peruana } \\
\text { manifiesta en la comunicación oral o discursiva? } \\
\text { D: Bueno las características de la cultura se evidencian en el } \\
\text { diálogo que se emplea en clase, donde los estudiantes } \\
\text { demuestran su nivel cultura a través de muletillas o la } \\
\text { pertinencia para responder una pregunta formulada por el } \\
\text { docente. }\end{array}$} & $\begin{array}{l}\text { Se evidencian en el } \\
\text { diálogo que se emplea } \\
\text { en clase }\end{array}$ & $\begin{array}{l}\text { Diálogo de } \\
\text { reconocimiento. }\end{array}$ & ED25 \\
\hline & & $\begin{array}{l}\text { La pertinencia para } \\
\text { responder una } \\
\text { pregunta formulada } \\
\text { por el docente. }\end{array}$ & $\begin{array}{l}\text { Respuestas } \\
\text { pertinentes. }\end{array}$ & ED26 \\
\hline \multirow[t]{2}{*}{$\begin{array}{l}\text { ITEM } \\
5\end{array}$} & \multirow{2}{*}{$\begin{array}{l}\text { E: ¿Cómo es el desarrollo discursivo de sus estudiantes } \\
\text { según el estatus social de su familia? } \\
\text { D: Normalmente como docente trato de no tocar temas } \\
\text { familiares ya que son personales, por eso considero que el } \\
\text { desarrollo de la sesión se trabaja de manera general y no } \\
\text { particular. }\end{array}$} & $\begin{array}{l}\text { Trato de no tocar } \\
\text { temas familiares ya } \\
\text { que son personales. }\end{array}$ & Ética profesional. & $\mathrm{ED} 27$ \\
\hline & & $\begin{array}{l}\text { La sesión se trabaja de } \\
\text { manera general y no } \\
\text { particular. }\end{array}$ & $\begin{array}{l}\text { Enseñanza } \\
\text { generalizada. }\end{array}$ & $\mathrm{ED} 28$ \\
\hline \multirow[t]{2}{*}{$\begin{array}{l}\text { ITEM } \\
\quad 6\end{array}$} & \multirow{2}{*}{$\begin{array}{l}\text { E: ¿Cuáles son los principios didácticos que aplica en una } \\
\text { sesión de clase? } \\
\text { D: Bueno en clase trato de utilizar videos para motivar a los } \\
\text { alumnos y también uso de imágenes que ayuden en el } \\
\text { entendimiento visual del concepto propuesto. }\end{array}$} & $\begin{array}{l}\text { Utilización de videos } \\
\text { para motivar a los } \\
\text { alumnos }\end{array}$ & Material didáctico. & $\mathrm{ED} 29$ \\
\hline & & $\begin{array}{l}\text { Uso de imágenes que } \\
\text { ayuden en el } \\
\text { entendimiento visual } \\
\text { del } \quad \text { concepto } \\
\text { propuesto. }\end{array}$ & Aprendizaje visual. & ED30 \\
\hline $\begin{array}{l}\text { ITEM } \\
7\end{array}$ & $\begin{array}{l}\text { E: ¿Realiza un análisis de diagnóstico durante el desarrollo } \\
\text { de una sesión de clase? }\end{array}$ & $\begin{array}{ll}\text { El examen final } \\
\text { demuestra si el }\end{array}$ & $\begin{array}{l}\text { Evaluación } \\
\text { tradicional. }\end{array}$ & ED31 \\
\hline
\end{tabular}




\begin{tabular}{|c|c|c|c|c|}
\hline \multirow{2}{*}{$\begin{array}{l}\text { ITEM } \\
9\end{array}$} & $\begin{array}{l}\text { D: Eso en realidad lo veo al final del ciclo, con el examen final } \\
\text { ya que influye si el estudiante estuvo atento a las clases. } \\
\text { E: ¿Cómo adapta las actividades de aprendizaje según las } \\
\text { necesidades del estudiante? } \\
\text { D: Eso ya viene planteado en el silabo, entonces nos guiamos } \\
\text { de esos contenidos para brindar toda la información que } \\
\text { necesita el estudiante. }\end{array}$ & $\begin{array}{l}\text { estudiante estuvo } \\
\text { atento a las clases. }\end{array}$ & $\begin{array}{l}\text { Estructura } \\
\text { curricular. }\end{array}$ & ED32 \\
\hline & $\begin{array}{l}\text { E: ¿Cuál es su preparación previa para desarrollar una } \\
\text { sesión de clase? } \\
\text { D: Al realizar mis diapositivas busco información sobre el tema } \\
\text { y con eso me preparo para la sesión de clase. }\end{array}$ & Busco información. & $\begin{array}{l}\text { Búsqueda } \\
\text { información. }\end{array}$ & ED33 \\
\hline \multirow[t]{2}{*}{$\begin{array}{c}\text { ITEM } \\
10\end{array}$} & \multirow{2}{*}{$\begin{array}{l}\text { E: ¿Qué criterios aplica para determinar el trabajo } \\
\text { individual y colaborativo en la resolución de tareas de } \\
\text { aprendizaje? } \\
\text { D: Eso depende de la exigencia del trabajo, si es muy extenso } \\
\text { pues lo formo en grupo y si la actividad es pequeña entonces es } \\
\text { individual, además también tenemos que tener en cuenta la } \\
\text { cantidad de alumnos ya que si son bastantes entonces siempre } \\
\text { será por grupo. }\end{array}$} & Exigencia del trabajo. & $\begin{array}{l}\text { Indicadores } \\
\text { logro. }\end{array}$ & ED34 \\
\hline & & $\begin{array}{ll}\text { Tener en cuenta la } \\
\text { cantidad } & \text { de } \\
\text { estudiantes. } & \end{array}$ & $\begin{array}{l}\text { Cantidad } \\
\text { estudiantes. }\end{array}$ & ED35 \\
\hline
\end{tabular}


ANEXO 12

PROCESAMIENTO DE INFORMACIÓN DE ENCUESTA A ESTUDIANTES

\section{Tabla 1}

El docente utiliza autores que sustentan el análisis del contenido visual.

\begin{tabular}{lll}
\hline & Frecuencia & Porcentaje \\
NUNCA & 7 & 70,0 \\
CASI NUNCA & 1 & 10,0 \\
A VECES & 2 & 20,0 \\
Total & $\mathbf{1 0}$ & $\mathbf{1 0 0 , 0}$ \\
\hline
\end{tabular}

De la tabla 1, se evidencia que el $70 \%$ de los estudiantes respondió que el docente nunca utiliza autores que sustentan el análisis de contenido visual, mientras que un $20 \%$ menciono que a veces y un $10 \%$ indicó que casi nunca.

Tabla 2

Identifico de forma clara cuál es el mensaje de los contenidos vistos en clase.

\begin{tabular}{lll}
\hline & Frecuencia & Porcentaje \\
\hline CASI NUNCA & 3 & 30,0 \\
A VECES & 7 & 70,0 \\
Total & $\mathbf{1 0}$ & $\mathbf{1 0 0 , 0}$ \\
\hline
\end{tabular}

De la tabla 2, se evidencia que el $70 \%$ de los estudiantes respondió que a veces identifica de forma clara cuál es el mensaje de los contenidos vistos en clase, mientras que un30\% menciono que casi nunca.

\section{Tabla 3}

El docente nos incentiva a realizar diversos organizadores visuales para resumir el tema trabajado en clase.

\begin{tabular}{lll}
\hline & Frecuencia & Porcentaje \\
\hline NUNCA & 6 & 60,0 \\
CASI NUNCA & 4 & 40,0 \\
Total & $\mathbf{1 0}$ & $\mathbf{1 0 0 , 0}$ \\
\hline
\end{tabular}

De la tabla 3, se evidencia que el $60 \%$ de los estudiantes respondió que el docente nunca los incentiva a realizar diversos organizadores visuales para resumir el tema trabajado en clase, mientras que un $\mathbf{4 0 \%}$ menciono que casi nunca. 


\section{Tabla 4}

Identifico el uso de la comunicación verbal y/o no verbal en las publicidades mostradas por el docente.

\begin{tabular}{lll}
\hline & Frecuencia & Porcentaje \\
\hline CASI NUNCA & 3 & 30,0 \\
A VECES & 7 & 70,0 \\
Total & $\mathbf{1 0}$ & $\mathbf{1 0 0 , 0}$ \\
\hline
\end{tabular}

De la tabla 4, se evidencia que el $70 \%$ de los estudiantes respondió que a veces identifica el uso de la comunicación verbal y/o no verbal en las publicidades mostradas por el docente, mientras que un $30 \%$ menciono que casi nunca.

\section{Tabla 5}

Mi expresión oral en una exposición es clara, coherente y precisa

\begin{tabular}{lll}
\hline & Frecuencia & Porcentaje \\
\hline NUNCA & 2 & 20,0 \\
CASI NUNCA & 1 & 10,0 \\
A VECES & 5 & 50,0 \\
CASI SIEMPRE & 1 & 10,0 \\
SIEMPRE & 1 & 10,0 \\
Total & $\mathbf{1 0}$ & $\mathbf{1 0 0 , 0}$ \\
\hline
\end{tabular}

De la tabla 5, se evidencia que el $50 \%$ de los estudiantes respondió que a veces su expresión oral en una exposición es clara, coherente y precisa, mientras que un $20 \%$ menciono que nunca y un $10 \%$ indicó que casi nunca, de igual manera un $10 \%$ casi siempre y otro $10 \%$ siempre.

\section{Tabla 6}

Identifico el tipo de lenguaje empleado en las publicidades que se analiza en clase.

\begin{tabular}{lll}
\hline & Frecuencia & Porcentaje \\
\hline CASI NUNCA & 5 & 50,0 \\
A VECES & 4 & 40,0 \\
CASI SIEMPRE & 1 & 10,0 \\
Total & $\mathbf{1 0}$ & $\mathbf{1 0 0 , 0}$
\end{tabular}

De la tabla 6, se evidencia que el 50\% de los estudiantes respondió que casi nunca identifica el tipo de lenguaje empleado en las publicidades que se analiza en clase, mientras que un $40 \%$ menciono que a veces y un $10 \%$ casi siempre. 


\section{Tabla 7}

El docente me motiva a indagar y analizar mi contexto para extraer características del público objetivo.

\begin{tabular}{lll}
\hline & Frecuencia & Porcentaje \\
\hline NUNCA & 8 & 80,0 \\
CASI NUNCA & 1 & 10,0 \\
A VECES & 1 & 10,0 \\
Total & $\mathbf{1 0}$ & $\mathbf{1 0 0 , 0}$
\end{tabular}

De la tabla 7, se evidencia que el $80 \%$ de los estudiantes respondió que el docente nunca motiva a indagar y analizar mi contexto para extraer características del público objetivo, mientras que un $10 \%$ menciono que a veces y un $10 \%$ casi siempre.

\section{Tabla 8}

El docente propone actividades de aprendizaje en equipo.

\begin{tabular}{lll}
\hline & Frecuencia & Porcentaje \\
\hline NUNCA & 3 & 30,0 \\
CASI NUNCA & 2 & 20,0 \\
A VECES & 3 & 30,0 \\
CASI SIEMPRE & 1 & 10,0 \\
SIEMPRE & 1 & 10,0 \\
Total & $\mathbf{1 0}$ & $\mathbf{1 0 0 , 0}$
\end{tabular}

De la tabla 8, se evidencia que el 30\% de los estudiantes respondió que el docente nunca propone actividades de aprendizaje en equipo, mientras que un $30 \%$ menciono que a veces, un $20 \%$ casi nunca y un $10 \%$ casi siempre.

\section{Tabla 9}

Mi lenguaje es el adecuado para expresarme en el aula de clase.

\begin{tabular}{lll}
\hline & Frecuencia & Porcentaje \\
\hline NUNCA & 1 & 10,0 \\
CASI NUNCA & 4 & 40,0 \\
A VECES & 2 & 20,0 \\
SIEMPRE & 3 & 30,0 \\
Total & $\mathbf{1 0}$ & $\mathbf{1 0 0 , 0}$
\end{tabular}

De la tabla 9, se evidencia que el $40 \%$ de los estudiantes respondió que su lenguaje casi nunca es el adecuado para expresarme en el aula de clase, mientras que un $30 \%$ menciono que siempre, un $20 \%$ a veces y un $10 \%$ nunca. 


\section{Tabla 10}

El docente emplea estrategias didácticas en la sesión de clase.

\begin{tabular}{lll}
\hline & Frecuencia & Porcentaje \\
\hline NUNCA & 9 & 90,0 \\
CASI NUNCA & 1 & 10,0 \\
Total & $\mathbf{1 0}$ & $\mathbf{1 0 0 , 0}$ \\
\hline
\end{tabular}

De la tabla 10, se evidencia que el $90 \%$ de los estudiantes respondió que el docente nunca emplea estrategias didácticas en la sesión de clase, mientras que un $10 \%$ menciono que casi nunca.

\section{Tabla 11}

Al iniciar un nuevo módulo el docente realiza una prueba de entrada

\begin{tabular}{lll}
\hline & Frecuencia & Porcentaje \\
\hline NUNCA & 8 & 80,0 \\
CASI NUNCA & 1 & 10,0 \\
A VECES & 1 & 10,0 \\
Total & $\mathbf{1 0}$ & $\mathbf{1 0 0 , 0}$ \\
\hline
\end{tabular}

De la tabla 11, se evidencia que el $80 \%$ de los estudiantes respondió que al iniciar un nuevo módulo el docente nunca realiza una prueba de entrada, mientras que un $10 \%$ menciono que casi nunca y un $10 \%$ a veces.

\section{Tabla 12}

El docente realiza una retroalimentación al finalizar la sesión de clase

\begin{tabular}{lll}
\hline & Frecuencia & Porcentaje \\
\hline NUNCA & 8 & 80,0 \\
CASI NUNCA & 1 & 10,0 \\
A VECES & 1 & 10,0 \\
Total & $\mathbf{1 0}$ & $\mathbf{1 0 0 , 0}$ \\
\hline
\end{tabular}

De la tabla 12, se evidencia que el $80 \%$ de los estudiantes respondió que al iniciar un nuevo módulo el docente nunca realiza una prueba de entrada, mientras que un $10 \%$ menciono que casi nunca $y$ un $10 \%$ a veces. 


\section{Tabla 13}

El docente incentiva en la búsqueda de nueva información adicional a la presentada en clase.

\begin{tabular}{lll}
\hline & Frecuencia & Porcentaje \\
\hline NUNCA & 7 & 70,0 \\
CASI NUNCA & 2 & 20,0 \\
A VECES & 1 & 10,0 \\
Total & $\mathbf{1 0}$ & $\mathbf{1 0 0 , 0}$ \\
\hline
\end{tabular}

De la tabla 13, se evidencia que el $70 \%$ de los estudiantes respondió que el docente nunca incentiva en la búsqueda de nueva información adicional a la presentada en clase, mientras que un $20 \%$ menciono que casi nunca y un $10 \%$ a veces.

\section{Tabla 14}

El docente analiza las necesidades de aprendizaje de todos mis compañeros para incluirlo dentro de las sesiones de clases.

\begin{tabular}{lll}
\hline & Frecuencia & Porcentaje \\
\hline NUNCA & 7 & 70,0 \\
CASI NUNCA & 3 & 30,0 \\
Total & $\mathbf{1 0}$ & $\mathbf{1 0 0 , 0}$ \\
\hline
\end{tabular}

De la tabla 14, se evidencia que el $70 \%$ de los estudiantes respondió que el docente nunca analiza las necesidades de aprendizaje de todos mis compañeros para incluirlo dentro de las sesiones de clases, mientras que un $30 \%$ menciono que casi nunca.

\section{Tabla 15}

El docente domina los temas de las sesiones de clases de la asignatura Producción Gráfica.

\begin{tabular}{lll}
\hline & Frecuencia & Porcentaje \\
\hline NUNCA & 5 & 50,0 \\
A VECES & 4 & 40,0 \\
CASI SIEMPRE & 1 & 10,0 \\
Total & $\mathbf{1 0}$ & $\mathbf{1 0 0 , 0}$ \\
\hline
\end{tabular}

De la tabla 15, se evidencia que el $50 \%$ de los estudiantes respondió que el docente nunca domina los temas de las sesiones de clases de la asignatura Producción Gráfica, mientras que un $\mathbf{4 0 \%}$ menciono que a veces y un $10 \%$ casi siempre. 


\section{Tabla 16}

Durante la sesión de clase el docente orienta el trabajo de producción gráfica

\begin{tabular}{lll}
\hline & Frecuencia & Porcentaje \\
\hline NUNCA & 4 & 40,0 \\
CASI NUNCA & 4 & 40,0 \\
A VECES & 2 & 20,0 \\
Total & $\mathbf{1 0}$ & $\mathbf{1 0 0 , 0}$ \\
\hline
\end{tabular}

De la tabla 16, se evidencia que el $40 \%$ de los estudiantes respondió que durante la sesión de clase el docente nunca orienta el trabajo de producción gráfica, mientras que un $40 \%$ menciono que casi nunca y un $20 \%$ a veces.

\section{Tabla 17}

Comprendo de manera consciente los contenidos que brinda el docente

\begin{tabular}{lll}
\hline & Frecuencia & Porcentaje \\
\hline CASI NUNCA & 3 & 30,0 \\
A VECES & 5 & 50,0 \\
CASI SIEMPRE & 2 & 20,0 \\
Total & $\mathbf{1 0}$ & $\mathbf{1 0 0 , 0}$ \\
\hline
\end{tabular}

De la tabla 17, se evidencia que el $50 \%$ de los estudiantes respondió que comprende de manera consciente los contenidos que brinda el docente, mientras que un $30 \%$ menciono que casi nunca y un $20 \%$ casi siempre.

\section{Tabla 18}

Resuelvo las actividades encomendadas por el docente reconociendo su importancia en mi aprendizaje.

\begin{tabular}{lll}
\hline & Frecuencia & Porcentaje \\
\hline CASI NUNCA & 2 & 20,0 \\
A VECES & 7 & 70,0 \\
CASI SIEMPRE & 1 & 10,0 \\
Total & $\mathbf{1 0}$ & $\mathbf{1 0 0 , 0}$ \\
\hline
\end{tabular}

De la tabla 18, se evidencia que el $70 \%$ de los estudiantes respondió que a veces resuelve las actividades encomendadas por el docente reconociendo su importancia en mi aprendizaje, mientras que un $20 \%$ menciono que casi nunca y un $10 \%$ casi siempre. 


\section{ANEXO 13 \\ PROCESAMIENTO DE INFORMACIÓN PRUEBA PEDAGÓGICA}

\section{Tabla 19}

Niveles de competencia comunicativo

\begin{tabular}{lll}
\hline & Frecuencia & Porcentaje \\
\hline LOGRO EN INICIO & 2 & 20,0 \\
LOGRO EN PROCESO & 6 & 60,0 \\
LOGRO DESTACADO & 1 & 10,0 \\
PERDIDO/SISTEMA & 1 & 10,0 \\
Total & $\mathbf{1 0}$ & $\mathbf{1 0 0 , 0}$ \\
\hline
\end{tabular}

De la tabla 19, se evidencia que el $60 \%$ se encuentra en logro en proceso, mientras que un $20 \%$ logro en inicio y un $10 \%$ obtuvo logro destacado.

\section{Tabla 20}

Resultados de prueba

\begin{tabular}{lll}
\hline & Frecuencia & Porcentaje \\
\hline DESAPROBADO & 8 & 80,0 \\
APROBADO & 2 & 20,0 \\
Total & $\mathbf{1 0}$ & $\mathbf{1 0 0 , 0}$ \\
\hline
\end{tabular}

De la tabla 19, se evidencia que el $80 \%$ se encuentra desaprobado, mientras que un $20 \%$ aprobado en el resultado de la prueba. 


\section{ANEXO 14}

TABLA DE CODIFICACIÓN DE DATOS

\begin{tabular}{|c|c|c|}
\hline $\begin{array}{l}\text { ASIGNACIÓN DE } \\
\text { CÓDIGOS }\end{array}$ & CONCEPTOS CODIFICADOS & $\begin{array}{l}\text { POSIBLE CATEGORÍAS } \\
\text { EMERGENTE - } \\
\text { ENTREVISTAS }\end{array}$ \\
\hline ED1 & Existencia del ser humano & \multirow{2}{*}{ Comunicación humana } \\
\hline ED2 & Trascender del ser humano & \\
\hline ED3 & Saberes previos & \multirow{4}{*}{$\begin{array}{l}\text { Conocimiento parcial de } \\
\text { los fundamentos teóricos } \\
\text { de la comunicación }\end{array}$} \\
\hline ED4 & Desviación de la intención comunicativa & \\
\hline ED5 & Expresión comunicativa & \\
\hline ED6 & Desconocimiento de las formas elocutivas & \\
\hline ED 7 & Dialogo como sensibilización. & \multirow{4}{*}{$\begin{array}{c}\text { Diálogo activo y } \\
\text { participante para conocer } \\
\text { el contexto }\end{array}$} \\
\hline ED8 & Modelo a seguir para los estudiantes. & \\
\hline ED9 & Abstención de diálogos personales & \\
\hline ED10 & $\begin{array}{l}\text { Reflexión de temas coyunturales de la } \\
\text { sociedad. }\end{array}$ & \\
\hline ED11 & Teoría constructivista. & \multirow{3}{*}{$\begin{array}{c}\text { Conocimiento parcial } \\
\text { teórico y procedimental de } \\
\text { estrategias didácticas }\end{array}$} \\
\hline ED12 & Participación activa. & \\
\hline ED13 & Nivel de perspectiva docente. & \\
\hline ED14 & $\begin{array}{l}\text { Recolección de información a través del } \\
\text { diálogo. }\end{array}$ & $\begin{array}{l}\text { Dificultad en el desarrollo } \\
\text { del diálogo activo. }\end{array}$ \\
\hline ED15 & Técnica de casuística & \multirow{6}{*}{$\begin{array}{c}\text { Acciones metodológicas } \\
\text { orientadas al desarrollo de } \\
\text { la competencia } \\
\text { comunicativa }\end{array}$} \\
\hline ED16 & Procesos de enseñanza - aprendizaje. & \\
\hline ED17 & Fuentes de información. & \\
\hline ED18 & Informe de evaluación. & \\
\hline ED19 & Criterios de evaluación. & \\
\hline ED20 & $\begin{array}{l}\text { Desconocimiento de los fundamentos } \\
\text { teóricos. }\end{array}$ & \\
\hline ED21 & Autoaprendizaje. & \multirow{3}{*}{$\begin{array}{l}\text { Manejo del mensaje } \\
\text { comunicativo }\end{array}$} \\
\hline ED22 & Interpretación subjetiva del mensaje. & \\
\hline ED23 & Objetivo del mensaje. & \\
\hline
\end{tabular}




\begin{tabular}{|c|c|c|}
\hline ED24 & Desconocimiento de las formas elocutivas. & \\
\hline ED25 & Diálogo de reconocimiento. & \multirow{5}{*}{$\begin{array}{c}\text { Dificultades en el } \\
\text { desarrollo de habilidades y } \\
\text { capacidades }\end{array}$} \\
\hline ED8 & Ética profesional. & \\
\hline ED26 & Enseñanza generalizada. & \\
\hline ED27 & Material didáctico. & \\
\hline ED28 & Aprendizaje visual & \\
\hline ED29 & Evaluación tradicional. & \multirow{4}{*}{$\begin{array}{c}\text { Poca claridad para guiar el } \\
\text { autoaprendizaje }\end{array}$} \\
\hline ED8 & Estructura curricular. & \\
\hline ED30 & Búsqueda de información. & \\
\hline ED31 & Indicadores de logro. & \\
\hline ED32 & Cantidad de estudiantes. & \multirow{3}{*}{ Poco manejo del aula } \\
\hline ED33 & Exigencia del trabajo. & \\
\hline ED34 & Poca participación oral & \\
\hline
\end{tabular}

\begin{tabular}{|c|c|}
\hline CONCEPTUALIZACIONES & $\begin{array}{l}\text { POSIBLE CATEGORÍAS EMERGENTE - } \\
\text { ANALISIS DE RESULTADO ENCUESTA }\end{array}$ \\
\hline $\begin{array}{l}\text { Falencia por parte del docente en la utilización de autores que } \\
\text { sustenten el análisis del contenido visual. }\end{array}$ & Falencia en habilidades investigativas \\
\hline $\begin{array}{l}\text { Poca identificación de forma clara cuál es el mensaje de los contenidos } \\
\text { vistos en clase. }\end{array}$ & \multirow{2}{*}{$\begin{array}{l}\text { Falta de reconocimiento en el mensaje } \\
\text { empleado en el proceso de enseñanza } \\
\text { aprendizaje. }\end{array}$} \\
\hline $\begin{array}{l}\text { El docente no incentiva a realizar diversos organizadores visuales para } \\
\text { resumir el tema trabajado en clase. }\end{array}$ & \\
\hline $\begin{array}{l}\text { Poca identificación con el uso de la comunicación verbal y/o no verbal } \\
\text { en las publicidades mostradas por el docente. }\end{array}$ & \multirow{3}{*}{$\begin{array}{l}\text { Carencia de la competencia comunicativa } \\
\text { oral. }\end{array}$} \\
\hline Mi expresión oral en una exposición no es clara, coherente ni precisa. & \\
\hline $\begin{array}{l}\text { No logra identificar el tipo de lenguaje empleado en las publicidades } \\
\text { que se analiza en clase. }\end{array}$ & \\
\hline $\begin{array}{l}\text { El docente no motiva a indagar y analizar el contexto para extraer } \\
\text { características del público objetivo. }\end{array}$ & $\begin{array}{l}\text { Desconocimiento del contexto sociocultural } \\
\text { de los estudiantes }\end{array}$ \\
\hline El docente no propone actividades de aprendizaje en equipo. & \multirow{3}{*}{$\begin{array}{l}\text { Mal manejo de la metodología didáctica por } \\
\text { parte del docente. }\end{array}$} \\
\hline $\begin{array}{l}\text { El lenguaje empleado a veces es el adecuado para expresarme en el } \\
\text { aula de clase. }\end{array}$ & \\
\hline El docente no emplea estrategias didácticas en la sesión de clase. & \\
\hline
\end{tabular}


Al iniciar un nuevo módulo el docente no realiza una prueba de entrada.

El docente no realiza una retroalimentación al finalizar la sesión de clase.

El docente no incentiva en la búsqueda de nueva información adicional a la presentada en clase.

El docente no analiza las necesidades de aprendizaje de todos los estudiantes para incluirlo dentro de las sesiones de clases.

El docente domina poco los temas de las sesiones de clases de la asignatura Producción Gráfica

Durante la sesión de clase el docente no monitorea o vigila la creación de nuevos conocimientos.

Los estudiantes no comprenden de manera consciente los contenidos que brinda el docente.

Resuelven sin interés las actividades encomendadas por el docente sin reconocer su importancia en el aprendizaje.
El docente no guía correctamente el aprendizaje significativo.
Falta de preparación teórica.

El docente no cumple el rol de facilitador. 


\section{ANEXO 15 \\ TABLA DE VALIDACIÓN DE EXPERTOS}

\section{Tabla 1}

Especialistas que realizaron la validación de los instrumentos:

\begin{tabular}{|c|c|c|c|c|}
\hline $\begin{array}{l}\text { Nombres y } \\
\text { Apellidos }\end{array}$ & Grado Académico & $\begin{array}{l}\text { Especialidad } \\
\text { profesional }\end{array}$ & Ocupación & Años de servicio \\
\hline $\begin{array}{l}\text { Herrera Montoya, } \\
\text { María Teresa. }\end{array}$ & $\begin{array}{lr}\text { Magister } & \text { en } \\
\text { Psicopedagogía } & \text { y } \\
\text { Diplomado } & \text { en } \\
\text { Gestión da } & \text { la } \\
\text { Educación. } & \end{array}$ & $\begin{array}{l}\text { Psicopedagoga, } \\
\text { docente. }\end{array}$ & $\begin{array}{l}\text { Docente de la Universidad San } \\
\text { Ignacio de Loyola. }\end{array}$ & 40 años \\
\hline $\begin{array}{l}\text { Garnelo Escobar, } \\
\text { Ronald }\end{array}$ & $\begin{array}{l}\text { Magister en } \\
\text { Educación. }\end{array}$ & $\begin{array}{l}\text { Docente, } \\
\text { Antropólogo } \\
\text { investigador. }\end{array}$ & $\begin{array}{l}\text { Docente de la Universidad San } \\
\text { Ignacio de Loyola. }\end{array}$ & 15 años \\
\hline $\begin{array}{l}\text { Eusebio Asarías, } \\
\text { Leandro Huaytan }\end{array}$ & $\begin{array}{l}\text { Magister en } \\
\text { Educación. }\end{array}$ & $\begin{array}{l}\text { Docente de Artes } \\
\text { Plásticas }\end{array}$ & $\begin{array}{l}\text { Docente de la Universidad Las } \\
\text { Américas. }\end{array}$ & 30 años. \\
\hline
\end{tabular}

Fuente: propia de la autora. 
ANEXO 16

\section{SESIÓN DE APRENDIZAJE NRO. 1}

\section{Datos Generales:}

. Institución de Educación Superior: CIMA’S

. Carrera :Diseño Gráfico

. Nivel

- Asignatura

. Duración

. Tema
:Cuarto ciclo

:Producción Gráfica

:5 horas semanales

:Conociendo el origen de la escritura en el mundo antiguo.

\section{Organización de Aprendizajes para la sesión 1 del curso de Producción Gráfica}

\begin{tabular}{|c|c|c|c|}
\hline Conceptos & Procedimientos & Actitudes & Indicador \\
\hline $\begin{array}{l}\text { - Definición del concepto } \\
\text { de Producción Gráfica. } \\
\text { - Primeros inicios de la } \\
\text { escritura. } \\
\text { - La imprenta en el } \\
\text { renacimiento. } \\
\text { - Repercusiones de la } \\
\text { imprenta en la sociedad. }\end{array}$ & $\begin{array}{l}\text { Reconoce y conceptualiza los } \\
\text { principios básicos de la } \\
\text { Producción Gráfica- } \\
\text { Conoce la importancia de la } \\
\text { escritura a lo largo de la historia. } \\
\text { Identifica la influencia de la } \\
\text { escritura en la sociedad. }\end{array}$ & $\begin{array}{l}\text { Participar en la secuencia del } \\
\text { curso, así como en la } \\
\text { elaboración de actividades } \\
\text { colaborativas. } \\
\text { Valorar los aprendizajes } \\
\text { desarrollados a nivel } \\
\text { interpersonal y grupal } \\
\text { Debate el campo de estudio } \\
\text { de la Producción Gráfica. } \\
\text { Tiene un juicio critico }\end{array}$ & $\begin{array}{l}\text { Analiza, los } \\
\text { conceptos } \\
\text { relacionados a la } \\
\text { producción } \\
\text { gráfica. } \\
\text { Discrimina } \\
\text { información sobre } \\
\text { la producción } \\
\text { gráfica y sus } \\
\text { inicios a través de } \\
\text { la imprenta. } \\
\text { Desarrolla } \\
\text { organizador visual } \\
\text { que muestra la } \\
\text { evolución de la } \\
\text { producción gráfica } \\
\text { hasta la actualidad. }\end{array}$ \\
\hline
\end{tabular}

Aprendizajes esperados

Analiza los conceptos teóricos de la producción gráfica.

Discrimina información sobre producción gráfica y su importancia en el desarrollo del país.

Sabe distinguir la importancia de la imprenta en la sociedad.

Reconoce momentos importantes de la historia y los movimientos del diseño gráfico.

\section{Valores y Actitudes}

\begin{tabular}{|l|l|}
\hline \multicolumn{1}{|c|}{ Ejes transversales } & \multicolumn{1}{|c|}{ Valores } \\
\hline $\begin{array}{l}\text { Educación para la identidad nacional e } \\
\text { Interculturalidad }\end{array}$ & $\begin{array}{l}\text { Responsabilidad, laboriosidad, ética } \\
\text { honestidad, solidaridad, respeto }\end{array}$ \\
\hline
\end{tabular}




\section{SECUENCIA DIDÁCTICA DE LA SESIÓN DE CLASE Nro. 1}

\begin{tabular}{|c|c|c|}
\hline Momentos & Actividades / Estrategias & $\begin{array}{l}\text { Medios y } \\
\text { Materiales }\end{array}$ \\
\hline $\begin{array}{l}\text { Inicio } \\
15 \mathrm{~min} .\end{array}$ & $\begin{array}{l}\text { Motivación: } \\
\text { El docente da la bienvenida a los estudiantes en el aula de Producción Gráfica. } \\
\text { Presentación del extracto laboral del docente. } \\
\text { Estrategias para activar los conocimientos previos. } \\
\text { Se plantea la dinámica "Conexiones Forzadas" para estimular el desarrollo creativo de los } \\
\text { estudiantes. } \\
\text { Se prepara una diapositiva donde se presentan imágenes relacionados a la imprenta y } \\
\text { elementos de la vida cotidiana que no guardan relación con el diseño gráfico. } \\
\text { Los estudiantes responden de manera divertida e interactúan con sus compañeros. }\end{array}$ & $\begin{array}{l}\text { Imágenes } \\
\text { Diálogo } \\
\text { Diapositiva }\end{array}$ \\
\hline $\begin{array}{l}\text { Desarrollo } \\
60 \mathrm{~min} \text {. }\end{array}$ & 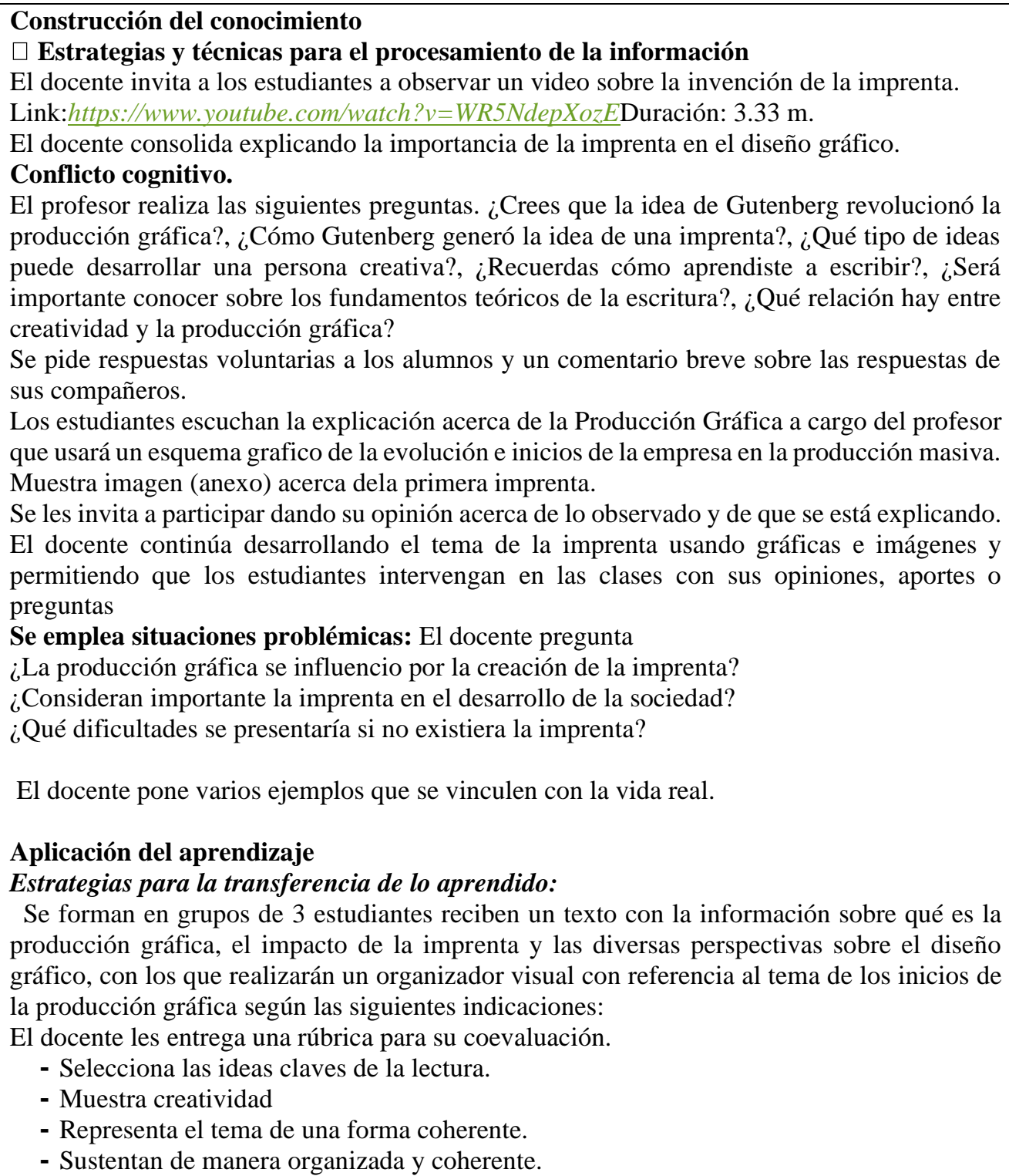 & $\begin{array}{l}\text { evaluación } \\
\text { del } \\
\text { organizador } \\
\text { visual } \\
\end{array}$ \\
\hline
\end{tabular}




\begin{tabular}{|c|c|c|}
\hline $\begin{array}{l}\text { Cierre } \\
15 \text { min. }\end{array}$ & $\begin{array}{l}\text { Exponen los resultados del grupo y se hacen preguntas. } \\
\text { Se plantean las conclusiones del tema junto con el profesor. } \\
\text { Se realiza una metacognición donde explican los pasos seguidos: } \\
\text { - ¿Qué pasos realicé para asimilar el tema abordado? } \\
\text { - ¿Para qué me sirve lo aprendido? } \\
\text { - ¿Cómo lo aplicaré en la profesión y en la vida diaria? } \\
\text { Presenta los resultados de la rúbrica con su autoevaluación. } \\
\text { Se deja como tarea: } \\
\text {. Investigar las habilidades que posee un diseñador en el área de producción gráfica. }\end{array}$ & $\begin{array}{l}\text { Rúbrica de } \\
\text { evaluación } \\
\text { Material } \\
\text { impreso }\end{array}$ \\
\hline
\end{tabular}

\section{Referencias}

Santarsiero, M (2009). Producción Gráfica y Multimedial. Buenos Aires, Argentina: Ediciones

Producción Gráfica.

Santarsiero, M (2013). Preimpresión. Preprensa. Buenos Aires, Argentina: Ediciones Producción Gráfica 


\section{ANEXO 17}

\section{RÚBRICA DE COEVALUACIÓN}

OBJETIVO: Determinar si los estudiantes emplearon su habilidades comunicacionales y creativas en el desarrollo del organizador visual.

INDICACIONES:Se evalúa de manera individual el aporte de cada estudiante, procediendo a la evaluación de cada uno de los indicadores expresados en la primera fila, teniendo su respectiva calificación cuantitativa.

\begin{tabular}{|c|c|c|c|c|c|c|}
\hline Nombres y apellidos & $\begin{array}{c}\text { Participé activamente en } \\
\text { el desarrollo del } \\
\text { organizador visual } \\
\text { (3) }\end{array}$ & $\begin{array}{l}\text { Demuestro una actitud } \\
\text { positiva frente al } \\
\text { trabajo. } \\
\text { (4) }\end{array}$ & $\begin{array}{l}\text { Identifique de } \\
\text { manera coherente } \\
\text { y concisa el } \\
\text { mensaje. } \\
\text { (4) }\end{array}$ & $\begin{array}{c}\text { Empleo el uso de } \\
\text { mis habilidades en } \\
\text { la realización del } \\
\text { organizador visual. } \\
\text { (5) }\end{array}$ & $\begin{array}{l}\text { Empleo elementos } \\
\text { visuales para } \\
\text { identificar con } \\
\text { rapidez el } \\
\text { contenido del } \\
\text { tema. } \\
(0-2-4)\end{array}$ & Nota final \\
\hline 1. & & & & & & \\
\hline 2. & & & & & & \\
\hline 3. & & & & & & \\
\hline 4. & & & & & & \\
\hline 5. & & & & & & \\
\hline
\end{tabular}




\section{ANEXO 18}

\section{RÚBRICA DE AUTOEVALUACIÓN}

OBJETIVO: Determinar si los estudiantes emplearon su habilidades comunicacionales y creativas en el desarrollo del organizador visual.

INDICACIONES: Se evalúa la exposición grupal de los estudiantes dentro del primer cuadro, luego se procede con la evaluación de cada uno de los indicadores expresados en la primera fila, teniendo su respectiva calificación cuantitativa.

\begin{tabular}{|l|c|c|c|c|c|}
\hline Grupos De Exposición & $\begin{array}{c}\text { Presentan Las Ideas } \\
\text { De Manera } \\
\text { Simplificada } \\
(\mathbf{3})\end{array}$ & $\begin{array}{c}\text { Adecuado Manejo } \\
\text { Del Programai En } \\
\text { El Desarrollo Del } \\
\text { Organizador Visua } \\
(\mathbf{3})\end{array}$ & $\begin{array}{c}\text { Respeta Los Niveles } \\
\text { Que Contienen Un } \\
\text { Organizador Visual } \\
\text { (5) }\end{array}$ & $\begin{array}{c}\text { Utiliza Elementos } \\
\text { Gráficos Que } \\
\text { Faciliten La Lectura } \\
\text { (4) }\end{array}$ & $\begin{array}{c}\text { Sustentan Su } \\
\text { Creación De } \\
\text { Manera Fluida Y } \\
\text { Coherente } \\
\text { (5) }\end{array}$ \\
\hline 1. & & & & & \\
\hline 2. & & & & & \\
\hline 3. & & & & & \\
\hline 4. & & & & & \\
\hline
\end{tabular}




\section{ANEXO 19 \\ SESIÓN DE APRENDIZAJE NRO. 2}

\section{Datos Generales:}

- Institución de Educación Superior: CIMA'S

. Carrera

: Diseño Gráfico

. Nivel

: Cuarto ciclo

- Asignatura

: Producción Gráfica

. Duración

: 5 horas semanales

. Tema

:Desarrollando mis habilidades en la Producción Gráfica

\section{Organización de Aprendizajes para la sesión 2 del curso de Producción Gráfica}

\begin{tabular}{|c|c|c|c|}
\hline Conceptos & Procedimientos & Actitudes & Indicador \\
\hline $\begin{array}{l}\text { - Definición del concepto } \\
\text { de habilidades. } \\
\text { - Procesos de la producción } \\
\text { gráfica. } \\
\text { - Habilidades de un } \\
\text { diseñador gráfico. }\end{array}$ & $\begin{array}{l}\text { Reconoce y conceptualiza los } \\
\text { principios básicos de las } \\
\text { habilidades de un diseñador } \\
\text { gráfico. } \\
\text { Conoce la importancia de la } \\
\text { rapidez en los procesos gráficos. } \\
\text { Identifica las cualidades que } \\
\text { posee como diseñador. }\end{array}$ & $\begin{array}{l}\text { Participar en la secuencia del } \\
\text { curso, así como en la } \\
\text { elaboración de actividades } \\
\text { colaborativas. } \\
\text { Valorar los aprendizajes } \\
\text { desarrollados a nivel } \\
\text { interpersonal y grupal } \\
\text { Debate el campo de estudio } \\
\text { de la Producción Gráfica. } \\
\text { Tiene un juicio critico }\end{array}$ & $\begin{array}{l}\text { Analiza, los conceptos } \\
\text { relacionados a las } \\
\text { habilidades necesarias } \\
\text { para la producción } \\
\text { gráfica. } \\
\text { Discrimina información } \\
\text { sobre los procesos de la } \\
\text { producción gráfica y las } \\
\text { técnicas de rapidez. } \\
\text { Desarrolla una } \\
\text { infografía que muestra } \\
\text { los procesos de la } \\
\text { producción gráfica. }\end{array}$ \\
\hline \multicolumn{4}{|l|}{ Aprendizajes esperados } \\
\hline $\begin{array}{l}\text { Analiza los conceptos teórico } \\
\text { Discrimina información sobre } \\
\text { Sabe distinguir entre las habil }\end{array}$ & $\begin{array}{l}\text { sobre el desarrollo de habilidades. } \\
\text { los procesos de la producción gráf } \\
\text { dades que posee y las que aún no d }\end{array}$ & $\begin{array}{l}\text { ca. } \\
\text { esarrolla. }\end{array}$ & \\
\hline
\end{tabular}

Valores y Actitudes

\begin{tabular}{|l|l|}
\hline \multicolumn{1}{|c|}{ Ejes transversales } & \multicolumn{1}{|c|}{ Valores } \\
\hline $\begin{array}{l}\text { Educación para la identidad nacional e } \\
\text { Interculturalidad }\end{array}$ & $\begin{array}{l}\text { Responsabilidad, laboriosidad, ética } \\
\text { honestidad, solidaridad, respeto }\end{array}$ \\
\hline
\end{tabular}




\section{SECUENCIA DIDÁCTICA DE LA SESIÓN DE CLASE Nro. 2}

\begin{tabular}{|c|c|c|}
\hline Momentos & Actividades / Estrategias & $\begin{array}{l}\text { Medios y } \\
\text { Materiales }\end{array}$ \\
\hline $\begin{array}{l}\text { Inicio } \\
15 \mathrm{~min} .\end{array}$ & $\begin{array}{l}\text { Motivación: } \\
\text { El docente formula algunas preguntas para saber cómo les ha ido a los estudiantes a lo largo } \\
\text { del día. } \\
\text { Estrategias para activar los conocimientos previos. } \\
\text { Se plantea la dinámica "Zoom divertido" para estimular el desarrollo creativo de los } \\
\text { estudiantes. } \\
\text { Se prepara una diapositiva donde se presentan pequeños fragmentos de imágenes relacionados } \\
\text { a objetos cotidianos. } \\
\text { Los estudiantes responden de manera divertida e interactúan con sus compañeros para } \\
\text { adivinar cuál es el objeto escondido. }\end{array}$ & $\begin{array}{l}\text { Imágenes } \\
\text { Diálogo } \\
\text { Diapositiva }\end{array}$ \\
\hline $\begin{array}{l}\text { Desarrollo } \\
60 \mathrm{~min} .\end{array}$ & $\begin{array}{l}\text { Construcción del conocimiento } \\
\square \text { Estrategias y técnicas para el procesamiento de la información } \\
\text { El docente invita a los estudiantes a observar un video sobre los procesos de la imprenta. } \\
\text { Link:https://www.youtube.com/watch?v=7LyC9EazdcYDuración: } 6.29 \mathrm{~m} \text {. } \\
\text { El docente consolida explicando la importancia de conocer los procesos de una imprenta en } \\
\text { el diseño gráfico. } \\
\text { Conflicto cognitivo. } \\
\text { El profesor realiza las siguientes preguntas. ¿Qué opinión te merece?, ¿Consideras } \\
\text { que tienes las habilidades para desarrollar la producción gráfica?, ¿Crees que la producción } \\
\text { gráfica complementará en tu desarrollo profesional?, ¿Qué habilidades necesitamos para } \\
\text { desarrollar la producción gráfica? } \\
\text { Se pide respuestas voluntarias a los alumnos y un comentario breve sobre las respuestas de } \\
\text { sus compañeros. } \\
\text { Los estudiantes escuchan la explicación acerca de las habilidades necesarias para la } \\
\text { Producción Gráfica a cargo del profesor que usará un mapa conceptual sobre las habilidades } \\
\text { y destrezas de un estudiante de diseño que debe implementar en su formación profesional. } \\
\text { El docente continúa desarrollando el tema de las habilidades mostrando un cuadro con } \\
\text { características que un diseñador debe considerar, luego procede a preguntar quienes } \\
\text { consideran que cumplen con dicha característica. } \\
\text { Aplicación del aprendizaje } \\
\text { Estrategias para la transferencia de lo aprendido: } \\
\text { Se forman en grupos de } 2 \text { estudiantes reciben un texto sobre las habilidades artísticas, } \\
\text { destrezas en la producción gráfica, con los que realizarán una infografía con referencia a las } \\
\text { habilidades para la producción gráfica que el grupo posee. } \\
\text { El docente les entrega una rúbrica para su coevaluación. } \\
\text { - Selecciona las ideas claves de la lectura. } \\
\text { - Muestra creatividad } \\
\text { - Representa el tema de una forma coherente. } \\
\text { - Sustentan de manera organizada y coherente. }\end{array}$ & $\begin{array}{l}\text { Evaluación } \\
\text { de la } \\
\text { infografía. } \\
\text { Coevaluació } \\
\text { n }\end{array}$ \\
\hline
\end{tabular}




\begin{tabular}{|l|l|l|}
\hline $\mathbf{1 5} \mathbf{~ m i n .}$ & $\begin{array}{l}\text { Exponen los resultados del grupo y se hacen preguntas. } \\
\text { Se plantean las conclusiones del tema junto con el profesor. } \\
\text { Se realiza una metacognición donde explican los pasos seguidos: } \\
\text { - ¿Qué pasos realicé para asimilar el tema abordado? } \\
\text { - ¿Para qué me sirve lo aprendido? } \\
\text { - ¿Cómo lo aplicaré en la profesión y en la vida diaria? } \\
\text { Presenta los resultados de la rúbrica con su autoevaluación. } \\
\text { Se deja como tarea: } \\
\text {. Investigar sobre los formatos de impresión empleados en la actualidad. }\end{array}$ & Material \\
& & impreso \\
\hline
\end{tabular}

\section{Referencias}

Santarsiero, M (2009). Producción Gráfica y Multimedial. Buenos Aires, Argentina: Ediciones Producción Gráfica.

Santarsiero, M (2013). Preimpresión. Preprensa. Buenos Aires, Argentina: Ediciones Producción

Gráfica 
ANEXO 20

FICHA DE VALIDACIÓN DE LA PROPUESTA DIDÁCTICA

\section{Datos generales.}

1.1. Apellidos y nombres del especialista:

1.2. Grado de estudios alcanzado :

1.3. Resultado científico en valoración:

1.4. Autor del resultado científico :

\section{Aspectos a observar}

\section{VALIDACIÓN INTERNA}

\begin{tabular}{|c|c|c|c|c|c|c|c|c|}
\hline \multirow{3}{*}{ Indicadores } & \multirow{2}{*}{\multicolumn{5}{|c|}{$\begin{array}{l}\text { Escala de } \\
\text { valoración }\end{array}$}} & \multicolumn{3}{|c|}{ Aspectos } \\
\hline & & & & & & \multirow{2}{*}{$\begin{array}{l}\text { Positi } \\
\text { vos }\end{array}$} & \multirow{2}{*}{$\begin{array}{l}\text { Negat } \\
\text { ivos }\end{array}$} & \multirow{2}{*}{$\begin{array}{l}\text { Sugere } \\
\text { ncias }\end{array}$} \\
\hline & 1 & 2 & 3 & 4 & 5 & & & \\
\hline \multicolumn{9}{|l|}{ Factibilidad de aplicación del resultado que se presenta. } \\
\hline \multicolumn{9}{|l|}{ Claridad de la propuesta para ser aplicado por otros } \\
\hline \multicolumn{9}{|c|}{ Posibilidad de la propuesta de extensión a otros contextos semejantes } \\
\hline \multicolumn{9}{|c|}{ Correspondencia con las necesidades sociales e individuales actuales } \\
\hline \multicolumn{9}{|l|}{ Congruencia entre el resultado propuesto y el objetivo fijado. } \\
\hline \multicolumn{9}{|c|}{ Novedad en el uso de conceptos y procedimientos de la propuesta. } \\
\hline \multicolumn{9}{|c|}{$\begin{array}{l}\text { La modelación contiene propósitos basados en los fundamentos } \\
\text { educativos, curriculares y pedagógicos. detallado, preciso y efectivo }\end{array}$} \\
\hline \multicolumn{9}{|l|}{ La propuesta está contextualizada a la realidad en estudio } \\
\hline \multicolumn{9}{|l|}{ Presenta objetivos claros, coherentes y posibles de alcanzar } \\
\hline Contiene un plan de acción de lo general a lo particular & & & & & & & & \\
\hline
\end{tabular}




\section{FICHA DE VALIDACIÓN EXTERNA (FORMA)}

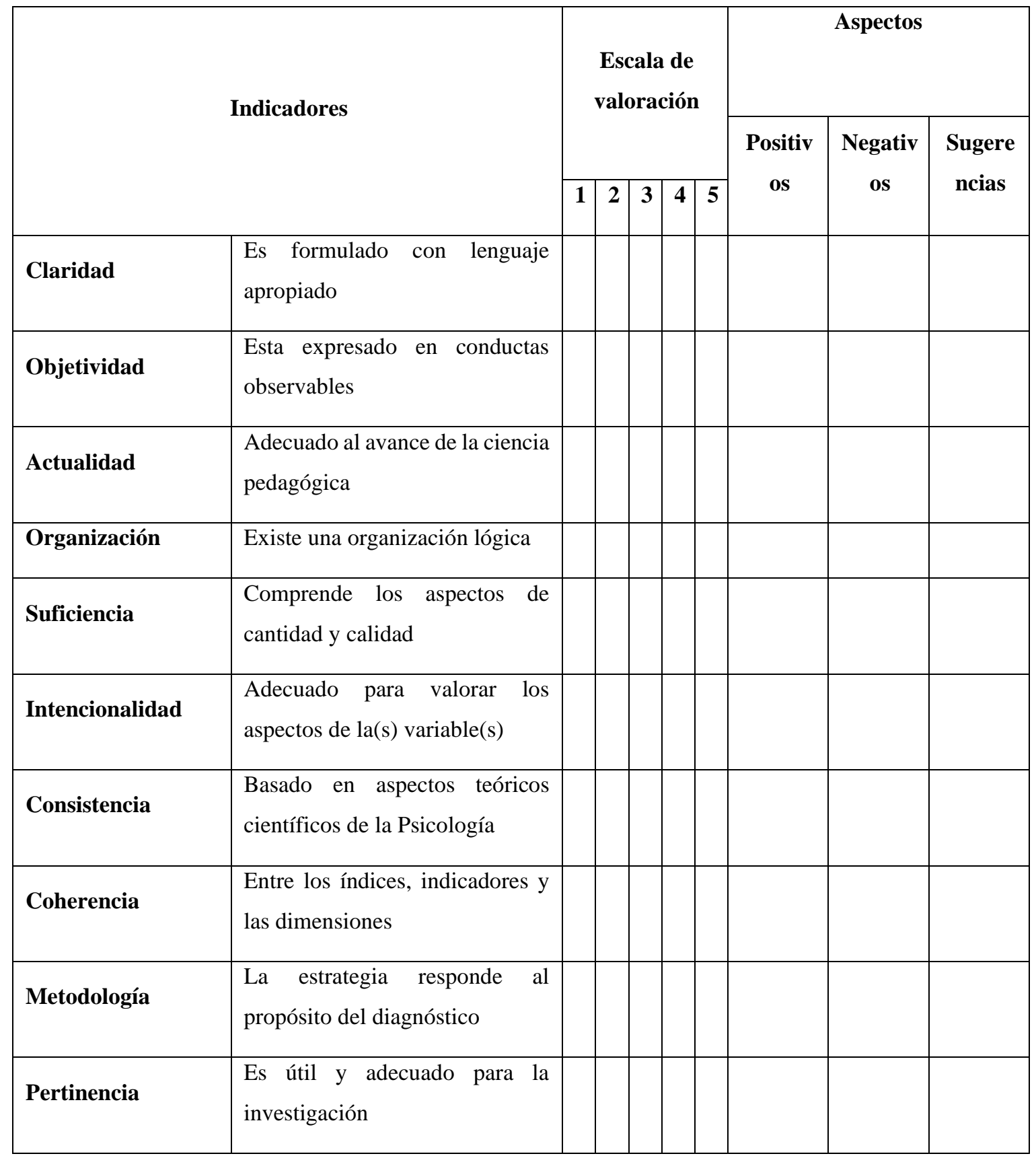


I. $\quad$ Aportes o sugerencias para el perfeccionamiento del resultado científico:

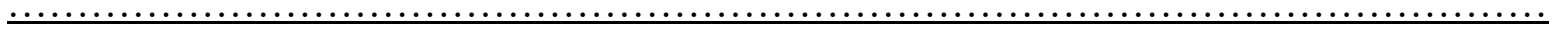

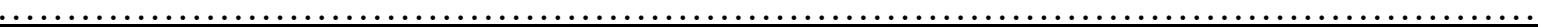


\section{Opinión de aplicabilidad.}

III. RESULTADOS

PROMEDIO DE VALORACIÓN INTERNA: $(50 \%)+$ PUNTAJE DE VALORACIÓN EXTERNA: $(\mathbf{5 0 \% )}$

RESULTADO DE VALORACIÓN:

Tabla de Valoración

\begin{tabular}{|l|l|}
\hline Deficiente & $\mathbf{0}-\mathbf{2 5}$ \\
\hline Baja & $\mathbf{2 5}-\mathbf{5 0}$ \\
\hline Regular & $\mathbf{5 1}-\mathbf{7 0}$ \\
\hline Buena & $\mathbf{7 1 - \mathbf { 8 5 }}$ \\
\hline Muy Buena & $\mathbf{8 6 - 1 0 0}$ \\
\hline
\end{tabular}


1. Deficiente ( )

2. Baja ( )

3. Regular ( )

4. Buena ( )

5. Muy buena ( )

\section{OPINIÓN DE APLICABILIDAD:}
a) Deficiente ( )
b) Baja ( )
c) Regular ( )
d) Buena ( )
e) Muy Buena ( )

\begin{tabular}{|l|l|l|l|}
\hline Nombres y Apellidos & DNI No & \\
\hline Dirección domiciliaria & & Teléfono & \\
Celular & \\
\hline $\begin{array}{l}\text { Título profesional / } \\
\text { Especialidad }\end{array}$ & & \\
\hline Grado Académico & & \\
\hline Mención & \multicolumn{2}{|l}{} \\
\hline
\end{tabular}

Firma

Lugar y

fecha: 


\section{ANEXO 21}

VALIDACIÓN DE MODELACIÓN: EXPERTO 1

Ficha de validación externa (forma)

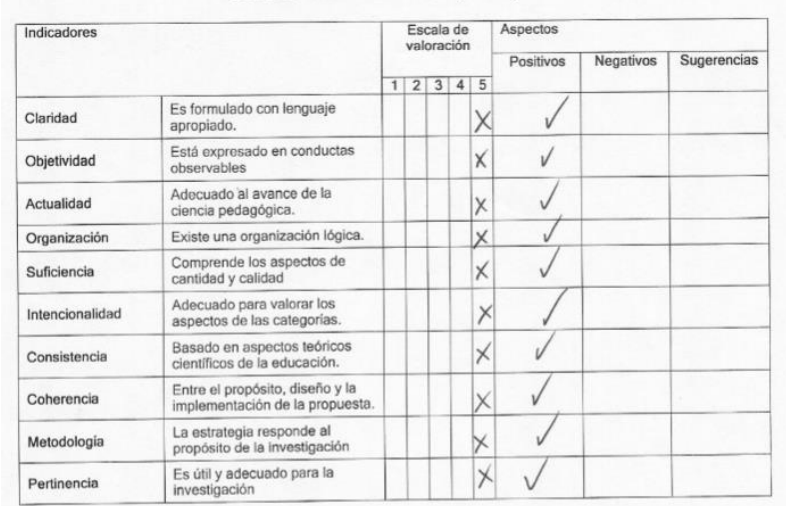

Aportes o sugerencias para el perfeccionamiento del resultado cientifico:

Opinión de aplicabilidad.

Resultados

Promedio de valoración $=\frac{\text { Valoracían interaat valoración externa }}{2}$

Resultado de valoración: $100 \%$

$\underline{\text { Aspectos a observar }}$

Validación interna

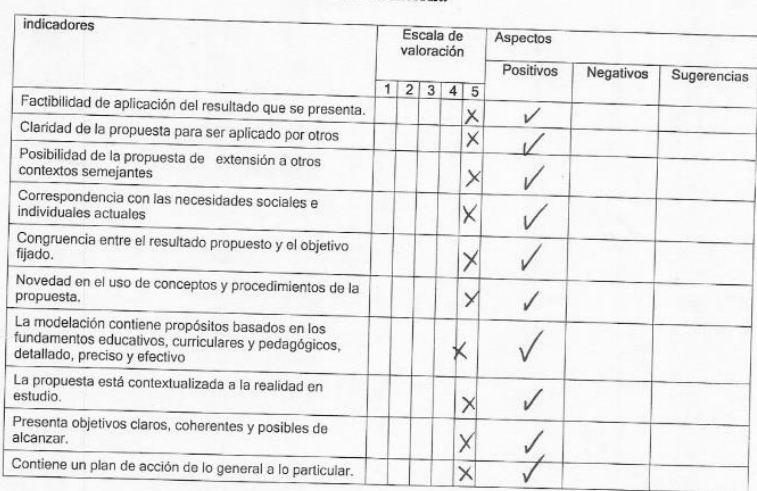

Escala de valoración

\begin{tabular}{lcc}
\hline Escala & Rango frecuencia & Rango porcentaje \\
\hline Deficiente & {$[10-17]$} & {$[20 \%-35 \%]$} \\
Baja & {$[18-25]$} & {$[36 \%-51 \%]$} \\
Regular & {$[26-33]$} & {$[52 \%-67 \%]$} \\
Buena & {$[34-41]$} & {$[68 \%-83 \%]$} \\
Muy buena & {$[42-50]$} & {$[84 \%-100 \%]$} \\
\hline
\end{tabular}

Opinión de aplicabilidad:

a) Deficiente ( ) b) Baja ( ） c) Regular ( ) d) Buena ( ） e) Muy Buena ( )

\begin{tabular}{|c|c|c|c|}
\hline Nombres y Apellidos & ALDO ALPONSO LOPEZ KITANO & $\mathrm{DNIN}^{\circ}$ & 09754852 \\
\hline Dirección domiciliaria & AN.Puente PIEDRA 737 & Teléfono / Celular & 959332301 \\
\hline $\begin{array}{l}\text { Titulo profesional/ } \\
\text { Especialidad }\end{array}$ & \multicolumn{3}{|c|}{ MAESTRO EN EDUCACION EINVES7IGACION PEOAgOGIC } \\
\hline Grado Académico & \multicolumn{3}{|c|}{ MAESTRO } \\
\hline $\begin{array}{l}\text { Ocupación y año de } \\
\text { experiencia }\end{array}$ & \multicolumn{3}{|c|}{ SUPERIOR } \\
\hline Metodólogo/temático & \multicolumn{3}{|l|}{ ME TODOLOGO } \\
\hline
\end{tabular}

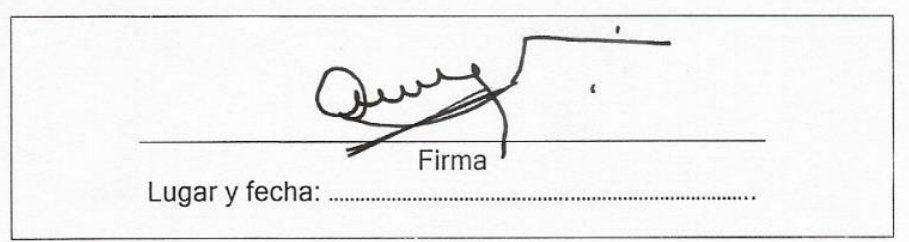




\section{ANEXO 22}

\section{VALIDACIÓN DE MODELACIÓN: EXPERTO 2}

Ficha de validación externa (forma)

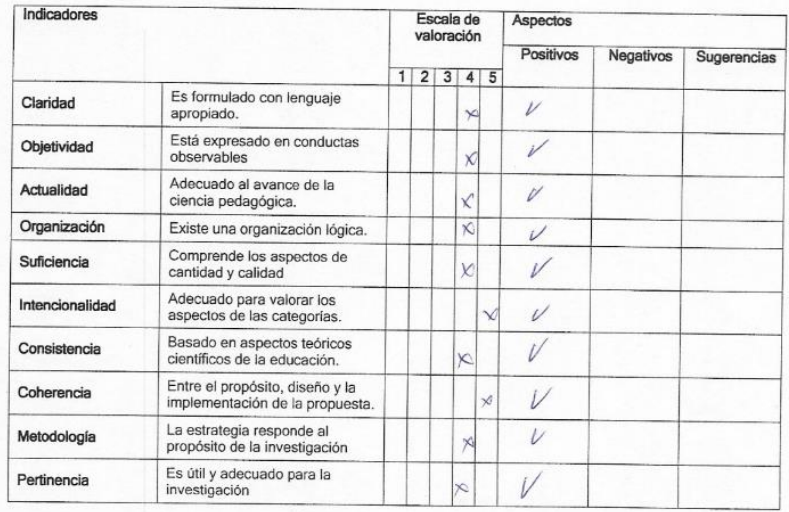

Aportes o sugerencias para el perfeccionamiento del resultado cientifico:

\section{Opinión de aplicabilidad.}

\section{Resultados}

Promedio de valoración $=\frac{\text { Valoración interna }+ \text { valoración externa }}{2}$

Resultado de valoración: 84

\section{Aspectos a observar}

Validación interna

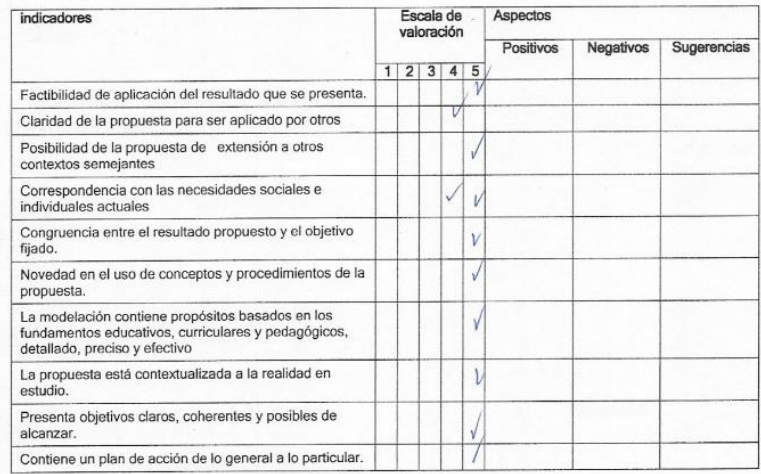

Escala de valoración

\begin{tabular}{lcc}
\hline Escala & Rango frecuencia & Rango porcentaje \\
\hline Deficiente & {$[10-17]$} & {$[20 \%-35 \%]$} \\
Baja & {$[18-25]$} & {$[36 \%-51 \%]$} \\
Regular & {$[26-33]$} & {$[52 \%-67 \%]$} \\
Buena & {$[34-41]$} & {$[68 \%-83 \%]$} \\
Muy buena & {$[42-50]$} & {$[84 \%-100 \%]$} \\
\hline
\end{tabular}

Opinión de aplicabilidad:

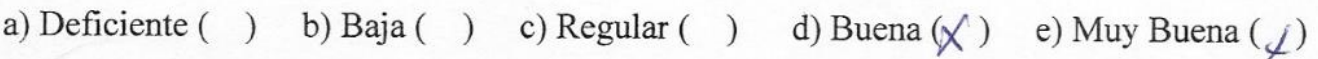

\begin{tabular}{|c|c|c|c|}
\hline Nombres y Apellidos & Fernando Soñi Gro & $\mathrm{DNIN}^{\circ}$ & 09446915 \\
\hline Dirección domiciliaria & Jr. Cañte $<67$ linat & Teléfono / Celular & 985412510 \\
\hline $\begin{array}{l}\text { Titulo profesional / } \\
\text { Especialidad }\end{array}$ & Ducende de Física-Maben & atica & \\
\hline Grado Académico & Dr.en ciencies de la & ducaciồ & \\
\hline $\begin{array}{l}\text { Ocupación y año de } \\
\text { experiencia }\end{array}$ & Q) oc encia seifpenior & & \\
\hline Metodólogo/temático & & & \\
\hline
\end{tabular}




\section{ANEXO 23}

\section{VALIDACIÓN DE MODELACIÓN: EXPERTO 3}

Ficha de validación externa (forma)

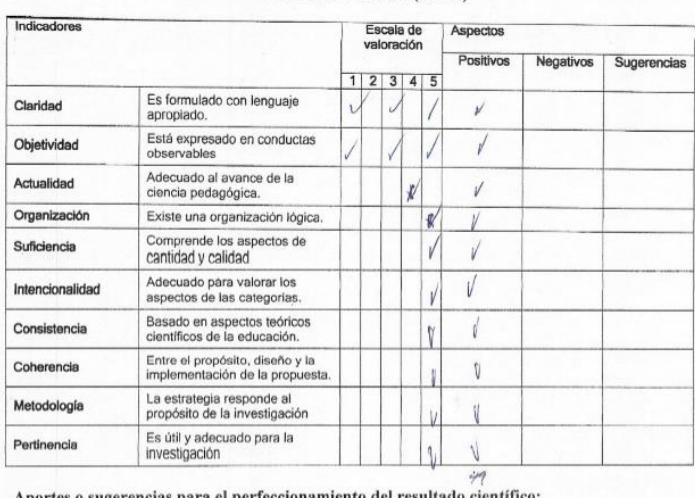

portes o sugerencias nara el perfeccionamiento del resultado cientifice:

Opinión de aplicabilidad

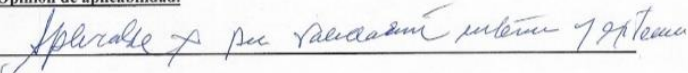

Resultados

Promedio de valoración $=\frac{\text { Valoracib́n internat valoraceín externa }}{2}$

Resultado de valoración: $90 \%$

Aspectos a odservar

Validación interna

\begin{tabular}{|c|c|c|c|c|}
\hline \multirow[t]{2}{*}{ indicadores } & \multirow{2}{*}{$\begin{array}{l}\text { Escala de } \\
\text { valoración }\end{array}$} & \multicolumn{3}{|l|}{ Aspectos } \\
\hline & & Positivos & Negativos & Sugerencias \\
\hline Factibilidad de aplicación del resultado que se presenta. & & $r$ & & \\
\hline Claridad de la propuesta para ser aplicado por otros & $x$ & $\checkmark$ & & \\
\hline $\begin{array}{l}\text { Posibilidad de la propuesta de extensión a otros } \\
\text { contextos semejantes }\end{array}$ & $x$ & $\sigma$ & & \\
\hline $\begin{array}{l}\text { Correspondencia con las necesidades sociales e } \\
\text { individuales actuales }\end{array}$ & $x$ & 1 & & \\
\hline $\begin{array}{l}\text { Congruencia entre el resultado propuesto y el objetivo } \\
\text { fijado. }\end{array}$ & $\infty$ & 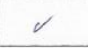 & & \\
\hline $\begin{array}{l}\text { Novedad en el uso de conceptos y procedimientos de la } \\
\text { propuesta. }\end{array}$ & $x$ & ' & & \\
\hline 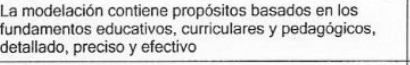 & & $\checkmark$ & & \\
\hline $\begin{array}{l}\text { La propuesta está contextualizada a la realidad en } \\
\text { estudio. }\end{array}$ & $x$ & $\alpha$ & & \\
\hline $\begin{array}{l}\text { Presenta objetivos claros, coherentes y posibles de } \\
\text { alcanzar. }\end{array}$ & $x$ & $d$ & & \\
\hline Contiene un plan de acción de lo general a lo particular. & $\infty$ & $\gamma$ & & \\
\hline
\end{tabular}

Opinión de aplicabilidad:

a) Deficiente ( ) b) Baja ( ) c) Regular ( ) d) Buena ( ) e) Muy Buena (X)

\begin{tabular}{|c|c|c|c|}
\hline Nombres y Apellidos & HzANÁ Flores VAzd errezo & $\mathrm{DNIN}^{\circ}$ & 06055101 \\
\hline $\begin{array}{l}\text { Dirección domiciliaria } \\
\text { Titulo profesional/ }\end{array}$ & Hos capulias 159(201) & $\begin{array}{l}\text { Teléfono / Celular } \\
\text { n exéc }\end{array}$ & 999461104 \\
\hline $\begin{array}{l}\text { Título profesional/ } \\
\text { Especialidad } \\
\text { Grado Académico }\end{array}$ & \multirow{2}{*}{\multicolumn{3}{|c|}{ Mayesls }} \\
\hline $\begin{array}{l}\text { Grado Académico } \\
\text { Ocupación y año de }\end{array}$ & & & \\
\hline $\begin{array}{l}\text { Ocupación y año de } \\
\text { experiencia } \\
\text { Metodólogo/temático }\end{array}$ & \multirow{2}{*}{ 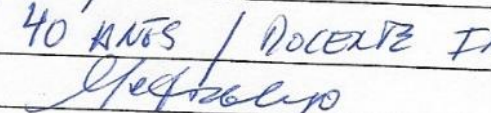 } & GADER & $\operatorname{cs} 15$ \\
\hline Metodólogo/temático & & & \\
\hline
\end{tabular}

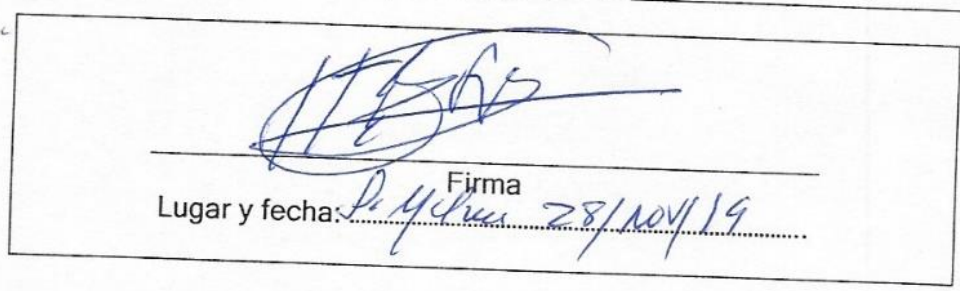

